TESIS DOCTORAL

\title{
MUJER Y MEMORIA EN LAS SERIES DE PRIME TIME DE LA 1 DE TVE (2008-2017): \\ LA SEÑORA, 14 DE ABRIL. LA REPÚBLICA, ISABEL Y EL MINISTERIO DEL TIEMPO
}

AUTORA: Laura Castillo Mateu

DIRECTORA: María José Gámez Fuentes

ENERO 2019 


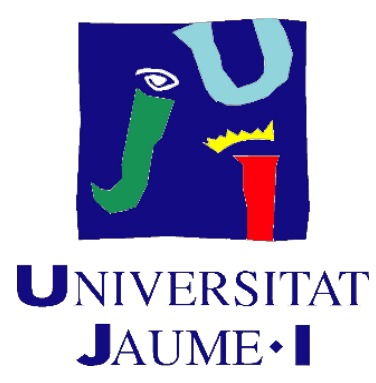

\section{Programa de Doctorat en Estudis Internacionals en Pau, Conflictes i Desenvolupament}

Escola de Doctorat de la Universitat Jaume I

Títol de la tesi:

MUJER Y MEMORIA EN LAS SERIES DE PRIME TIME DE LA 1 DE TVE (2008-2017):

LA SEÑORA, 14 DE ABRIL. LA REPÚBLICA, ISABEL Y EL MINISTERIO DEL TIEMPO

Memòria presentada per LAURA CASTILLO MATEU per a optar al grau de doctor/a per la Universitat Jaume I

LAURA CASTILLO MATEU

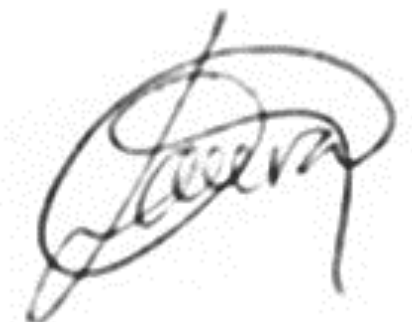

MARÍA JOSÉ GÁMEZ FUENTES

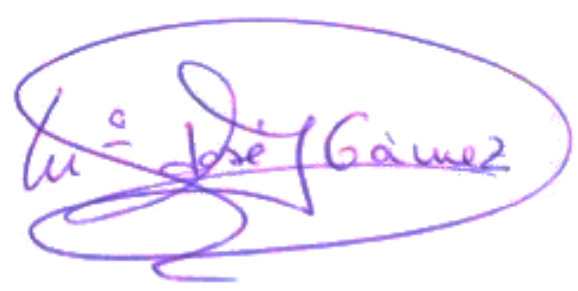

Castelló de la Plana, GENER del 2019 


\section{Finançament rebut}

- Contracte pre-doctoral FPU13/05010 del Ministeri d’Educació i Formació Professional (abans Ministeri d’Educació, Cultura i Esport: MECD) adscrit al Departament de Ciències de Comunicació de l'UJI.

- Ajuda Erasmus a la mobilitat de doctorat 2016 de l'ORI de I'UJI. Destinació: University of Nottingham (Regne Unit). 
WOMEN AND MEMORY IN THE PRIME TIME SERIES OF TVE-LA 1 (2008-2017):

LA SEÑORA, 14 DE ABRIL. LA REPÚBLICA, ISABEL AND EL MINISTERIO DEL TIEMPO

\begin{abstract}
:
The aim of this thesis is to analyze where the mainstream discourse has placed women in fiction stories about different episodes of the recent history of the Spanish state. To do this, we have analyzed four series starring women that have been broadcast on TVE's channel La 1 between 2008 and 2017: "La Señora», "14 de abril. La República», "Isabel» and "El Ministerio del Tiempo». The Feminist Critical Discourse Analysis methodology has been used to see how these narratives by the public television symptomatize the rise of State feminism and the promotion of legislation for memory recovering in our recent political context. In our analysis, we contend that the four series have reworked the imaginary of the democratic identity from the socialist feminist institutionalized agenda, which entails cutting across the categories of women and memory. In this sense, women are presented as the protagonists of democratic memory from the convergence of two profiles: the liberal bourgeois and the socialist. These types of women act as mnemonic references for women in contemporary democracy. Moreover, the storylines problematize the relationship between femininity and power as well as the relationship between the personal and political. In this regard, the stories contribute creative solutions that break the cycle of representing revictimized women and with the idea of empowerment as an individual process. What we find in the scripts are actions in the form of fictionalized caring experiences that evoke female emancipation from a sustained collective project of what they have in common. By doing so they invite reflection on the structural and cultural scope of patriarchal violence and allow space for the representation of collective survival strategies from a genealogical perspective.
\end{abstract}

Key words:

Gender, Feminism, Media, Memory, Peace, Women 


\section{Agraïments}

Amb el permís del Ministeri d’Educaciói espanyol, al qual no estic massa segura de si he d'incloure en una nota tan personal com aquesta, vaig a procedir a expressar els meus agraïments en la meua llengua mare, en la qual -cal dir- m'haguera agradat escriure aquesta tesi. A hores d'ara em penedisc de no haver sigut més valenta i d'haver accedit a traduir al castellà els primers esborranys. Sé que hauria d'haver fet constar amb més vehemència que escriure un text acadèmic en valencià era part de la meua opció personal i política, la mateixa que pose en pràctica cada dia. Potser el pes de la institució em va fer desistir massa prompte (abans, però, que el desgast fora irremeiable). Aquesta actitud, pel que es veu, l'hem emprada molt les dones al llarg de la història. Hem sabut mesurar les conseqüències i reconfigurar l'estratègia, donar un pas al costat (mai enrere!) per avançar amb més fermesa quan l'oportunitat pinte millor.

Dit açò i per reconduir aquest fragment, que he començat -no sé si massa encertadament- amb un avís i una disculpa, m’agradaria recordar uns consells que em van donar a l'acabar l'institut i que deien:

No demanes mai disculpes per ser dona,

No demanes mai disculpes per sentir-te valenciana

No demanes mai disculpes per res.

Així que vaig a deixar les pretextos de banda per a passar als agraïments, que és el que volia fer des del principi. I tinc la necessitat de començar esmentant a les meues amigues. A totes. A les que alguna vegada ho han estat molt, a les que ara són només conegudes i a les que ja no hi són. Durant aquests anys m'han acompanyat moltes de les experiències que he compartit amb vosaltres i crec que ara us comprenc a totes un poc millor, inclús des del desacord.

\footnotetext{
¿ Esta tesis se ha realizado gracias a la financiación recibida a través de la beca para la Formación de Profesorado Universitario (FPU) del Ministerio de Educación y Formación Profesional (antes Ministerio de Educación, Cultura y Deporte), con código FPU 13/05010.
} 
A les amigues del present, totes les que m'han vist perdre els nervis, la fam, el pes i les ganes per culpa de la tesi i les frustracions professionals i personals que l'envoltaven. Gràcies per la paciència, per l'estima i per l'ajuda. Especialment a Maria, perquè segueix sent l'espill en què em mire; a Andrea, per rescatar-me cada dissabte (i algun altre dia, també) del sense sentit de la rutina; a Aida per ser sempre el contrapunt. També a les "sororitraumàtiques": a Laia, per ajudar a què em reconciliara amb el poble i donar-li sempre importància a les coses que faig (i a mi, al cap i a la fi); a Íngrid, perquè ens cauen mal les mateixes persones i ens agraden els mateixos concursants d'OT; i a Marta, per ser una valenta i ensenyar-me que se pot aconseguir que "tabicon" al Congreso sense perdre el "decoro". Cal fer també especial menció ací a l’amic Diego per tots aquests anys de companyia i d'escolta. I també a Emma i Xavi, que m'han omplert la cistella de cures, diversions, ximos amb cava, vermut i verduretes de temporada.

Gràcies a totes les companyes i companys de I'UJ que m'han acompanyat en este procés d'aprenentatge. Al departament de Ciències de la Comunicació per acollir-me aquests anys (Alicia, Laura, Sílvia, Amparo, Robert, Pablo, Esteban, Agustín, Estela, Lorena, Andreu, Jèssica, Hugo, Palao, Shaila, Marta...). I com no, gràcies a la gent del IUDESP i del grup d'investigació 030, especialment a Alessandra, per ser una bona companya i estar pendent de mi a tot hora; a Eloísa, sense la qual crec que mai se m'haguera ocorregut doctorar-me, ni fer un màster de Pau, ni un Projecte-Servei durant la carrera, ni que el rock de vegades es portava bé amb l'acadèmia, ni, ni... També a Irene, Adela i María Jesús pel treball que han de fer des de la rereguarda burocràtica. I a Rebeca i a Fabricio, per estar sempre disposats a tirar una mà i veure en mi uns «altos vuelos» que jo interpretava com una simple addicció a I'entreteniment televisiu. I com no, a la meua tutora, María José, per haver-me ajudat a créixer i conèixer-me un poc millor en tot este procés; per donar-me un espai per explorar-me personalment a través de l'acadèmia i resignificarii políticament la meua pròpia memòria matrilineal, que al final és un poc la de totes.

\footnotetext{
ii Investigadora principal (IP) dels projectes UJI P1·1B2015-21 i MINECO/FEDER FEM2015-65834-C2-2-P, els quals han finançat gran part de les activitats de formació i difusió de la investigació en les quals he participat com a doctoranda/membre de l'equip d'investigació i treball, respectivament.
} 
També voldria mencionar a la gent de la Plataforma Veïnal Fem l’Escola de les Useres, concretament a les dones que l'han impulsada i que m'han mostrat com es transformen els conflictes en comú i en femení. Gràcies per recordar-me que hi ha vida més enllà de tesis, universitats i oficialismes. I per a què conste (ja que tenim nom i, per tant, existim), gràcies a les persones que estan fent possible el projecte d'Avancem. M'esteu donant molts bons motius per seguir intentant que les coses es fagen d'una altra manera i per seguir trencant esquemes de normalitat a cada pas que donem.

I gràcies de tot cor a Josep, perquè va arribar (fa un número indefinit d'anys) i es va quedar, sense imaginar-se on s'havia ficat. No m'ho imaginava ni jo, però al final ha resultat ser part fonamental de tot este camí que no sabem ben bé on ens durà. I finalment, però no per això menys important: gràcies a la família, la que m’ha acompanyat sempre i per la què sóc el què, com i on sóc. A la mamà, al papà, a Pau i Lorena; a la teta Vanessa i a Alfonso; al papaïto i a la mamaïta; a Encarnita i Jose, Ivan i Víctor i a Diego; a Trini i Joaquinet, i a Tània i Quim. Tant de bo este treball reverbere en alguna part de vosaltres, perquè sou vosaltres qui, sense saber-ho, I'heu emplenat de sentit, ja siga des del passat, el present o el futur. Tampoc me n'oblide de la meua família d'acollida: Eva i Jose, Dafne i Carles, germanes, gendres, cosines i àvies, gràcies per fer-me part de la vostra història.

I per tancar els agraïments, no trobe millor manera que fer meus els versos de «Divisa», de Maria-Mercè Marçal, on hi veig reflectides les motivacions que hi ha rere aquest treball i de qualsevol empresa a la meua vida:

A l'atzar agraeixo tres dons: haver nascut dona, de classe baixa i nació oprimida.

I el tèrbol atzur de ser tres voltes rebel. 


\section{ÍNDICE}

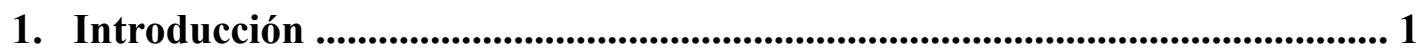

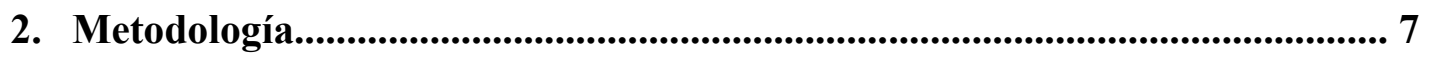

2.1. Temática y objetivos: justificación...................................................... 7

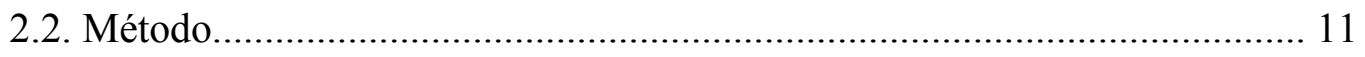

2.2.1. Marco de análisis.......................................................................... 12

2.2.2. Pregunta de investigación ........................................................... 19

2.2.3. Delimitación del corpus de análisis y justificación ............... 21

2.2.4. Estrategia de análisis ........................................................ 25

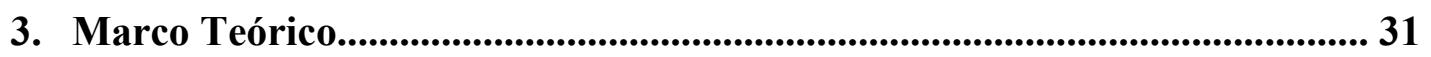

3.1. Paz y Cultura: hacia la transformación de los conflictos ...........................31

3.2. Cultura para la Paz: la intersubjetividad y la comunicación en la nueva agenda de los Estudios para la Paz .................................................... 35

3.3. La memoria en la vertiente reconstructiva de los Estudios para la Paz ...... 41

3.4. Introducción de la perspectiva de género en los Estudios para la Paz ....... 45

3.4.1. La perspectiva de género sobre el discurso y el poder.................... 48

3.4.2. Marcos de interpretación actual: entre la institucionalización y el mito del feminismo neoliberal ................................................. 56

3.4.3. El género y la necesidad de una memoria matrilineal: poder y sororidad 61 
4.1. La televisión pública en la era Zapatero: servicio público de calidad ..... 70

4.1.1. La introducción de la agenda política en la ficción pública: género con memoria ............................................... 73

4.2. Reconocimiento y concepto de víctima en la era Zapatero............... 75

4.2.1. El revulsivo para la memoria ............................... 75

4.2.2. El reconocimiento a las víctimas políticas en la era ZP ..........80 80

4.3. El feminismo institucional y el socialismo en España ................... 85

4.3.1. El legado feminista para la democracia ........................ 90

4.3.2. La sociedad formalmente igualitaria $\ldots \ldots \ldots \ldots \ldots \ldots \ldots \ldots \ldots \ldots$

4.4. La llegada de la crisis, del 15-M a las calles y del PP al gobierno......... 100

4.5. Temas pendientes: la cuestión territorial y el tabú de los nacionalismos

106

5. Análisis

5.1. Reconstruyendo el modelos de feminidad del feminismo institucional socialista

5.1.1. Las mujeres de la memoria democrática: Victoria Márquez ( $L a$

Señora) y Encarna Alcántara (14 de abril. La República)............. 117

5.1.1.1.Victoria: de señorita rebelde a empresaria minera ...................117

5.1.1.2. Encarna: la activista socialista sufragista 123

5.1.2. El giro conservador y la complejización del discurso feminista en la cultura popular

5.1.2.1. Isabel: el ideal de la mujer con poder 131

5.1.2.2. Amalia (EMDT): la mujer en la institución 136 
5.2. La representación del empoderamiento femenino, de sus límites y de otras estrategias de emancipación 141

5.2.1. La vulnerabilidad y la victimización en La Señora

5.2.2. La mujer frente al patriarcado: más allá de la violencia de género. 145

5.2.3. Sororidad y matrilinaje en 14 de abril. La República. 148

5.2.4. La reconstrucción del mito de feminidad nacional en Isabel. 152

5.2.5. El cuestionamiento de la legitimidad institucional en El Ministerio del Tiempo 157

5.3. Recapitulación y discusión de resultados 160

5.3.1. El modelo de feminidad del feminismo institucional. 160

5.3.2. La evolución argumental y la relación entre género y memoria ... 162

6. Conclusions 169

6.1. Closure and starting point for future research 177

Bibliografía. 183 


\section{Introducción}

La redacción de la presente tesis doctoral es el último resultado de mi trayectoria como estudiante universitaria, iniciada con la Licenciatura en Comunicación Audiovisual y seguida por la posterior realización del Máster en Estudios Internacionales de Paz, Conflictos y Desarrollo. Mis intereses de investigación ya se vieron plasmados en el Trabajo Fin de Máster (TFM) titulado Isabel, una lectura desde la Comunicación para la Paz con perspectiva de género, que constituyó una primera aproximación al estudio de la representación historicista de la mujer en la cultura popular televisiva española. Este sería el embrión de mi proyecto en el programa de doctorado en Estudios Internacionales de Paz, Conflictos y Desarrollo (línea de Comunicación y Educación para la Paz), que se ha centrado en analizar dónde ha situado el discurso mainstream a la mujer en los relatos de ficción sobre distintos episodios de la historia del estado español y qué relación establecen estas narrativas sobre mujer y memoria con el auge del feminismo de Estado en nuestro contexto político reciente. Cabe añadir, además, que esta tesis doctoral se ha llevado a cabo gracias a la financiación del Ministerio de Educación, a través de una beca para la Formación de Profesorado Universitario (FPU 13/05010) adscrita al Departamento de Ciències de la Comunicació de la Universitat Jaume I de Castelló y en el marco de investigación del IUDESP (Instituto Interuniversitario de Desarrollo Social y Paz) y del grupo Desarrollo Social y Paz (Filosofía, Comunicación, Educación y Ciudadaníacódigo 030).

Es importante tener en cuenta el contexto académico en el que se fragua y desarrolla la idea de la tesis para comprender que lo que motiva la elección del tema y el enfoque metodológico es el interés por la carga significante de los discursos públicos. 
Concretamente por su poder para re-reproducir o transformar los marcos cognitivos que articulan el modo en que los sujetos miran al mundo. Y más específicamente, en el origen de esta tesis se encuentra la necesidad de abordar cómo la incorporación transversal de la perspectiva de género de estos discursos resignifica no solo la mirada a nuestro presente sino al pasado. Este interés, que se relaciona teóricamente con las líneas de investigación sobre Comunicación para el Cambio Social con perspectiva de género desarrolladas por el IUDESP, se ha proyectado por nuestra parte en el estudio de los discursos y narrativas audiovisuales referentes a la situación del feminismo político y académico contemporáneo sintomatizados en la cultura popular televisiva.

Así, hemos realizado un trabajo de documentación y análisis sobre producciones audiovisuales protagonizadas por mujeres y de tipo historicista que tuvieron cabida en la programación de prime time de la televisión pública estatal, más concretamente en su canal principal $L a$, desde el año 2008 y hasta el 2017. Nuestra intención es la de dilucidar cómo las instituciones comunicativas de ámbito público incorporan el debate feminista a través de distintos productos (de ficción, en nuestro caso) y qué elementos del contexto sociopolítico del momento contribuyen a que ciertos ítems de la agenda feminista se manifiesten o no en la cultura popular. En esta línea es importante señalar que también prestaremos atención a otros ejes del debate público sobre identidad política en el contexto español que se vinculan a las cuestiones de género desde el momento que se ven atravesadas por la perspectiva de la memoria histórica en las tramas analizadas.

Para tal fin, se ha llevado a cabo la redacción de un marco teórico (capítulo tres) y un marco histórico (capítulo cuatro) que ofrecen las claves de lectura del corpus de análisis audiovisual (capítulo cinco). Así, una vez establecidos los ejes temáticos representativos de la agenda del feminismo institucionalizado en consonancia y 
contraposición a los discursos públicos de los movimientos de base reactivados a partir del 15M, se ha llevado a cabo la selección de los productos culturales que han formado parte finalmente del corpus de análisis de la tesis porque imbrican la perspectiva de género con la perspectiva histórica. De esta manera se han podido vislumbrar tanto los $\operatorname{arquetipos}^{1}$ femeninos reproducidos en los discursos televisivos como las nuevas claves representativas desde las que se proponen una revisión transgeneracional de las relaciones femeninas en contextos públicos y privados a través de relatos protagonizados por mujeres.

En relación con esto, se recoge en el marco histórico cómo el desarrollo y la promoción de las políticas de la memoria ponen de manifiesto un posicionamiento por parte de la izquierda gobernante que se pronuncia, después de tres décadas desde la Transición española, a favor del reconocimiento de los colectivos silenciados e invisibilizados por los mitos identitarios de la historia reciente. De nuevo, veremos como las tendencias discursivas académicas y políticas se acompañan entre si y se ven a su vez representadas en los relatos televisivos de ficción contemporáneos, los cuales funcionan como mediación del debate público sobre mujer y memoria y lo trasladan al terreno de la cotidianidad con una notable potencialidad transformadora del imaginario colectivo respecto a las cuestiones de mujer y memoria.

Así pues, la perspectiva de género resulta esencial para deconstruir los elementos del discurso audiovisual y localizar tanto los clichés representativos como las innovaciones en la representación de identidades femeninas en relación con los propios debates reproducidos en los relatos. La aplicación de la mirada feminista - en tanto que hermenéutica de la sospecha - contribuirá a dar complejidad a la lectura de los elementos que, en el discurso, sintomatizan precisamente el debate sobre las políticas de 
género en el espacio histórico-político en el que adquieren sentido las diferentes producciones que hemos analizado.

Los cuatro productos culturales escogidos para realizar este trabajo de análisis han sido cuatro series de televisión que han sido producidas para su emisión en la televisión pública de ámbito estatal $L a 1$ de TVE. Se trata de La Señora y la primera temporada de su secuela ${ }^{2}, 14$ de abril. La República, Isabel y El Ministerio del Tiempo, respectivamente. Todas ellas están protagonizadas por mujeres y empiezan a emitirse en prime time a partir de la octava legislatura de la democracia, esto es, bajo el primer mandato del socialista José Luís Rodríguez Zapatero. La emisión de las dos primeras series y de la primera temporada de la tercera se prolongará a lo largo de la novena legislatura, todavía con Zapatero al frente del legislativo estatal, que supuso el pico formal de la institucionalización del feminismo en España.

Tras el 15M, la convocatoria de elecciones y la llegada del Partido Popular al gobierno, se eliminó 14 de abril. La República de la parrilla de la televisión pública y el seguimiento de Isabel estuvo en la cuerda floja. Finalmente, se decidió seguir emitiendo la serie de los hermanos Olivares, que en sus segunda y tercera temporadas representaban la etapa de madurez, maternidad y decadencia del mito de la reina Isabel la Católica. Más tarde, en 2015 (coincidiendo con el final de la primera legislatura de Rajoy), otra creación de los Olivares, El Ministerio del Tiempo, se introduce en la parrilla de la televisión pública.

\footnotetext{
${ }^{2}$ Durante el periodo de planificación y redacción de la presente tesis se ha trabajado solo esta primera temporada, ya que la emisión de la serie fue anulada una vez el Partido Popular, con Mariano Rajoy al frente, llegó al gobierno estatal por mayoría absoluta. Curiosamente, justo al cierre de este trabajo que tenemos entre manos (cuando ha prosperado una moción de censura al presidente Rajoy y el socialista Pedro Sánchez ha sido elegido como nuevo presidente de la cámara legislativa), la segunda temporada de este spin off de La Señora, que -cabe decir- estaba ya grabada, ha empezado a emitirse de nuevo en La 1 de TVE, lo que parece simbolizar una continuidad con la anterior etapa socialista.
} 
El elenco de protagonistas de todas estas series transita del perfil de burguesa liberal (en La Señora) al de proletaria militante socialista feminista (en 14 de abril. La República) y, más tarde, hacia el mito de la génesis de la unidad nacional (Isabel) y, finalmente, a jefa de patrulla de funcionarios públicos (El Ministerio del Tiempo). Esta diversidad de prototipos de líderes femeninas, ubicadas en episodios de referencia de la historia de España, se introduce en las series a medida que los discursos públicos sobre igualdad de género en el ámbito público y privado y contra la violencia de género van enriqueciéndose gracias a los matices que aporta el debate entre las perspectivas más institucionales y activistas, que tomó fuerza especialmente con el resurgimiento de los movimientos sociales alrededor del hito del 15M.

Teniendo pues en cuenta este contexto, vamos a analizar cualitativamente estas manifestaciones culturales como espacios de negociación en que se reproducen los discursos públicos que se emiten respecto a la agenda del feminismo institucional y la revisión del sistema democrático, que centra su atención en las políticas por la recuperación de la memoria histórica. Es nuestra intención poner de manifiesto como estos textos audiovisuales producen y reproducen las tensiones sociales respecto a las dos cuestiones que hemos mencionado.

Finalmente, en nuestro apartado de conclusiones, corroboraremos la relevancia de los puntos destacables del análisis teniendo en cuenta la relectura feminista de los acontecimientos políticos más recientes en el estado español a través de los productos culturales y esbozaremos las futuras líneas de trabajo manifiestas tras la finalización de la presente tesis doctoral. 


\section{Metodología}

La metodología que se ha utilizado en la búsqueda de resultados es el análisis crítico del discurso desde una perspectiva culturalista y feminista. Consideramos que los productos mediáticos, como son las series de televisión que forman parte de nuestro corpus de estudio, son unos de tantos elementos del contínuum discursivo que constituyen la cultura. Esto es, consideramos que los argumentos de nuestras series son, en sí mismos, una manifestación de las tensiones y los debates políticos que se dan en el contexto de su génesis. En ese sentido, la perspectiva de género no entrará solo a través del marco teórico feminista, sino también auspiciada por la propia agenda política de la última década, cuando los avances en legislación por la igualdad de género han reavivado e impulsado, por una parte, el debate en el seno del movimiento feminista así como, por otra, el rechazo de los sectores más reaccionarios.

\subsection{Temática y objetivos: justificación}

La tesis que presentamos se desarrollará alrededor del tema de la representación de la mujer y de la memoria en las series historicistas de $L a 1$ de Televisión Española (TVE). Sostenemos que los argumentos de estas producciones audiovisuales vienen motivados por los debates surgidos alrededor de la discusión pública acerca de la recuperación de la memoria histórica y de la necesidad de incluir la mirada de la mujer en la reconstrucción de la misma. Precisamente ese «carácter reconstructivo» Hueso (1991: 15) es el que nos hace preferir el término el uso del adjetivo «historicista» en lugar, por ejemplo, de «histórico». Aunque bien es cierto que las series que estudiamos se clasifican bajo la categoría del género histórico, nos parece 
adecuado optar por el término «historicista» para marcar el carácter revisionista de las mismas.

Por otro lado, el hecho de fijarnos específicamente en las emisiones de la televisión pública se debe a varios factores que tienen que ver con la función social de los medios de comunicación públicos y con la preservación del derecho a la información y a un entretenimiento de calidad, tal y como detalla la misma Ley 17/2006, de 5 de junio, de la radio y la televisión de titularidad estatal (BOE: 2006). En concreto, el documento dice que los canales de la RTVE tienen por objeto «satisfacer necesidades de información, cultura, educación y entretenimiento de la sociedad española; difundir su identidad y diversidad culturales» (art. 2) y explicita, entre otros de sus deberes, los siguientes:

- «Promover el conocimiento y difusión de los principios constitucionales y los valores cívicos» (Art. 1, apartado a.)

- «Promover la cohesión territorial, la pluralidad y la diversidad lingüística y cultural de España». (Art. 3, apartado e.)

- «Fomentar la protección y salvaguarda de la igualdad entre hombre y mujer, evitando toda discriminación entre ellos». (Art. 3, apartado k.)

- «Promover el conocimiento de las artes, la ciencia, la historia y la cultura.» (Art.3, apartado i.).

Si atendemos a estos ejes, en torno a los cuales se articula la misión de la televisión pública y su propia identidad de marca, entendemos que los productos de ficción que produce y emite se caracterizarán especialmente por proteger ese derecho al entretenimiento de calidad. Una calidad que en estos puntos anteriores se define a partir de una serie de «valores cívicos» que configuran presumiblemente el modelo de sujeto 
ciudadano del estado democrático. Estos, según se lee, se articulan en base al apoyo de la unidad de España, al mandato explícito de la difusión del conocimiento histórico y a la igualdad de género. Esta última cuestión, como señalará Palacio (2007: 76), traspasa la normativa para plasmarse en el ejercicio real de la televisión pública:

Hay un aspecto llamativo que se destaca en la simple enumeración de las series producidas en la "televisión de Zapatero": prácticamente todas, salvo Amar en tiempos revueltos, son series cuyas protagonistas principales son mujeres. Este fenómeno no deja de ser sugerente en cuanto al análisis si recordamos que coincide con un tiempo histórico en el que el gobierno español está a la vanguardia europea de las políticas paritarias y de discriminación positiva [sic], esforzándose en promulgar leyes a favor de la igualdad entre géneros. Más aún, esta política se ha convertido en uno de los elementos centrales para la imagen de las actuaciones públicas; hasta la prensa internacional refleja ese esfuerzo del gobierno de España y la singularidad que supone en el contexto europeo. (2007: 76)

Estos parámetros se verían complementados con la aprobación de la Ley 8/2009, de 28 de agosto, de financiación de la Corporación de Radio y Televisión Española (BOE: 2009), que supondría el fin de los ingresos obtenidos a través la publicidad comercial, reforzando así la independencia económica y política del ente ${ }^{3}$. Finalmente, la Ley 7/2010, de 31 de marzo, General de la Comunicación Audiovisual (BOE: 2010) supone el paso final de la reforma del sector audiovisual del gobierno Zapatero, emprendida ya en la primera de sus dos legislaturas como presidente del Gobierno con la aprobación de las dos leyes anteriores. Toda esta normativa surgió especialmente ante la necesidad de dotar el sector audiovisual (tanto público como

3 Ver: http://www.rtve.es/noticias/20090729/senado-aprueba-definitivamente-ley-suprime-publicidadtve/286994.shtml [Último acceso: 19/06/2018] 
privado) de unos parámetros comunes desde los que proteger ese derecho ciudadano a gozar de una comunicación de calidad, en conexión con los valores cívicos de los que venimos hablando a colación de la ley de medios públicos y coincidiría con el fenómeno que nos proponemos estudiar en esta tesis: el protagonismo de las mujeres en los argumentos de ficción en el prime time de La 1 de TVE.

Teniendo en cuenta lo anterior, el objetivo general de nuestra tesis se puede delimitar de la siguiente manera: averiguar qué debates públicos sobre mujer, memoria e identidad se manifiestan en los argumentos de las series de televisión que forman parte de nuestro corpus de análisis y cómo se articulan estos discursos a través de estos relatos de ficción. De este objetivo global se desprenden otros secundarios que pasamos a detallar a continuación y que nos guiarán a la hora de estructurar y delimitar el contenido de los diferentes apartados que componen este trabajo:

- Articular ejes de análisis comunes entre los Estudios para la Paz (campo académico interdisciplinar donde se inserta nuestro proyecto de tesis) y los Estudios Feministas en torno al papel y la voz de la mujer en la recuperación de la memoria silenciada.

- Establecer una relación entre el marco teórico anterior y los Estudios Culturales para poner de relevancia del rol de las industrias culturales (a través de los fenómenos de la performatividad del lenguaje y del género) en la construcción de imaginarios que sitúan a la mujer en un lugar concreto de la historia y de la narración de la memoria.

- Delimitar el marco histórico-político en el que se insertan los relatos audiovisuales que presentamos y localizar los temas o núcleos teórico-discursivos que, a colación del debate feminista sobre las cuestiones de género y de la recuperación de la 
memoria histórica, adquieren relevancia en la agenda pública y se articulan en las tramas de las series en el momento de emisión/recepción de las mismas.

- Establecer un marco de interpretación a partir de los puntos anteriores desde el cual deconstruir y analizar el discurso sobre mujer, memoria e identidad manifestado en los productos culturales seleccionados para el análisis.

\subsection{Método: marco de análisis, pregunta de investigación, delimitación del corpus y estrategia de análisis}

Debemos tener en cuenta que la presente tesis corresponde al programa de Estudios Internacionales de Paz, Conflictos y Desarrollo, en su vertiente de Comunicación, espacio donde han proliferado los resultados de las y los investigadores del Instituto de Desarrollo Social y Paz, en su sede en la Universitat Jaume I de Castelló. Incidimos en esta cuestión para situar la perspectiva para la cual articulamos la metodología del presente trabajo, que aúna la visión de los Estudios para la Paz y del papel de la Comunicación en la transformación pacífica de conflictos y la promoción de la cultura para hacer las paces desde los discursos públicos (Nos Aldás, 2010). En nuestro caso, concretamente, proponemos explorar el terreno de las series de televisión como espacios que, en la ficción, reproducen los conflictos vinculados a la memoria histórica del Estado español y que recurren al papel de las mujeres para representar espacios de resistencia y de transformación pacífica de tales conflictos.

Esta visión de los productos culturales de masas (como lo son nuestras series) la tomamos de la perspectiva de los Estudios Culturales, que «consideraban la comunicación de masas como un texto indicativos de los valores culturales emergentes y de los significados de un período histórico determinado concreto» y que, por tanto, 
«ponían de manifiesto la estructura más profunda de la sociedad» (Rodrigo, 2001: 204). Hall (1981) señalará la relación entre comunicación e ideología cuando apunta que los medios construyen de manera selectiva el conocimiento y los imaginarios sociales y los dotan de legitimidad en un proceso dialéctico con el contexto histórico y social (citado en Rodrigo, 2001: 205). Acorde con estos planteamientos, es nuestro deseo el de aplicar la metodología propia de los Estudios Culturales, el análisis del discurso, teniendo en cuenta que:

Un discurso consiste en asociaciones de ideas expuestas a través de textos y representaciones producidos cultural o socialmente. Los discursos representan estructuras de pensamiento y de poder y el análisis del discurso revela estas estructuras y ubica el discurso en unas relaciones históricas, culturales y sociales más amplias. (Rodríguez, 2009: 39)

Trabajaremos pues, desde la concepción de los medios de comunicación como espacios estratégicos en los que se codifican, complejizan y negocian los conflictos sociales (Hall, 1981). Además, cuando hablemos de cultura popular, nos estaremos refiriendo precisamente a los productos de las industrias culturales que, desde la visión de Martín Barbero (1987), funcionaran como lugares de «circulación cultural» o de mediación entre lo hegemónico y lo contra hegemónico, en donde las clases populares tienen la «oportunidad de hacer comunicable su memoria y su experiencia» (Martín Barbero, 1987: 110).

\subsubsection{Marco de análisis}

El carácter cualitativo de la presente tesis doctoral y la necesidad de poner en relación el texto con su contexto (que nos señalan los Estudios Culturales) nos obliga, pues, en primera instancia a confeccionar un marco de interpretación que nos 
permita establecer las categorías necesarias para desarrollar el análisis de nuestro corpus de estudio. Este marco de interpretación vendrá configurado por:

\section{a) Mujer, memoria e identidad en el debate académico:}

La situación del debate académico sobre la recuperación de la memoria silenciada de los pueblos y la relevancia de la perspectiva de género en esta tarea parte de las premisas del giro epistemológico de Vicent Martínez Guzmán (2010) en la filosofía «para hacer las paces». De ésta se desprenden conceptos como los de identidad, reconocimiento y empoderamiento ${ }^{4}$. En este sentido, nos interesará reflexionar en torno al carácter performativo de los discursos y a la importancia de la comunicación en la transformación de la violencia simbólica desde los discursos públicos emergentes en la cultura popular televisiva. La integración de la perspectiva feminista al análisis crítico del discurso pondrá de relevancia la necesidad de situar las epistemologías tradicionales y de deconstruir la condición androcentrista del saber académico y, apostará, por otro lado, por la aplicación la hermenéutica de la «sospecha feminista» (Puleo, 2013) para la lectura y análisis de los discursos manifiestos en los productos culturales.

Además, los Estudios Culturales y su interés por «las pequeñas historias» (Mattelart y Neveu, 2003: 57) reforzarán el interés por la interpretación de los textos de la alteridad. Precisamente, la condición de alteridad de la mujer ha sido puesta en valor por parte de filósofas feministas históricas como Simone de Beauvoir (1949). En nuestro contexto académico más próximo y reciente, nos interesará también la herencia

\footnotetext{
${ }^{4}$ En el marco de la CEDAW (Convención sobre la Eliminación de todas las Formas de Discriminación contra la Mujer) de Naciones Unidas, la idea de «empoderamiento» de las mujeres se articula a partir de varios ejes de acción, hacia los que van destinados sus recomendaciones en políticas públicas para los gobiernos estatales. Entre ellos figura el acceso a los sistemas de educación y a la salud, así como a los recursos y los medios de producción. Ver definición de «empoderamiento» en el Glosario del Centro de Capacitación online de ONU Mujeres: https://goo.gl/5ETfnH [Último acceso: 19/06/2018]
} 
de filósofas como Celia Amorós (1985), quien pone en el foco del debate la exclusión de las mujeres en la confección de los sistemas políticos modernos en su crítica feminista a la razón ilustrada. Asimismo, una de sus pupilas y heredera del pensamiento de los seminarios Feminismo e Ilustración, Ana de Miguel, ha reflexionado recientemente entorno al «mito de la libre elección» (2015) para poner sobre la mesa algunas de las paradojas que la ideología neoliberal produce en contextos a los que la filósofa denomina «de igualdad formal», como podría ser el español, con una legislación avanzada en materia de igualdad de género y no discriminación desde la aprobación de la Ley Orgánica 3/2007, de 22 de marzo, para la igualdad efectiva de mujeres y hombres (BOE: 2007).

Teniendo esto en mente, vemos que nuestra tesis dialogará con aquellos estudios centrados en «els productes i polítiques culturals de la dictadura, la democràcia i/o la relació entre ambdúes» y en «la reconstrucció del passat, la reconstrucció democràtica, la reinscripció de gèneres populars, la identitat de gènere/sexualitat i la identitat nacional enfront de l'autonòmica» que se han producido desde el campo de los Spanish Cultural Studies (Gámez Fuentes, 2002: 34). En nuestro caso, se pretende indagar en cómo los productos culturales analizados codifican en nuestro contexto político reciente (el cual enmarcamos en el posterior epígrafe) esas cuestiones de la identidad nacional respecto a las categorías de memoria y género. $\mathrm{O}$ dicho de otra manera, cómo la cultura popular está reconstruyendo la memoria a través del condicionante de género y qué lecturas nos sugiere este tipo de representación en el contexto democrático del presente. 


\section{b) Mujer, memoria e identidad en el debate político español reciente:}

Si como ya venimos apuntando, partimos de la perspectiva de los Estudios Culturales, debemos tener en cuenta el contexto histórico en el que se insertan y toman sentido las obras audiovisuales que forman parte de nuestro corpus de estudio. En nuestro caso, consideramos que el contenido, es decir, los temas y las elecciones narrativas que marcan los diferentes relatos escogidos, sintomatizan la necesidad popular de saberse inscritos e inscritas en la narración de la cultura y de la identidad nacional que ya se ponen de manifiesto con la aprobación de la Ley 52/2007, de 26 de diciembre, por la que se reconocen y amplian derechos y se establecen medidas en favor de quienes padecieron persecución o violencia durante la guerra civil y la dictadura (BOE:2007). Por eso, de entrada, sostenemos que la idiosincrasia de las historias que proponemos analizar manifiesta un interés de tipo identitario en la ciudadanía del estado español que, en un momento concreto de la historia, necesita situarse respecto a una memoria nacional que intuye sesgada y ocultista. La entrada en el nuevo milenio, con el que se conmemorarán hitos como el vigésimo quinto aniversario de la democracia, favorecerá precisamente la reapertura del debate público sobre los factores posibilitadores del régimen del '78. Un régimen democrático pero con un fuerte componente traumático marcado por los silencios y perdones gratuitos de la Transición (1975-1978) que, tres décadas más tarde, motivarán ese interés popular por releer el pasado desde otras miradas. La finalidad de esa actividad retrospectiva parece venir motivada por la necesidad de comprender el lugar de uno o una en el contínuum de una cultura política basada en la paradoja generada, precisamente, en torno al perdón y el silenciamiento del trauma social de la Guerra Civil (1936-1939) y el franquismo (1939-1975). 
Así pues, estaríamos hablando, más que de la mera necesidad del sentimiento de pertenencia al grupo, de la necesidad de situarse respecto a la memoria del grupo y que esta adquiera un mismo sentido político respecto a un sistema democrático que en el nuevo milenio se demostrará fallido. Esta necesidad también se hará patente en las calles y a colación de los acontecimientos políticos que tuvieron lugar alrededor del 15 de Mayo de $2011(15 \mathrm{M})^{5}$, un hito que ha transformado profundamente la manera de entender la participación y la representación política en el conjunto del estado español en las últimas legislaturas.

Nuestra lectura sobre este episodio lo sitúa un paso más allá de la mera respuesta ciudadana a la corrupción y la falta de diligencia política en la gestión de la crisis económica. Desde nuestro punto de vista, el 15M fue también un síntoma más de esa necesidad de posicionamiento político de la gente de a pie, que cuestionaba un sistema político heredado que, más que ejemplarizante, había resultado alienante y fraudulento a ojos de la ciudadanía ${ }^{6}$. En esta línea se sitúan autores como Antentas (2013), Candón (2013) o Lobera y Sampedro (2014). Es más, los episodios de violencia sufridos por las activistas feministas en Acampada Sol (Gámez Fuentes, 2015) denotan el carácter patriarcal en el que se gesta el régimen del '78 y ponen de manifiesto la necesidad de incorporar la perspectiva de género no solo a la crítica estructural del sistema democrático de poder, sino también a las nuevas propuestas políticas de resistencia y transformación de la sociedad civil organizada.

\footnotetext{
${ }^{5}$ Cabe también recordar que el 15M (15 de mayo) tuvo lugar tan solo dos meses antes de que Zapatero convocara unas elecciones generales anticipadas ( 29 de julio de 2011) que se celebrarían en noviembre de ese mismo año, esto es, cuatro meses antes del cumplimiento del cuarto año de su segunda legislatura como presidente del gobierno. También, que esas serían las elecciones generales que le darían la mayoría absoluta al PP de Mariano Rajoy, cuyos recortes, a su vez, insuflaron las protestas de la sociedad civil organizada, reactivada ya durante el mayo de las acampadas.
}

${ }^{6}$ Ver: http://www.publico.es/espana/sol-apunta-deficits-transicion.html [Último acceso: 19/06/2018] 
La Transición, por tanto, aflora como un el eje de conflicto en la identidad unitaria de la que presume la democracia. Si seguimos con la línea de justificación de nuestro marco temporal, veremos como el hito histórico sobre el que se articula la problemática de la «desmemoria» (Golob, 2008) es precisamente el proceso de instauración democrática tras la muerte del dictador Francisco Franco. Este proceso resulta de alguna manera fraudulento, en tanto que el nuevo sistema político se descubre $^{7}$ construido sobre los privilegios asentados durante anterior régimen y no logra superar, por tanto, el binomio de vencedores y vencidos. Parece necesario, por tanto, ir más allá, atrás en el tiempo, en busca de una genealogía de la resistencia que contribuya a localizar el origen de este relato dicotómico, que complejice el pasado para poder comprendernos en nuestro presente.

Los ejes del debate sobre mujer y memoria que hemos desarrollado se encuentran, pues, latentes en el contexto histórico en el que se inserta la producción y emisión de las series y este hecho le conferirá un sentido político concreto a los relatos audiovisuales que analizaremos. Así, como referencias temporales tomaremos, en primer lugar, el período correspondiente a las legislaturas de la democracia española presididas por José Luís Rodríguez Zapatero, el entonces secretario general del Partido Socialista Obrero Español (PSOE), que tuvieron lugar entre los años 2004 y 2011.

Nos interesará especialmente el período correspondiente a su segunda legislatura (2008-2011), ya que con ella se inician las emisiones de las series que constituyen nuestro corpus de análisis. Además en estos momentos tiene lugar un hito

\footnotetext{
${ }^{7}$ Usamos el verbo «descubrir» siendo conscientes de que las críticas al proceso de la Transición democrática existen desde los tiempos en que se fraguó el nuevo régimen político. Sin embargo, con esta expresión intentamos marcar la novedad que implica el referirse a las fallas de la Transición de manera abierta en los discursos públicos y sin miedo a que ello fuese tomado por la opinión pública como un ataque o falta de reconocimiento al esfuerzo en la negociación pacífica entre los bandos ideológicos, como había sucedido hasta el momento.
} 
que representa muy bien el asentamiento del feminismo institucional ${ }^{8}$ en el estado: la inauguración del Ministerio de Igualdad. Este hito supuso un avance conceptual en los debates sobre igualdad ya iniciados en la legislatura anterior a tenor de la aprobación de la Ley de Igualdad (BOE: 2007), aunque estos parecían estar especialmente asentados en la discusión iniciada acerca de la violencia machista como consecuencia de la aprobación de la Ley Orgánica 1/2004, de 28 de diciembre, de Medidas de Protección Integral contra la Violencia de Género (BOE: 2004).

No obstante, la inauguración de un ministerio cuya materia expresa es la garantía de igualdad invita a revisar la cuestión política de las violencias en un sentido holístico desde la perspectiva de género, y se empezará entonces a incidir sobre la omnipresencia social y cultural de la violencia patriarcal. El final de la época Zapatero vendrá marcado por las protestas ciudadanas, organizadas alrededor del movimiento 15M, en mayo de 2011. En el contexto de las movilizaciones se producirá además un punto de inflexión en la reflexión pública sobre la tradición política heredada del régimen del ’78 y los retos de la democracia representativa del nuevo siglo.

Sin embargo, las elecciones generales anticipadas de 2011 dan la victoria a Mariano Rajoy, del Partido Popular, como presidente del Gobierno central. Este hecho implicará un cambio de tendencia en materia de igualdad y memoria y el consiguiente giro en el debate oficialista sobre la mainstreamización del feminismo en las instituciones y sobre la recuperación de la memoria histórica y su vínculo con la cultura

\footnotetext{
${ }^{8}$ Por institucionalización del feminismo o feminismo institucional(-izado) entendemos las secciones del feminismo que han llegado a posicionarse en las estructuras del Estado, tales como la Academia o los partidos políticos, desde donde articulan su práctica y su discurso. Ver: Reverter Bañón, Sonia (2011), Valiente Fernández, Celia (2006) y Lombardo, Emmanuela (2003).
} 
democrática. Este cambio de color en el discurso público marcará también el tipo ${ }^{9}$ de representación de la mujer que se proyecta a través de la ficción histórica de la televisión pública.

Por último, fijaremos el límite de nuestro marco temporal en el año 2017 ya que sostenemos que en este período de nueve años (que incluye el final de la era Zapatero, la mayoría absoluta de Mariano Rajoy y otras dos campañas electorales más que han devenido en una segunda legislatura con mayoría simple de los populares en el Congreso de los Diputados) queda bien patente este contraste de discursos al que hacemos referencia.

\subsubsection{Pregunta de investigación}

Teniendo en cuenta la perspectiva culturalista y los antencedentes académicos e históricos detallados anteriormente, que configuraran en su conjunto el marco de interpretación de nuestro corpus de estudio, nuestra pregunta principal de investigación tomará la siguiente forma:

¿Cómo manifiestan los productos culturales propuestos para el análisis ( $\mathrm{La}$ Señora ${ }^{10}, 14$ de abril. La República ${ }^{11}$, Isabel y El Ministerio del Tiempo ${ }^{12}$ ) el estado del debate sobre mujer, memoria e identidad en España durante el período 2008-2017?

\footnotetext{
${ }^{9}$ A lo largo de la tesis, nos aproximaremos de manera crítica a tales tipos de representación mediante el uso de términos como «arquetipo»o «mito». Sin embargo, estos no serán usados para realizar una definición esencialista de la representación de lo femenino.

${ }^{10}$ En adelante: LS

${ }^{11}$ En adelante: 14 ALR

${ }^{12}$ En adelante: EMDT
} 
A colación de esta pregunta de investigación principal, también surgen otras complementarias que nos ayudarán a afinar nuestro análisis de acuerdo a los objetivos que nos marcábamos al principio de este capítulo:

* ¿Cuál es perfil de mujer que presentan los relatos? O ¿qué prototipo de mujer se reconoce en estos relatos?

* ¿Qué tipo de voces femeninas reproducen la memoria colectiva? ¿Desde qué situaciones sociales la reproducen? ¿En qué episodios de la Historia oficial se ven envueltas?

* ¿Qué papel y qué posicionamientos políticos otorgan estas series a los personajes femeninos principales?

* ¿Cuál es la perspectiva (tendencia de pensamiento) feminista (si existe) que reproducen estas series? $O$, ¿qué posicionamientos feministas (si se dan) reproducen los personajes femeninos relevantes?

* ¿Cómo son las relaciones entre las protagonistas y los demás personajes femeninos relevantes en estas series?

* ¿Qué paradigma de empoderamiento/poder femenino reproducen las tramas? ¿Sobre qué elementos se construye este empoderamiento?

* ¿Respecto a qué valores y condicionantes configuran las protagonistas sus elecciones vitales? 


\subsubsection{Delimitación del corpus de análisis y justificación}

Nuestro universo de análisis lo configuran las siguientes cuatro series, concretamente las temporadas que señalamos a continuación que suponen la totalidad de las emisiones del programa hasta el momento en La 1 de TVE:

a) La Señora (2008-2010): 3 temporadas.

b) 14 de abril. La República (spin off de La Señora) (2011- ?): 1 temporada.

c) Isabel (2012-2014): 3 temporadas.

d) El Ministerio del Tiempo (2015-2017): 3 temporadas.

Como puede observarse, hemos enumerado el corpus de forma cronológica, ya que consideramos que, así estructurado, el análisis permite recorrer las tramas de las series en relación paralela a los procesos políticos que se van sucediendo en el momento original de la emisión. Esto nos permitirá ver cómo se representa, por ejemplo, la discusión sobre los condicionantes de género y clase respecto al concepto de empoderamiento en LS y 14ALR, la institucionalización del feminismo y su decadencia en Isabel, o la problemática de la introducción de la figura de la mujer en las instituciones políticas y en la memoria histórica en el argumento de EMDT.

Para delimitar nuestro corpus de estudio hemos tenido en cuenta que todas las series cumplan una serie de requisitos, entre los que se encuentran:

a) Que estén protagonizadas por un personaje femenino. Esta condición nos permite presuponer que el argumento de la serie se verá fuertemente influenciado por la mirada de una mujer. A partir de esa mirada, nos interesará ver cómo se representan elementos como la violencia simbólica, institucional y directa y cómo, mediante qué recursos, estas mujeres consiguen subvertirlas. Esto es, nos interesa 
conocer la mirada de las mujeres protagonistas respecto a los procesos de empoderamiento que sus personajes experimentan en la ficción. En este sentido, también nos fijaremos en cuáles son los espacios que permiten ese empoderamiento y qué factores identitarios (como los de clase) y relacionales los posibilitan o los dificultan.

b) Ambientación historicista verosímil y condicionante. Partimos de la premisa de que se trata en todo momento de argumentos de ficción. No obstante, y a pesar de que no siempre nuestras protagonistas sean personajes históricos reales (como sí sería el caso, por ejemplo, de Isabel de Castilla en Isabel), las tramas en las que ellas intervienen sí que están directamente condicionadas por un contexto histórico real. Esto permite recrear situaciones verosímiles alrededor de las protagonistas que aportan una mirada o una versión diferente $\mathrm{y}$, por tanto, complementaria al relato oficial de la Historia. En este sentido, como podremos comprobar, la ambientación de todos los productos culturales escogidos recae en épocas no contemporáneas pero que marcan hitos clave en la construcción de la memoria nacional, entre ellas:

* La unificación cristiana de la Corona de Aragón y de Castilla en el s. XV, como marca de origen medieval de la unidad de los territorios que en la actualidad configuran el estado español. Como veremos más adelante, esta versión romantizada de los hechos históricos se reproduce obviamente en la serie Isabel, coincidiendo en el tiempo de emisión con los debates en torno a la sentencia del Tribunal Constitucional ${ }^{13}$ (BOE, 2010) que anulaba, a petición del Partido Popular, parte del Estatut d'Autonomia catalán de $2005^{14}$. Esta sentencia contra el Estatut energizó las proclamas por el derecho

\footnotetext{
${ }^{13}$ Ver: Pleno. Sentencia 31/2010, de 28 de junio de 2010. Recurso de inconstitucionalidad 8045-2006.

14 Ver: http://www.publico.es/espana/constitucional-amputa-parte-del-estatut.html [Último acceso: $19 / 06 / 2018]$
} 
a la autodeterminación e hizo emerger también las fricciones entre PSOE y PSC (Partit dels Socialistes de Catalunya) ${ }^{15}$, así como los debates internos sobre sobre la posibilidad de articulación federalista del territorio.

* La proclamación de II República, como episodio de referencia para la memoria compartida de la izquierda española, en tanto que paradigma democrático de transformación social progresista truncada por los sectores conservadores simpatizantes con la dictadura franquista. En este caso, la marca hace referencia a la necesidad de reafirmación del Partido Socialista como representante legítimo de la lucha por las libertades de las clases populares a lo largo del siglo XX, en un momento de impulso político para la revisión de la memoria histórica.

c) Emitidas en prime-time y coproducidas por TVE (La 1). La emisión en horario de máxima audiencia muestra el interés público por los temas y debates de los que se hacen eco las series. Recordemos que esta franja horaria ha sido tradicionalmente dedicada al consumo televisivo en familia, factor que desvela la necesidad política e institucional (estamos hablando en todo momento de una apuesta del canal principal de la televisión pública estatal) de poner encima de la mesa relatos que legitiman la revisión de la memoria (pre-)democrática del Estado desde la perspectiva de género en un contexto de recepción generalista, para todos los públicos, independientemente del target específico al que las industrias culturales los adscriban. Hay que tener en cuenta que las tramas de ficción protagonizadas por mujeres han tenido su horario habitual en la franja de la parrilla correspondiente al horario de sobremesa, un espacio de recepción pensado por y para las amas de casa.

\footnotetext{
15 Ver: https://elpais.com/diario/2010/07/17/espana/1279317602_850215.html [Último acceso: $19 / 06 / 2018]$
} 
Así, por el contrario, algunos de los factores que hemos descartado a la hora de configurar nuestro corpus de estudio son los siguientes:

a) Espectro horario de la parrilla televisiva dedicado a telenovelas (sobremesa-tarde), ya que consideramos que nos pueden ofrecer lecturas paralelas interesantes, pero la ubicación en la parrilla de $L a l$ de las series escogidas marcan interés generalista y no sesgado tradicionalmente por el género.

b) Productos protagonizados por hombres/unidades familiares. Consideramos que no aportan una innovación representativa respecto a memoria colectiva más mainstream reproducida tradicionalmente por los medios oficialistas (desde el propio franquismo) a partir de los años '60 del siglo XX. Dado que el propósito de nuestra tesis no es revisitar los espacios comunes de la melancolía de los hijos del baby boom y de las migraciones de las zonas rurales a las ciudades y otras zonas industrializadas, hemos decidido excluir productos del corte de Cuéntame, que responde precisamente a este paradigma de la memoria melancólica del hombre de mediana edad de la clase media emergente del último cuarto de siglo XX. ${ }^{16}$

c) Productos en formato telefilm, a pesar de que estén protagonizados por personajes femeninos y de que cumplan con los requisitos citados anteriormente. Es cierto que este formato tuvo una buena acogida en los primeros lustros de los 2000 . No fueron pocas las producciones de este tipo las que, por aquel entonces, se inspiraron en las biografías de figuras públicas femeninas de distinta idiosincrasia, especialmente las vinculadas con la cultura popular televisiva. Sería el caso de La Duquesa (Telecinco, 2010) sobre la vida de Cayetana Fitz-James Stuart, Duquesa de Alba; Hoy quiero

\footnotetext{
${ }^{16}$ Sobre el tratamiento de la nostalgia en Cuéntame, ver: Cobalán, Ana (2009) y Rueda Laffond, José Carlos y Amparo Guerra Gómez (2009).
} 
confesar (Antena 3, 2011) y Mi gitana (Telecinco, 2012), ambas sobre Isabel Pantoja; o

Clara Campoamor. La mujer olvidada (La 1, 2011), sobre la vida de la diputada sufragista de la II República española (Gámez Fuentes, 2014). Sin embargo, consideramos que este tipo de relatos se centran demasiado en ensalzar al personaje, en hilvanar los hitos destacables de su vida, los que han dado relevancia pública a su nombre, aquello excepcional, al fin y al cabo. Así pues, antes que decantarnos por estos formatos tipo compendio cuya lógica aleja a los personajes de las audiencias, preferimos los tiempos de las series. Consideramos que su extensión temporal permite que la narración descanse en lo cotidiano, en lo que resulta irrelevante a primera vista pero que permite, al final, familiarizarse con los personajes, que las audiencias se identifiquen con ellas y con lo ordinario de sus vidas.

\subsubsection{Estrategia de análisis}

Nuestra metodología se basa en el análisis crítico del discurso desde una perspectiva culturalista y feminista Así, de partida, consideramos los productos mediáticos que forman parte de nuestro corpus de estudio (las series de televisión) como un elemento del contínuum discursivo de la cultura que funciona como espacio de negociación respecto a los conflictos institucionales, las estructuras sociales y los sujetos. Mediante el análisis crítico del discurso, pondremos de relevancia las marcas o «huellas del contexto» (Van Dijk, 1992) que denotarán las tensiones existentes entre los discursos oficiales y las prácticas y aproximaciones populares a tales discursos. La práctica del análisis crítico del discurso implicará explicitar la posición socio-política desde la que el análisis desafía la posición dominante inscrita en los relatos audiovisuales respecto a un «problema social» (Silva, 2002). En nuestro caso, optamos 
por añadir la perspectiva feminista al ejercicio de análisis crítico del discurso porque esto supondrá «desplazar el pensamiento patriarcal» para ver mediante qué recursos retóricos (textuales o visuales) se representan los temas relacionados con el género (Urbain, 2018: 44).

Esto es, consideramos los argumentos de nuestras series una manifestación de las tensiones y los debates políticos que se dan en el contexto de su génesis. Es por esta razón, además, que empleamos predominantemente la perspectiva feminista a la hora de llevar a cabo el análisis crítico del discurso, ya que consideramos que resulta idónea e imprescindible en relación a la propia temática de la tesis, es decir, si queremos realizar una lectura crítica en la que la(s) figura(s) de la mujer centra nuestra atención. Además de proponer esta aplicación de la mirada feminista como hermenéutica de la sospecha (Puleo, 2013), como indicábamos al principio de este capítulo, pensamos que esta contribuirá a dar complejidad a nuestra lectura de los elementos que, en el discurso, sintomatizan precisamente el debate sobre las políticas de género en el espacio histórico-político en el que adquieren sentido las diferentes producciones que analizaremos.

La categoría de género se aplicará como herramienta de análisis porque nos permite percibir la motivación universalista androcéntrica en que se basan tanto las teorías del progreso como los marcos éticos y políticos (Harding, 1996) que también afectan, para nuestro caso, al relato de la memoria colectiva que se reproduce a través de los discursos públicos hegemónicos. Desde los Estudios para la Paz, Martínez Guzmán apuntaba que «la objetividad deja al otro fuera de la comunidad moral» (2001: 164), refiriéndose al término (objetividad) en su sentido moderno y cientifista. Como remedio, propone realizar un el ejercicio feminista en la producción de conocimiento y cuestionar la situación social desde la que se emite el mismo con el fin de valorar los 
límites de la validez del mismo. Así pues, gracias a la integración de la crítica discursiva feminista, podremos encontrar en el relato los espacios en los que tienen cabida las voces y los tipos de saberes que han sido silenciados en pro de la oficialización del discurso del poder.

En este sentido, la Teoría Feminista se nos presenta como necesaria, precisamente por este reto de situar el conocimiento. Haraway (1991: 329) apuesta por un universalismo (que no «relativismo», dice) en el conocimiento científico que parta de la integración y la intersubjetividad. La autora propone hablar precisamente de conocimientos situados frente a la neutralidad del discurso ilustrado y «las ideologías oficiales sobre la objetividad» (Haraway, 1991: 315) ejercidas, según la autora, como una «actitud de poder». Haraway señala que, más que un ejercicio de búsqueda de la verdad, la ciencia y su método resultan un ejercicio de retórica, un «artefacto» equiparable a la Historia (Haraway, 1991: 316-317) y revela que la «práctica» de los «científicos y filósofos masculinistas» a la hora de reproducir sólo un tipo de acceso al conocimiento (una metodología) limita precisamente el alcance presumiblemente universalista del saber que resulta de una investigación. Como alternativa al universalismo sesgado heredado de la modernidad y a la falacia de la neutralidad, la autora propone un ejercicio de «objetividad feminista» (Haraway, 1991: 324) en la academia. Ésta consistiría, en primer lugar, en reconocer la construcción de conocimiento y de la epistemología como tal artefacto, como una suerte de conexiones entrelazadas que permitiría, en segundo término, la contestación no sólo del contenido del saber sino también de su forma y de las limitaciones del método que ha sido empleado.

Vemos pues que la introducción de la perspectiva feminista al análisis crítico del discurso nos permitirá vislumbrar las manifestaciones intrínsecas de la 
ideología de género que, aunque es propia de una «sociedad formalmente igualitaria» (volveríamos a la nomenclatura de Ana de Miguel, 2015), se articulan en unos productos culturales escogidos para el estudio que se ambientan en el pasado. Siguiendo a Lazar (2010), nos interesará analizar cómo el discurso audiovisual construye las relaciones de poder interseccionadas por el factor del género y las dinámicas relacionales entre los sujetos femeninos representados:

The aim of feminist critical discourse studies, therefore, is to show up the complex, subtle, and sometimes not so subtle, ways in which frequently taken-for-granted gendered assumptions and hegemonic power relations are discursively produced, sustained, negotiated, and challenged in different contexts and communities. Such an interest is not merely an academic de-construction of texts and talk for its own sake, but comes from an acknowledgement that the issues dealt with (in view of effecting social change) have material and phenomenological consequences for groups of women and men in specific communities. (Lazar, 2010: 142)

Siguiendo a Lazar (2010: 150), en nuestro análisis del discurso, se prestará especial atención a la cuestión de la «relacionalidad» del género. Por este motivo, la caracterización de los personajes femeninos que protagonizan nuestras series no solo se leerá desde una dimensión individual o arquetípica, sino que también prestará atención al nivel relacional a partir de las interacciones establecidas con los demás personajes, tanto femeninos como masculinos. Consideramos que, de esta manera, analizando las relaciones de poder que se establecen entre las diferentes identidades individuales representadas desde la perspectiva de género, se vislumbran de manera más clara las cuestiones políticas y sociales que subyacen al texto audiovisual. Por esta razón nos centraremos en las secuencias que impliquen a las protagonistas y que sugieran lecturas 
entorno a los conceptos de las condiciones de género y clase, memoria, violencia y empoderamiento y sororidad ${ }^{17}$ revisadas en los marcos teórico e histórico de la tesis.

Por último, otro principio desde el que articularemos nuestro análisis, será el de «accountability» en Butler (2009), ya que el interés que marca nuestra aproximación a los textos visuales reside en analizar cómo estos dan cuenta del relato común desde el punto de vista omitido, el de las mujeres. Siguiendo la línea de la autora, este acto narrativo resultará en sí un acto de responsabilidad que defina nuestra posición respecto a tal relato. Nosotras consideramos que en este proceso de interpelación, además, el sujeto-mujer se desprende de los marcos de re-victimización que la sitúan como un elemento pasivo para narrarse como un sujeto activo y corresponsable (por acción y por omisión) de la situación en la que se encuentra en la actualidad.

${ }^{17}$ El concepto de «sororidad» con el que trabajaremos a lo largo de la tesis, se articula alrededor de la idea de «pacto entre mujeres» que encontramos en Lagarde, Marcela (2006). 


\section{Marco teórico}

Nuestra primera misión en el desarrollo del presente marco teórico se centra en vincular los conceptos de Paz, Género y Comunicación y justificar la relación entre estos tres ejes a partir de los cuales pretendemos articular el análisis de nuestros objetos de estudio. Habrá que aclarar, primordialmente, de qué hablamos cuando hablamos de paz y por qué nos resulta relevante la aplicación de la perspectiva de género en su definición. La relación de estas dos ideas nos llevará a hablar del poder y de cómo este posibilita o limita la construcción de la memoria colectiva de los pueblos desde un punto de vista genealógico. Igualmente, tendremos que hacer referencia a la dimensión performativa del discurso y de cómo los medios de comunicación, como dispositivos de la cultura, pueden contribuir a perpetuar o agrietar las lógicas de poder a partir de la transformación de los imaginarios culturales.

\subsection{Paz y Cultura: hacia la transformación de los conflictos}

Para encontrar una definición de paz que se adecúe a nuestro propósito de investigación tenemos que recurrir a lo que Vicent Martínez Guzmán ha llamado «Filosofía para hacer las Paces» (2001) y que a la vez se enmarca dentro de la nueva agenda de los Estudios para la Paz (Martínez Guzmán et al.: 2009). Para poder situar estas ideas dentro de la historia, será necesario que retrocedamos a la década de los sesenta, cuando Johan Galtung ${ }^{11}$ introduce el concepto de «paz», esta empieza a ser entendida en términos de justicia social y se incide en la denuncia de la violencia

\footnotetext{
11 Johan Galtung crea el Peace Research Institute de Oslo (PRIO) el 1959. En la década de los sesenta también aparecen publicaciones como el Journal of Peace Research, el nombre de la cual ya denota el giro hacia a una perspectiva pazológica de los estudios sobre conflictos.
} 
estructural (Martínez Guzmán, 2010: 293; 2001: 64-65). Hasta entonces, el concepto de paz había sido construido en un sentido negativo, es decir, como la «mera ausencia de guerra» (Martínez Guzmán, 2001: 63). Esto no es nada extraño si tenemos en cuenta que el interés originario de estos campos de estudio, en los años cincuenta, había sido articulado desde una perspectiva violentológica y una metodología cuantitativa empleadas para estudiar y valorar los daños causados por las dos guerras mundiales, así como para evitar el estallido de nuevos conflictos armados del mismo tipo.

Es el mismo Martínez Guzmán quien pone de relevancia la influencia de Galtung y su esfuerzo por vincular las dimensiones «sociedad civil, capital y estado» (Galtung, 1995 en Martínez Guzmán, 2010: 387) y diferenciar en base a éstas, las tres tipologías de violencia que conforman su conocido triángulo (Galtung, 1990). Esta diferenciación también nos resultará útil a la hora de vislumbrar el vínculo entre la paz, la cultura y la comunicación y las lógicas de dominación que se pueden perpetuar o transformar por la acción de las estructuras mediáticas. Paradójicamente, parece que no acabamos de rechazar la perspectiva violentológica para poder otorgar valor a la idea de paz. Sin embargo, Martínez Guzmán (2010: 387) apunta:

Son interesantes los tres tipos de violencia, el intento de positivar la paz como alternativa a la violencia estructural, su relación con las necesidades básicas y el desarrollo y, finalmente, la cultura de Paz como alternativa a la violencia cultural (Galtung, 2003). De este último tipo de violencia consideramos relevante que «pueda hacer opaca nuestra responsabilidad moral». Equiparamos la violencia cultural, a la violencia simbólica de Bourdieu (2000) y a los análisis feministas que consideran que hay formas de dominación para las que somos «ciegos» precisamente por la manera sutil en que penetran las relaciones humanas [...] y por su propia crítica de las ciencias modernas como fuente de violencia cultural. 
Como bien apunta el autor en la cita, Galtung diferencia tres tipos de violencia, situados a su tiempo en dos niveles de visibilidad, como se puede ver en la siguiente ilustración:

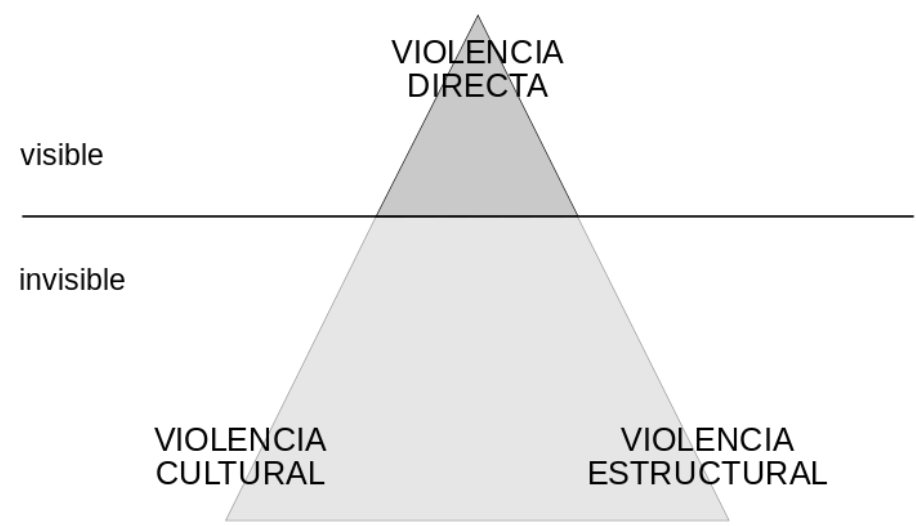

Imagen 1: «Triangulo de las violencias de Galtung». Fuente: Wikimedia Commons, por PepeEfe en CC.

En la parte superior, Galtung coloca la violencia directa, que contiene todas las manifestaciones de violencia que se pueden identificar fácilmente como un ataque a la integridad física o la vida del cuerpo. En la base del triángulo podemos encontrar, por un lado, la violencia estructural, la que se refiere a la falta de protección de los derechos humanos o la denegación de acceso a las necesidades básicas. Este tipo de violencia se asocia, por ejemplo, con la esfera institucional y las garantías de una sociedad de bienestar. Al otro lado, Galtung (1990) sitúa la violencia cultural, definida como el conjunto de actitudes y supuestos compartidos que simbólicamente sustentan la perpetuación de un sentido común violento que permite la tolerancia o la aceptación tanto de la violencia directa como de la estructural. Además, el autor sostiene que los tres vértices del triángulo están conectados y que el ciclo de la violencia se puede activar en cualquiera de ellos. 
Teniendo en cuenta esta diferenciación, vamos a lo que verdaderamente nos interesa, que es la relación opuesta a los tres tipos de violencias: las tres esferas de la paz que le dan sentido a la propuesta epistemológica de la filosofía de Martínez Guzmán. De acuerdo con esta, habría que diferenciar la paz negativa (como la ausencia de violencia directa ejercida tanto entre individuos civiles como por parte de las fuerzas del orden), la paz positiva (como la garantía de los derechos humanos en el marco del estado moderno pacífico, para nuestro caso) y la cultura de paz (la dimensión actitudinal compartida por una sociedad) (Martínez Guzmán, 2010: 73).

Al contrario de lo que decíamos antes que ocurre con la violencia, el estado de paz negativa (como la desaparición de la violencia directa contra los grupos o individuos políticamente oprimidos) no implica necesariamente la activación del ciclo de paz dentro del triángulo de Galtung. De hecho, incluso un Estado pacífico en el plano político puede ser sostenido por la violencia estructural y/o cultural para mantener los privilegios de los sectores más poderosos, lo que, al mismo tiempo, pone límites a los marcos de acción de los sectores tradicionalmente desempoderados.

La distinción que Galtung hace de las esferas y los niveles de visibilidad de la violencia, así como la equiparación que articula con los escenarios de paz, resulta de gran operatividad tanto en la vertiente de-constructiva como re-constructiva de los Estudios para la Paz. Martínez Guzmán, Comins Mingol y París Albert (2009: 97) hacen referencia a esta doble vertiente y la ponen en valor señalando tanto la necesidad de, por un lado, poner de relevancia el análisis y la denuncia de los actores y factores en una situación de violencia $\mathrm{y}$, por otro, vislumbrar posibles caminos para la transformación pacífica del conflicto generado en un escenario de violencia.

En la línea de lo expuesto en el anterior párrafo y en relación a las series que forman parte de nuestro corpus, veremos que nuestro trabajo se sitúa precisamente en el 
plano de la cultura. Nuestra tarea se centrará en analizar cómo los argumentos de las series articulan el debate público acerca de la situación de la mujer en la vida pública y del espacio que se le ha dado en la memoria democrática. Por eso nos interesa ver cómo las tramas que envuelven la acción de las protagonistas deconstruyen la cuestión de las violencias travesadas por la categoría de género y las explicitan desde una perspectiva genealógica. Eso, por un lado. Y, por otro, cómo reconstruyen escenarios y exploran creativamente posibilidades de empoderamiento y resistencia que, aunque condicionadas por la categoría del género, constituyen casos de transformación pacífica de conflictos

\subsection{Cultura para la paz: la intersubjetividad y la comunicación en la nueva agenda de los Estudios para la Paz}

En el último párrafo se ha hecho referencia a uno de los elementos clave que posibilitan la viabilidad de la propuesta de Martínez Guzmán (2005) dentro la nueva agenda de los Estudios para la Paz: la transformación de los conflictos. En lugar de hablar de «resolución» o de «gestión» de los conflictos (2005: 119-120), el autor apuesta por la idea de transformación y devuelve la dimensión del conflicto en el ámbito micro (2005: 137), al de las relaciones intersubjetivas del día a día. Así, Martínez Guzmán, considerará tales conflictos como intrínsecos a las relaciones humanas, adscribiéndolos connotaciones positivas en tanto que los considerará como una posibilidad de diálogo real y siempre imperfecta, inacabada, para la «reciprocidad y el reconocimiento» (2005: 119). 
En este sentido, el conflicto deja de percibirse como un asunto macro $^{12}$ del cual se habla y sobre el cual se decide en las altas esferas de poder, para pasar a tenerse como un factor inevitable y enriquecedor, como una oportunidad para el entendimiento y también para el empoderamiento, para el desarrollo y la recuperación de habilidades que conlleven la consecución de beneficios para la colectividad a pequeña escala. En esta línea, el giro epistemológico que plantea el filósofo (Martínez Guzmán, 2000: 9092), destaca la necesidad de la «interpelación mutua» sobre «lo que nos hacemos unos a otros» e incorpora la perspectiva del «cuidado» y la «vulnerabilidad» ${ }^{13}$ al sentido de la justicia social para una gobernabilidad al margen del estado-nación que tiene también en cuenta la categoría de género como instrumento de análisis de los conflictos.

Como ya habíamos apuntado, nuestro campo de interés se sitúa en el espacio de la cultura y, en concreto, de la comunicación. Es en el análisis deconstructivo de los discursos mediáticos donde la propuesta del giro epistemológico de Martínez Guzmán toma importancia. Lo hacen especialmente respecto al papel que el autor le otorga al carácter intersubjetivo de la comunicación en el proceso de transformación de los conflictos y de la necesidad de integración de las voces de la alteridad, que fomentan la investigación y la puesta en práctica de otros saberes que dan cuenta de maneras de subvertir conflictos de todo tipo, también en el plano de lo cotidiano. Es el propio filósofo quien, además, acabará poniendo matices a

\footnotetext{
${ }^{12}$ La visión macro de los conflictos en la peace research se relaciona con el carácter interestatal de los conflictos que motivan el inicio de este campo de estudio durante los años cincuenta.

${ }^{13}$ En los Estudios para la Paz, el uso del término «vulnerabilidad» suele usarse acompañado de las palabras «fragilidad»y «reconocimiento» y asociado a la vertiente reconstructiva (de la que hablaremos en las próximas páginas, a colación de la propuesta de ética comunicativa de Martínez Guzmán), centrada en la transformación pacífica de conflictos. Así pues, Martínez Guzmán y París Albert (2006) propondrán potenciar las interrelaciones humanas «desde la asunción de nuestra fragilidad (etimológicamente: con qué facilidad "nos rompemos") y nuestra vulnerabilidad (etimológicamente: con qué facilidad "nos sentimos heridos")».
} 
[...] la fórmula simple «cultura de paz»y atendemos a la diversidad de culturas, etimológicamente, de formas de cultivar las relaciones entre los seres humanos y entre estos y la naturaleza. Así, podemos hablar de «cultura» como característica peculiarmente humana y de «culturas»y «paces» en atención a la diversidad de maneras de cultivar las relaciones entre diferentes grupos humanos y la naturaleza (Martínez Guzmán, 2010: 299).

Esta apuesta por la pluralidad de subjetividades y de experiencias y la puesta en valor de los saberes de la alteridad, así como la centralidad de la comunicación para la transformación de los conflictos, nos resulta esencial para el análisis del discurso en las series que hemos propuesto para el estudio en esta tesis. En ellas la memoria de las mujeres es la que se presenta como ese «otro saber» que no consta en la construcción del imaginario de la democracia moderna o que, como mucho, se ha considerado una experiencia tangencial, circunstancial o anecdótica. Esta exclusión inicial, que se presenta como conflictiva per se, resulta, desde los Estudios para la Paz y mediante la introducción de la categoría de género, una oportunidad para transformar los conflictos políticos actuales. Del mismo modo que Martínez Guzmán propone mirar a los pueblos e individuos oprimidos, empobrecidos, colonizados, y reconocer las culturas minorizadas como fuentes de saber legítimo, cuando apuesta por incluir la perspectiva de género nos dice que también hay que empezar a poner en valor los conocimientos que tradicionalmente han estado en las manos de las mujeres como consecuencia de la separación dicotómica de los espacios públicos y privados en las sociedades modernas en función precisamente del género.

En esta línea, la nueva agenda de los Estudios para la Paz se caracterizará por la promoción de las culturas de paz, es decir, en cómo las personas hemos transformado, a lo largo de los tiempos y en las diferentes circunstancias y espacios 
geográficos, los contextos de violencia directa, estructural y cultural. Esta «misión» pasa por la interpelación necesaria de los criterios desde los cuales la Academia ha abordado los conflictos y sobre los que esta ha construido no solo la ciencia, sino el discurso de la Historia, siempre basada en la relación causal entre hitos catastróficos provocados y sufridos por la humanidad. La vocación de utilidad de esta disciplina filosófica deja patente que

Ya no se trata de aprender sobre la paz desde el que no es paz, sino de denunciar la violencia y la guerra, etc. desde la recuperación de los momentos de paz que, aunque imperfecta, también están presentes en la historia de las relaciones humanas. (Martínez Guzmán, 2001: 70)

La interdisciplinariedad, al igual que la interculturalidad y la intersubjetividad, formarán parte esencial de la nueva agenda de los Estudios para la Paz (Martínez Guzmán et al., 2009). En este sentido, los procesos comunicativos se situarán como eje vertebral de la propuesta para la transformación pacífica de los conflictos de Martínez Guzmán (Forastelli, 2013). Así, el análisis crítico del discurso se consolida como parte fundamental de la vertiente deconstructiva $\mathrm{y}$, por otra parte, la función performativa del lenguaje se situará en la vertiente reconstructiva, es decir, en la dimensión de la comunicación a través de la que se puede percibir la voluntad y la capacidad humana de hacer las paces, donde se perciben los cambios en las actitudes.

De esta manera:

[...] se incide en la importancia de los procesos simbólicos en los conflictos o acontecimientos sociales y culturales. Se pone de manifiesto (se detecta, se denuncia) toda forma de violencia cultural para proponer además discursos alternativos de cultura de paz. Se busca «des-legitimar» la violencia y la injusticia, a veces inherentes, asumidas, opacas en los discursos cotidianos y oficiales, para tratar de abrir espacios y dar una 
visibilidad similar a otros discursos con propuestas de justicia para todos y todas por igual. (Nos Aldás, 2010: 132)

Martínez Guzmán sostiene que las personas tenemos la capacidad de «tomar conciencia» de nuestras contradicciones morales y de cómo estas son fruto de la ficción sesgada de nuestra visión mundana (es decir, de las interpretaciones heredadas y aprehendidas a través del aprendizaje y la socialización). Y, según dice, esta capacidad configura el primer paso hacia la «subversión epistemológica» (2001: 11). Del mismo modo, podemos articular estrategias comunicativas para reconstruir alternativas pacíficas y transformar los conflictos intersubjetivos y políticos, sin necesidad de recurrir a la violencia ni a metodologías prescriptivas heredadas de la vieja agenda polemológica.

Así pues, será en la comunicación y en la intersubjetividad donde Martínez Guzmán detecta la oportunidad de hacer las paces o, lo que es lo mismo, articular la confianza entre sujetos, entre comunidades y culturas (2001: 109). Esta es una posición que se entiende por la influencia que en el autor han tenido sus investigaciones sobre fenomenología y pragmática del lenguaje, de la que recupera la idea de «performatividad» de los actos de habla, la cual pone en juego el compromiso con lo que decimos y la responsabilidad intersubjetiva:

A esta alternativa a la actitud objetiva se la denomina desde Austin (1971), actitud performativa, realizativa o ejecutiva [...] [que] incluye la gama de [...] sentimientos reactivos que son propias [sic] del compromiso y la participación en relaciones humanas interpersonales. (Martínez Guzmán, 2001: 164) [La cursiva es original]

Esta actitud performativa se vincula, en la pragmática lingüística de Austin (1971), con la fuerza ilocucionaria del lenguaje, la dimensión que pone de manifiesto que «decir es hacer $\mathrm{y}$, cuando decimos algo, lo que importa es [...] a qué nos 
comprometemos al decir lo que decimos» (Martínez Guzmán, 2001: 199). La posibilidad de producir confianza comunicativa a partir de lo que decimos, la responsabilidad con lo que hacemos, entra en juego en la inmediatamente posterior dimensión del lenguaje, la perlocucionaria, «que consiste precisamente en las consecuencias que se siguen de lo que nos decimos». Es en esta dimensión, en la que se ancla la confianza entre los interlocutores porque es el plano desde donde se nos puede «pedir cuentas» (Austin 1975). Por esa razón, será también el plano donde se puede valorar nuestra «solidaridad comunicativa», es decir, si se es sincera o sincero al hablar y si asumimos la responsabilidad de lo que hacemos al decir (Martínez Guzmán, 2001: 199-200).

Por otro lado, Judith Butler (2009 dirá que «la capacidad narrativa se erige en una precondición para dar cuenta de sí mismo [sic] y asumir la responsabilidad por los propios actos a través de este medio» (Butler, 2009: 25) y articulará el concepto de «accountability» desde la idea de interpelación como parte constituyente del sujeto. Así:

La interpelación establece el carácter de la razón que doy de mí como tal, y ésta sólo se complementa cuando es efectivamente extraída y expropiada del dominio de lo que es mío. Sólo en la desposesión puedo dar y doy cuenta de mí misma. [...] $\mathrm{Si}$ intento hacerme reconocible y entendible, podría comenzar con una descripción narrativa de mi vida. Pero ese relato perderá el rumbo a causa de lo que no es mío, o no lo es con exclusividad. [...] (Butler, 2009: 56)

Es decir, que la acción narrativa mediante la cual doy cuenta de mi misma denota la situación (por ejemplo, de privilegio o de poder) desde la que construyo el sentido del mundo a través del acto de habla. De la misma manera, en mi propia capacidad de interpelación reside la capacidad de reconocer la responsabilidad de mis actos respecto a esa situación contextual: 
La autoridad narrativa del «yo» debe ceder paso a la perspectiva y la temporalidad de un conjunto de normas que impugnan la singularidad de mi historia. (Butler, 2009: 56)

\subsection{La memoria en la vertiente reconstructiva de los Estudios para la Paz}

Siguiendo con el argumento que Butler expone en la cita anterior, repararemos ahora en la cuestión de la memoria y el papel que juega esa recuperación de experiencias de paz que también han configurado la historia. En las páginas anteriores también habíamos referenciado a Martínez Guzmán, cuando dice que la paz puede ser «imperfecta». En este caso el autor hace referencia a la teoría de Francisco Muñoz (2001). Esta se sustenta en el carácter procedimental de la paz, es decir, en su concepción como un proceso inacabado (Muñoz, 2001: 21, 42-44) y por lo tanto imperfecto. Así, Muñoz pone en primer plano el potencial humano para la construcción de paz y cuestiona la perspectiva negativista de la historia y de la concepción judeocristiana de la condición humana (Muñoz, 2001: 23) que permanece en los imaginarios occidentales. En esta línea, definirá su idea de la siguiente manera:

Podríamos agrupar bajo la denominación de paz imperfecta a todas estas experiencias y estancias en las que los conflictos se han regulado pacíficamente, es decir en las que los individuos y/o grupos humanos han optado por facilitar la satisfacción de las necesidades de otros, sin que ninguna causa ajena a sus voluntades lo haya impedido. (Muñoz, 2001: 38)

Efectivamente, y como también apunta el propio autor, esta definición de paz podría situarse a medio camino entre las dimensiones de paz negativa y paz positiva de Galtung. No obstante, Muñoz también tiene en cuenta la dimensión relacional, «las interacciones e interdependencias» intersubjetivas que favorecen o reclaman una 
transformación de los conflictos por medios pacíficos (Muñoz, 2001: 39-40). Lejos de querer aliviar la carga de la desigualdad en el acceso al poder y al reconocimiento y consecución de los Derechos Humanos fundamentales que se encuentra en la base de la conflictividad en las sociedades modernas, consideramos que la propuesta de Muñoz nos puede resultar operativa. Esto es, pensamos que la visión de la paz imperfecta nos puede ayudar a apreciar la complejidad de la intrahistoria, a tener en cuenta y poner en valor las historias de supervivencia en los márgenes o los espacios de «paz suficiente». Pero, a la vez, mostramos cierta precaución a la hora de asumir esa idea cuando esta contribuya a facilitar lecturas reduccionistas de los conflictos y motive lecturas donde la paz negativa no sea considerada como causante del sufrimiento sino como mera imperfección del sistema. Pensamos que, de tomar esta postura, la supervivencia dejaría de ser vista como un conjunto de estrategias vitales de resistencia y se desmotivaría la búsqueda de la justicia social.

De cualquier modo, debemos de retener la idea de que, al igual que la ciencia moderna ha desarrollado un discurso pretendidamente universal y objetivo pero sesgado por el punto de vista occidental, la Historia como disciplina solamente ha sido relatada, como se dice popularmente, por los ganadores. Es decir, por aquellos que han ostentado el poder. Así, la Historia de los Estados-nación modernos tendrá un claro sesgo de género, clase y procedencia y, por tanto, habrá sido construida desde la experiencia y la voz del hombre blanco y desde el punto de vista de los conflictos políticos. Por el contrario, han quedado excluidas esas experiencias al margen de esos grandes hitos de las relaciones institucionales. Esto es, los modos de vivir, sobrevivir y gobernar el espacio público más cercano, el nivel relacional entre iguales, el cuidado y la gestión de los espacios familiares o de todo lo que se ha entendido como privado y 
que ha sido mayoritariamente gobernado por las mujeres y excluido de los espacios de representación.

Los Estudios para la Paz, en ese sentido, se presentan como una disciplina transversal que se interesa por la complejidad y apuesta por recuperar alternativas y poner en valor las historias de la alteridad que puedan servir de referencia a la hora de reconstruir escenarios de paz y dar voz así a quienes tradicionalmente no la han tenido. En este afán por aportar complejidad a los imaginarios, reside el interés por la instersubjetividad y por explorar nuevos loci de enunciación que contribuyan a la apertura a nuevas epistemologías de paz (Nos Aldás, 2010: 129). Para operativizar esta idea nos resultará de gran ayuda acudir a la propuesta de Keightley y Pickering (2012) sobre la «imaginación mnemónica».

Los autores plantean que la memoria resulta una fuente vital para el acto de imaginar, es decir, ponen sobre la mesa la idea de que no podemos proyectar nuevos escenarios posibles o futuros (de cualquier clase: sociales, políticos, afectivos, etc.) sin recurrir a la experiencia pasada y sostienen que la misma imaginación es imprescindible para que el sujeto pueda dotar de coherencia sus propios recuerdos. Si seguimos esta afirmación, podremos sostener que nos resultaría imposible imaginar o plantear métodos o vías para la transformación pacífica de los conflictos y la resistencia si previamente no hemos tenido experiencia o constancia de estas. De hecho, los autores hablan del continuum del relato social que siempre se ha utilizado de los acontecimientos del pasado para proyectar posibilidades en el futuro.

Es inevitable que el concepto anterior nos recuerde y nos invite a vincularlo a la propuesta de Lederach (2005) sobre la «imaginación moral» como recurso para la transformación pacífica de los conflictos, sobre la cual dice: 
To imagine responses and initiatives that, while rooted in the challenges of the real world, are by their nature capable of rising above destructive patterns and giving birth to that which does not yet exist. In reference to peacebuilding, this is the capacity to imagine and generate constructive responses and initiatives that, while rooted in the day-to-day challenges of violent settings, transcend and ultimately break the grips of those destructive patterns and cycles. (Lederach, 2005: 182)

Este autor sostiene que la herramienta de la imaginación moral solo funciona si superamos el binomio dominado-dominador y pensamos las relaciones como una red de interdependencias y apuesta, de esta manera, por contar con la complejidad de las relaciones como un factor enriquecedor. Además, invita a poner la propia creatividad por delante del uso de la violencia como método para la seguridad de las comunidades y a aceptar la vulnerabilidad característica de la vida.

Resulta interesante cómo las premisas que presenta Lederach (2005: 173) para el desarrollo de estrategias de imaginación moral pueden clasificarse o ser tomadas como herramientas para el empoderamiento o como guías para la recuperación y enfatización de habilidades humanas que han sido puestas en juego en situaciones de resistencia o paz negativa. Es en este punto donde funciona la combinación entre las ideas de imaginación moral y mnemónica, ya que este segundo tipo puede inspirar al primero en la búsqueda de otras formas de hacer política desde espacios ${ }^{14}$ del no-poder, que son precisamente los espacios donde y para los que, por ejemplo, se ha socializado a la mujer.

\footnotetext{
${ }^{14}$ Para ampliar, ver a Lederach (2005): «Horizontal capacity: The ability to build and sustain relational spaces of constructive interaction across the lines of division in systems and societies divided by historic patterns of identity conflicts».
} 


\subsection{Introducción de la perspectiva de género en los Estudios para la Paz}

La aplicación de la perspectiva de género aparece de manera transversal en las investigaciones de los Estudios para la Paz a partir de la década de los ochenta. Una década en la que los avances en el otorgamiento de sentido al concepto de paz y su legitimación como objeto de estudio en el ámbito académico (Martínez Guzmán, 2001: 63) sufrieron un ligero retroceso debido a que las investigaciones ${ }^{15}$ en este campo volvieron a fijarse de nuevo en la denuncia de la violencia, debido a la carrera armamentista de la Guerra Fría y la amenaza de un conflicto bélico nuclear (Martínez Guzmán, 2001: 66). Sin embargo, esta década resultará fructífera en cuanto al activismo ciudadano.

Las aportaciones de los movimientos sociales, como el feminismo o el ecologismo, permitieron vislumbrar algunas de las cuestiones que se pondrán de relevancia con la caída del muro de Berlín y el inicio de la era global, como lo es la influencia del discurso mediático -especialmente, el televisivo- en la formación de la opinión pública (Martínez Guzmán, 2001: 67-68) y en la consecución de una cultura de paz a través de la inclusión de las voces silenciadas por la ideología patriarcal etnocéntrica occidental que impregna los discursos públicos. En concreto, tal y como señala Martínez Guzmán (2010: 388):

Elise Boulding (1995; 2000; Morrison, 2005), por su parte, introduce la perspectiva de género en la investigación para la paz que después será completada por Birgit Brock-Utne $(1987 ; 1989 ; 1990)$ y Betty Reardon y [...] Carmen Magallón (2003; 2004; 2006; 2007). Esta perspectiva influye en nuestra filosofía para hacer las paces hasta el punto de profundizar en

\footnotetext{
${ }^{15}$ Estas investigaciones pueden verse recogidas en publicaciones como el Nuclear Times o el Peace Review
} 
las éticas del cuidado además de las de la justicia (Comins Mingol, 2008; Martínez Guzmán, 2003), y en la elaboración de criterios para unas nuevas masculinidades desde las culturas para hacer las paces. (Martínez Guzmán, 2002)

Tal como Martínez Guzmán sostiene en su «giro epistemológico» (2001: 114-116), esta categoría analítica que tomamos de la tradición y la metodología de la Teoría Feminista cuestiona los estatutos científicos de la Modernidad occidental que se han configurado de manera excluyente y sesgada por el punto de vista masculino (blanco, occidental y de clase media-alta). Así, dirá que «reconstruimos como instrumento de análisis y estudio la categoría de género que nos hace ver cuando hemos excluido a las mujeres en nombre de la neutralidad».

También resulta parte imprescindible en cuanto a esa doble vertiente metodológica de los Estudios para la Paz (Magallón Portolés, 1999 citada en Martínez Guzmán, Comins Mingol i París Albert 2009: 106), en tanto que, desde un punto de vista de aplicación práctica, permiten, por un lado la denuncia de los tres tipos de violencia que diferencia Galtung -directa, estructural y cultural- y el planteamiento y/o recuperación de alternativas que subviertan las situaciones de conflicto. La propuesta de «inversión epistemológica» de Martínez Guzmán y su interés por reconocer «las competencias humanas para hacer las paces» (2000) dialoga perfectamente, pues, con una de las misiones de los Estudios de Género: la recuperación y reconstrucción del relato de la alteridad (es decir, de todo aquello diferente al prototipo hombre blanco, de mediana edad, clase media-alta y heterosexual). Así, concretamente dirá: «esos relatos explicativos que constituyen los saberes de las mujeres» (Martínez Guzmán, 2000: 8889), o también: 
Una perspectiva crítica de visibilización de los diferentes tipos de violencia directa, estructural y cultural a los que se ve sometida la mujer, de análisis y denuncia de su situación de subordinación y de la negación de sus derechos. Una perspectiva constructiva de reconocimiento de los diferentes modos en los que las mujeres han contribuido a la construcción de la paz, como activistas, organizadas en grupos internacionales o desde espacios más cotidianos de la sociedad civil; también desde esta perspectiva se plantea la construcción a través de la educación y los medios de comunicación de nuevos modos de ser femeninos y masculinos más flexibles y más pacíficos Martínez Guzmán, Comins Mingol y París Albert (2009: 106)

En este sentido, las diferentes corrientes del feminismo abren las puertas a estas nuevas epistemologías pazológicas a las que dan valor los Estudios para la Paz, ya que problematizan la exclusión de lo femenino en los procesos de definición de la historia y de la cultura y nos ofrecen la posibilidad reconocer las manifestaciones de la violencia (cultural, estructural y directa) a partir del propio cuestionamiento que las feministas han realizado de sus bases ideológicas.

A esta condición se le suma esta noción de compromiso con los valores que posiciona los Estudios para la Paz en contra de la unilateralitzación de la razón ilustrada (Martínez Guzmán, 2000: 91): « [...] no pretendemos ser neutrales respecto a los valores. Es más, denunciamos los valores, o mejor, disvalores que se esconden detrás de esta aparente neutralidad [...]». Así, esta nueva focalización micro aportada por las feministas en los estudios para la Paz, pone de manifiesto la relevancia del tercer tipo de violencia a que se refiere Galtung (1995) en su propuesta conceptual: la violencia cultural, que define como «justificación o legitimación de las otras (violencias: directa y estructural)» y sobre la que Martínez Guzmán (2001: 71) dice que «cambia el color moral de los actos: los hace opacos»». 


\subsubsection{La perspectiva de género sobre el discurso y el poder}

Martínez Guzmán dice que «la objetividad deja al otro fuera de la comunidad moral» (2001: 164), refiriéndose al término (objetividad) en el sentido moderno. En el caso, por ejemplo, de las investigadoras mujeres, el ejercicio feminista en la producción de conocimiento nos permite también cuestionar nuestros posicionamientos y valorar nuestras situaciones de privilegio relativo. En el espacio académico, la categoría de género se aplicará sistemáticamente en las investigaciones para la paz como elemento de análisis que nos permite percibir la motivación universalista androcéntrica en que se basan tanto las teorías del progreso como los marcos éticos y políticos que las siguen sustentando y perpetuando (Harding, 1996) a día de hoy por el discurso hegemónico.

Es necesario que en este punto demos espacio a las reflexiones de Haraway sobre los conocimientos situados, la hegemonía del discurso ilustrado y la neutralidad. La autora cuestiona «las ideologías oficiales sobre la objetividad» (Haraway, 1991: 315), ya que entiende que están ejercidas como una «actitud de poder». Haraway señala que, más que un ejercicio de búsqueda de la verdad, la ciencia y su método resultan un ejercicio de retórica, un «artefacto» equiparable a la Historia (Haraway, 1991: 316-317) y revela que la «práctica» de los «científicos y filósofos masculinistas» a la hora de reproducir sólo un tipo de acceso al conocimiento (una metodología) limita precisamente el alcance presumiblemente universalista del saber que resulta de una investigación.

Como alternativa al universalismo sesgado heredado de la modernidad y de la falacia de la neutralidad, la autora propone un ejercicio de «objetividad feminista» (Haraway, 1991: 324) en la academia. Esta consistiría, en primer lugar, en reconocer la construcción de conocimiento y de la epistemología como artefactos, como una especie 
de «conexiones entrelazadas» que permitiría, en segundo término, la «contestación» no sólo del contenido del saber sino también de su forma y de las limitaciones del método que ha sido empleado.

Atendiendo a estas reflexiones, que podemos situar en la línea de los Estudios para la Paz, podemos reafirmar que gracias a la integración de la crítica feminista nos resulta más fácil desentrañar los procesos de reconocimiento de unas voces y de unos tipos saberes en detrimento otros, que han sido silenciados, y apostar por un universalismo (que no «relativismo», como apunta Haraway, 1991: 329) integrador, intersubjetivo.

En la misma línea, encontramos a Joan Scott (1990), que apuesta por revisar métodos de análisis histórico y explicar la dinámica de los procesos de cambio desde la complejidad de los factores. Se trataría de «preguntarnos más a menudo cómo ocurrieron las cosas para encontrar por qué ocurrieron» (Scott, 1990: 65) para dejar de reducir a causalidad generalista el rumbo de la Historia y contribuir a una explicación significativa de las condiciones de desigualdad en las interacciones sociales que motivaron el deseo de cambio. De este modo, según Scott, es como se puede intuir cómo actúa el género en las interrelaciones de poder, en las motivaciones de los sujetos individuales y en el tipo de organización social presente en los momentos de cambio. La autora considera que aplicar la perspectiva de género en las investigaciones supone, por tanto, asumir la relevancia significativa de la dicotomía biológica de la tradición occidental judeocristiana en la distribución y el acceso al poder y recurre a la idea de «función legitimadora del género» de Bourdieu (Scott, 1990: 68-69) para explicar por qué el género (como concepto diferencial) facilita la decodificación del significado de las complejas interacciones humanas y nos confirma que el concepto género legitima y construye las relaciones sociales recíprocas sobre la base de la diferencia. A partir de 
aquí, podríamos ver cómo el género construye la política (las relaciones de poder) y viceversa.

No es extraño, por tanto, que Scott apueste por el sentido de poder de Foucault (1977), según el cual convendría empezar a descartar la idea del «poder social» como algo centralizado, unificado y coherente y empezar a tener en cuenta el sistema de «campos de fuerza sociales». Esto implicaría identificar los discursos que sustentan, resisten o reinterpretan un imaginario social y con ello, las desigualdades en la estructura social y en los procesos de cambio. De hecho, Foucault repara de manera muy clara en la conexión retroalimentativa entre saber y poder, lo que también sustenta el esfuerzo teórico contra la «unilateralitzación de la razón» presente en el discurso de Martínez Guzmán al que hemos hecho referencia antes. En concreto, dice: «no es posible que el poder se ejerza sin el saber, es imposible que el saber no engendre poder» (Foucault, 1977: 76).

Entendemos por tanto que, si el ejercicio del poder acompaña el desarrollo de un determinado tipo de saber (que a su vez sustenta pilares y configura los márgenes de lo que podemos llamar y dotar de sentido, lo cognoscible y normativo), las posibilidades de validar y posicionarse desde dentro de las estructuras académicas a partir de un discurso teórico sobre el poder (que cuestione de base su propia legitimidad genealógica), como es el caso del feminismo, serán (y están siendo) bastante limitadas.

Sin embargo, podemos recurrir aquí de nuevo a la idea de la «paz imperfecta» de Muñoz (2001) y a la centralidad de las interdependencias de los sujetos para acercarnos a la definición de Foucault sobre la «condición de posibilidad del poder». Esta le otorga una concepción móvil, cambiante y estratégica a las relaciones de poder, dota de sentido el concepto de empoderamiento que heredamos del feminismo: 
[...] por poder hay que comprender, primero, la multiplicidad de las relaciones de fuerza inmanentes y propias del dominio en que se ejercen, y que son constitutivas de su organización; el juego por medio de luchas y enfrentamientos incesantes las transforma, las refuerza, las invierte; [...] el poder no es una institución, y no es estructura, no es cierta potencia de la que algunos estarían dotados: es el nombre que se presta a una situación estratégica compleja en una sociedad dada. (Foucault, 2002: 112-113)

Sobre el empoderamiento, Martínez Guzmán dirá que «tiene el significado que alguien recupere sus poderes, capacidades; tenga la posibilidad de potenciar sus competencias, se sienta revalorizado o valorado». Esta idea de empoderamiento la llena de matices Lederach (2005) cuando atiende a las capacidades para transformar los conflictos pacíficamente (Martínez Guzmán, 2005: 133). Su potencial subversivo supone «un crecimiento moral desde dos dimensiones: la de la recuperación del valor propio, de las capacidades propias [...] y su interacción con la del reconocimientos de los y de las demás» (Martínez Guzmán, 2005: 133). Por ello, la aplicación de la perspectiva de género al análisis de ejercicios de imaginación mnemónica o en torno a los ejes que propone Lederach sobre la imaginación moral puede resultar una herramienta de gran utilidad a la hora de detectar, en los relatos del pasado, estrategias de resistencia y procesos de empoderamiento individuales y grupales aplicables a circunstancias y escenarios del presente.

Martínez Guzmán dice que « [...] hay relaciones entre lo que sabemos y lo que podemos hacer, entre saber y poder» (2000: 85). Nosotras diríamos, en esta línea, que, si excluimos o eliminamos del imaginario colectivo los saberes de las mujeres, de alguna manera nos estamos desempoderando, en tanto que estamos desaprendiendo conocimientos y dejando de adquirir habilidades por el hecho de no cuestionar la minusvaloración a la que está sometido «lo femenino». Por el contrario, si adquirimos la 
capacidad de comprender las maneras en que históricamente se ha dominado a las mujeres desde diferentes situaciones de poder, podremos detectar y transformar pacíficamente otras maneras de dominación (por razón de etnia, clase social, nacionalidad, etc.) donde la diferencia de género se presenta como una cuestión transversal. La incorporación metodológica de la perspectiva de género, ya sea en la lectura deconstructiva de los conflictos como en la mnemónica / reconstructiva de nuestras capacidades para hacer las paces, nos permite además reconocer nuestra situación de privilegio y ver las posibilidades estratégicas que podemos aprovechar (quizás imperfectamente).

No obstante, hablar de empoderamiento y de mujer, requiere todavía pasar por la idea de performatividad del género de Butler (2001). Si cruzamos la idea de la posibilidad de poder con la del empoderamiento femenino, se presentan algunas complicaciones derivadas de la subversión de la «ley de coherencia heterosexual» (Butler, 2001: 169) que sólo reconoce lo poderoso en lo masculino. Vincular el poder, el cual colocamos discursivamente en las esferas de la vida pública, con la idea de feminidad, como lo que por oposición no es ni masculino, ni público, genera en sí una paradoja que sólo podrá ser aceptada en circunstancias de excepción o anecdóticas. Esa subversión de las identidades de género pone en juego nuestra vulnerabilidad como sujetos sociales.

Exponer nuestra identidad fuera de los márgenes inteligibles problematiza la cuestión de la confianza intersubjetiva. En este sentido, la cuestión de la posibilidad de poder que habíamos traído a colación en relación al género puede no ser reconocida si la identidad de género que se nos adscribe culturalmente no se corresponde con el género del poder, con la forma (la actitud, los actos, el cuerpo) en la que entendemos que este poder se puede performativizar (Butler, 2001: 167). 
Podemos reflexionar sobre el caso contrario y entrar en la discusión del género de la violencia. Cuando hablamos, desde una perspectiva feminista, de erradicar el poder patriarcal nos referimos a eliminar los estándares desde los que los hombres han ejercido el poder. Cuando discutimos sobre el concepto del poder, solemos atribuirle una connotación negativa, asociamos su ejercicio al uso legítimo e impune de la violencia por parte de los sectores institucionales masculinizados para controlar las comunidades. Hablar, por tanto, de poder patriarcal nos remite a esta idea de rigidez y firmeza sobre la que se construye la masculinidad. Pero decir que la violencia es patriarcal y que se ejerce desde las estructuras de poder patriarcal no equivale a decir que los hombres son, exclusivamente, sujetos intrínsecamente violentos, ya que estaríamos cayendo entonces en el esencialismo de lo que intentamos huir con la deconstrucción de los discursos culturales que justifican la subordinación de los cuerpos clasificados como femeninos.

Como sabemos, las personas identificadas como mujeres reproducen también el poder patriarcal y violento. Lo que debemos de entender, es que la violencia y sus prácticas se configuran discursivamente $\mathrm{y}$, por tanto, culturalmente como un atributo de la masculinidad genérica y, en yuxtaposición, como algo que no pueden ni deben practicar las mujeres. Despatriarcalizar el poder conllevaría erradicar cualquier manifestación legal y legítima de violencia por razón de género, clase, etnia, etc.

Este es uno de los principales problemas con los que nos encontramos en este trabajo y que enlaza con la capacidad mediática para representar el empoderamiento subversivo (frente al poder patriarcal), performativizado por cuerpos de mujeres, por sujetos femeninos. Hasta el momento, observamos cómo se confunde la representación de procesos de empoderamiento «en femenino» con la representación de figuras femeninas o mujeres con poder. En este sentido, hay que tener en cuenta un 
apunte que Simone de Beauvoir introducía desde el principio en su obra El segundo sexo y que dice:

En el momento en que las mujeres empiezan a tomar parte en la elaboración del mundo, ese mundo es todavía un mundo que pertenece a los hombres; ellos no lo dudan, y ellas dudan apenas. Negarse a ser Alteridad, rechazar la complicidad con el hombre, sería para ellas renunciar a todas las ventajas que les puede procurar la alianza con la casta superior. (Beauvoir, 1998: 55)

¿De qué estamos hablando entonces, si también Foucault (1977: 124) deja patene que «No existe el discurso de poder por un lado y, enfrente, uno que se le oponga. Los discursos son elementos o bloques tácticos en el campo de las relaciones de fuerza; puede haberlos diferentes e incluso contradictorios en el interior de la misma estrategia $[\ldots] \gg$ ?

De lo que hablamos es que la posibilidad de poder está directamente relacionada con la posibilidad de saber. También, que el saber que posibilita el poder es aquel al que tienen acceso los hombres. No obstante, los Estudios para la Paz ponen en valor la experiencia y los saberes de las mujeres porque consideran que nos pueden llevar por caminos donde el empoderamiento, es decir, el desarrollo de las capacidades individuales, no genere sufrimiento en la vida de los y de las otras, sino que contribuya a generar redes de apoyo, de reconocimiento y de cuidado de lo común y lo vulnerable. Por ello, la propuesta del giro epistemológico cuenta metodológicamente con conceptos como la objetividad feminista de Haraway o con la perspectiva de género en el análisis de la historia que propone Scott. Así pues, el análisis de género nos resulta útil por la posibilidad que nos ofrece de saber diferente $y$, por tanto, de hacer diferente, de dar cabida en nuestro imaginario al reconocimiento de otras maneras de conocer. 
Desde una perspectiva culturalista, podríamos también observar la cuestión teórica como un síntoma más de la cultura política actual, a la que vinculamos o la que motiva el presente trabajo. La necesidad de mirar al pasado, de revisarlo, se nos presenta como un requisito en un contexto glocal ${ }^{16}$ de desclasamiento en que la promesa de la modernidad democrática revela sus fallas sistémicas y se descubre perpetuadora y reforzadora del statu quo. Esto desmontaría el concepto de poder que nos ofrece Foucault, ya que se pone de manifiesto la perpetuación de los privilegios de ciertos sujetos (que responden al perfil de hombre, heterosexual, blanco, occidental, de clase pudiente) respecto a otros que no se corresponden con ese perfil.

Sin embargo, parece que todavía queda un elemento sobre el que investigar y proyectar ilusiones emancipadoras y este es precisamente el género. En una conferencia $^{17}$, Beatriz Gimeno, comentó que «cuando el género se mueve, todo se mueve». Hemos entrado en la era de feminización de la clase trabajadora, es decir, del empobrecimiento y la desvalorización de lo único que la dignificaba: el trabajo. Quizás es momento de aprender de las mujeres por necesidad, más que por una cuestión de reconocimiento o por tener ganas de transformar los imaginarios.

\footnotetext{
${ }^{16}$ Con este termino nos referimos a la idea de articulacíon social desde lo local hacia lo global en el campo de la transformación pacífica de conflictos, que trabaja Vicent Martínez Guzmán en Podemos hacer las Paces (2005).

${ }^{17}$ Conferencia titulada «Nuevos significados de la violencia contra las mujeres en contextos de violencia generalizada», impartida en la Universitat Jaume I de Castelló a fecha de 11 de noviembre de 2016 en el marco de los proyectos «Testimonio ético y Comunicación para el Cambio: análisis de modos de resignificación de la figura de la víctima y re-situación de los agentes sociales» (UJI P1·1B2015-21) y «La re-significación de la mujer-víctima en la cultura popular: implicaciones para la innovación representacional en la construcción de la vulnerabilidad y la resistencia» (MINECO/FEDER FEM201565834-C2-2-P). Video disponible en: https://www.youtube.com/watch?v=Jx6EsrgYGqw [último acceso: $19 / 06 / 2018]$
} 


\subsubsection{Marcos de interpretación actual: entre la institucionalización y el mito del feminismo neoliberal}

Parece que la tarea del feminismo institucionalizado contemporáneo (tanto desde la academia como desde los espacios de representación política), por tanto, deba centrarse en el cambio generacional y en la revisión del papel de la mujer en las revoluciones sociales $\mathrm{y}$ en las metas de transformación y transición política. La discusión a nivel de calle, el discurso popular de raíz patriarcal, deja claramente patente que muy lejos de disolver el sistema de dominación masculina, este se diluye aprovechando las diferentes corrientes de pensamiento neoliberal, camuflándose en la presumida bondad de la libre elección, así como sostiene Ana De Miguel (2015).

Esta tesitura está suponiendo a día de hoy un reto más para un movimiento en constante cuestionamiento de su sujeto de lucha y sus bases ideológicas, como el feminismo. Este movimiento se ha replanteado continuamente su situación en el contexto político, dependiendo del lugar que iba adquiriendo el sujeto femenino respecto a las violencias patriarcales. Para ver esta cuestión, se presenta como necesario en este momento realizar un pequeño recorrido diacrónico del feminismo. En Los feminismos a través de la Historia de Ana de Miguel (1995), la autora señala algunas de las principales aportaciones del feminismo a la discusión filosófica en relación a diferentes contextos que, como en el caso de los Estudios para la Paz, le han dado forma y contenido a este movimiento teórico, social y político en el que ahora miramos con tanto interés desde tantos ámbitos de aplicación.

Nos remitiremos con De Miguel al siglo XVII y la publicación de Sobre la igualdad de los sexos (1673), donde el filósofo cartesiano Poulain de la Barre fundamentaba las demandas de igualdad de las mujeres. Según De Miguel, la obra sintomatizaba que el centro del debate público había superado la cuestión de las 
diferencias entre sexos y sus capacidades (más característica de las discusiones de la era premoderna) para desplazarse hacia la cuestión de la igualdad desde el prisma de la Ilustración. Así, el movimiento feminista haría uso de la racionalidad crítica ilustrada para evidenciar las contradicciones del patriarcado y argüía las premisas de la libertad y de la igualdad de derechos (civiles y políticos) con la que nacían los hombres por «irracionalizar [los] usos interesados e ilegítimos» de la demanda de universalidad, que paradójicamente dejaba a las mujeres fuera del proyecto igualatorio. La explicitación de la cuestión en la esfera pública supuso, sin embargo, un final trágico para muchas feministas que, por ejemplo, fueron guillotinadas por los jacobinos de la Revolución Francesa (siglo XVIII). Así, la autora apunta que, según la «prensa revolucionaria», el proyecto político y democrático de estas mujeres había «transgredido las leyes de la naturaleza abjurando su destino de madres y esposas, queriendo ser "hombres de Estado"» (De Miguel, 1995:12)

No será hasta el siglo XIX cuando el movimiento feminista adquiere carácter internacional (teórica y organizativamente) de la mano del anarquismo y del socialismo, intentando dar respuesta a las necesidades del proletariado en el nuevo contexto de industrialización capitalista. Sin embargo, el nulo acceso a derechos y la desigual repartición de riqueza industrial hizo que la miseria fuera el sino de las mujeres proletarias, desprovistas de «cualquier atisbo de autonomía personal» (De Miguel, 1995:12). Mientras se iba armando el argumentario de las teorías emancipadoras de las feministas de la clase obrera, fue tomando forma el movimiento sufragista de las mujeres burguesas, cuyos destinos se encontraban también en el lado de la miseria si no alcanzaban la condición de «posesión legal» de un hombre, es decir, si no contraían matrimonio. 
[...] las sufragistas luchaban por la igualdad en todos los terrenos apelando a la auténtica universalización de los valores democráticos y liberales. Sin embargo, y desde un punto de vista estratégico, consideraban que, una vez conseguido el voto y el acceso al parlamento, podrían comenzar a cambiar el resto de las leyes e instituciones. Además, el voto era un medio de unir a mujeres de opiniones políticas muy diferentes. Su movimiento era de carácter interclasista, pues consideraban que todas las mujeres sufrían en cuanto mujeres, e independientemente de su clase social, discriminaciones semejantes. (De Miguel, 1995: 13)

Como vemos en esta cita, la idea de sororidad (o sea, de hermandad y de reconocimiento recíproco en un sentido ético y político) desde la que los diferentes grupos feministas contemporáneos (independientes $\mathrm{y} / \mathrm{o}$ incardinados en otras organizaciones con perspectivas políticas diversas) conciben la transversalidad de sus acciones y estrategias, ya se encontraba presente en las mentes de las sufragistas. Este carácter interclasista que destaca De Miguel, nos remite a la idea de intersubjetividad de los Estudios para hacer las Paces, a una pretensión de universalidad guiada por la inclusividad y los objetivos de mínimos, y no por asimilación de los valores de máximos (libertad, igualdad, etc.), aunque sean estos últimos los que sirvan como herramienta discursiva para la justificación de los propósitos feministas.

El carácter interclasista, como es lógico, no guiaba la lucha del feminismo marxista y anarquista. Mientras que las marxistas recalcaban las diferencias entre mujeres de diferente condición social y atribuían sus problemáticas a la cuestión de la «superestructura», las anarquistas se sumaban a la oposición hacia las sufragistas apelando a la «propia fuerza»y al «esfuerzo individual» de las mujeres como medio para «vencer todo el peso de la ideología tradicional» que, consideraban, también oprimía a las marxistas pesar de su acceso al trabajo asalariado. Las anarquistas llevaban su lucha como «mujeres libres» para el activismo cotidiano: 
Consideraban que la libertad era el principio rector de todo y que las relaciones entre los sexos han [sic] de ser absolutamente libres. Su rebelión contra la jerarquización, la autoridad y el Estado, las llevaba, por un lado y frente a las sufragistas, a minimizar la importancia del voto y las reformas institucionales; por otro, veían como un peligro enorme lo que a su juicio proponían los comunistas: la regulación por parte del Estado de la procreación, la educación y el cuidado de los niños. (De Miguel, 1995: 13)

Lo que se describe, sin embargo, son las diferencias que, entrado el siglo XX, no salvaban a unas y a otras de los dilemas intrínsecos a la idiosincrasia de los grupos ideológicos a los que se adscribían, en los cuales el patriarcado cristalizaba en la negación sistemática de la igualdad salarial y de derechos y la relegación de la mujer a las tareas vinculadas con el hogar y la crianza. Más adelante, el acceso de la población femenina al derecho a voto generó, según la autora, una sensación de aparente «igualdad legal» (De Miguel, 1995: 21).

La situación de la mujer en las sociedades occidentales no se volvería a problematizar de manera relevante hasta que teóricas feministas como la francesa Simone de Beauvoir o la estadounidense Betty Friedan actualizaran, tras la II Guerra Mundial, la discusión sobre la desigualdad como problema político invisibilizado por las estructuras de poder patriarcal. El constructo cultural de la identidad femenina, objeto de estudio de Beauvoir en El segundo sexo (1949), o la idea de la «mística de la feminidad» de Friedan (en 1963), cobran relevancia en torno al eslogan «lo personal es político», acuñado por la feminista radical Carol Hanisch en 1969.

Podríamos leer el estado de la cuestión feminista en este momento a partir de la nomenclatura que usamos en los Estudios de la Paz. Y es que todas las reflexiones anteriores coinciden en señalar la violencia cultural (la cultura patriarcal) como el origen de la violencia estructural (desigualdad política fáctica) que sufren las mujeres a 
pesar de encontrarse en un contexto de paz positiva (de reconocimiento de derechos sociales). Así las cosas, el feminismo llega al punto de inflexión que marcó el hito de Mayo del '68, que redefinirá el movimiento y en el que se han materializado sus corrientes contemporáneas. Sin embargo, como veremos, las cuestiones que centran las energías de las feministas parecen entrar en una especie de espiral de eterno retorno a la que se incorporan nuevos conceptos discursivos a medida que avanzamos hacia las coyunturas políticas y el imaginario de la posmodernidad actual: se siguen sintomatizando las mismas problemáticas en torno al acceso al poder y a la realización del proyecto de vida de las mujeres en las denominadas sociedades avanzadas. Así pues:

De nuevo fue a través del activismo político junto a los varones, como en su día las sufragistas en la lucha contra el abolicionismo, como las mujeres tomaron conciencia de la peculiaridad de su opresión. [...] La primera decisión política del feminismo fue la de organizarse en forma autónoma, separarse de los varones [...]. Así se produjo la primera gran escisión dentro del feminismo radical: la que dividió a las feministas en «políticas» y «feministas» (De Miguel, 1995: 24-25).

Como decíamos, esta escisión explícita se parece al contexto desde el que se plantea la lucha feminista a día de hoy en el Estado español. Hoy en día aún podemos apreciar el conflicto interno de un movimiento que, a pesar de tener un mismo sujeto de análisis, se dedica a transformar el conflicto desde dos ámbitos que se retroalimentan discursivamente: las agrupaciones civiles de base y las instituciones. A partir de aquí se distinguirán en la historia dos esferas políticas a partir de las cuales trabajar y que, insistimos, se mantienen: por una parte, las «políticas», que atribuyen que la opresión de las mujeres al sistema capitalista (en la línea de las marxistas a que nos referíamos anteriormente); por otro, las «feministas», que reconocían patrones de dominación 
también entre el compañerismo de izquierdas que, finalmente, beneficiaban a los hombres.

La lógica de la discusión llevó, según De Miguel, a que las «políticas» dejaran de denominarse «feministas» como resultado de una discusión constante (volvemos a los paralelismos heredados hasta el contexto actual). En dicha discusión, las segundas hacían por dar a entender a las primeras que el sistema de dominación no era exclusivamente un sistema económico (que también reconocía los hombres como víctimas y que evitaba, con ello, la confrontación con ellos y la relegación de la desigualdad de género en una cuestión tangencial) sino que era la consecuencia de un sistema de valores (patriarcado) que sustentaban ideológicamente las estructuras de poder, entre ellas, el capitalismo.

\subsubsection{El género y la necesidad de una memoria matrilineal: poder y sororidad}

La cuestión de la violencia cultural y estructural sufrida por el sujeto femenino era objeto de estudio teórico para las feministas radicales y cristalizaría en lo que conocemos como «feminismo de la diferencia» tras varios replanteamientos coyunturales en los que se amplió el sujeto de lucha feminista para incluir temas como la identidad sexual y la heteronormatividad, la discriminación por etnia o la cuestión de clase. El debate sobre el sujeto político del feminismo y la relación que se establece con la cuestión de la identidad subjetiva y la interseccionalidad, no solo se ha mantenido sino que se ha complejizado hasta llegar a la actualidad. Debemos tener en cuenta que el feminismo contemporáneo se enfrenta a los retos planteados por una sociedad globalizada y postmoderna en la que la categoría de género comienza también a entrar 
en un proceso de resignificación teórica y política. Con todo, Ana De Miguel (1995), señala la vocación aglutinadora de los feminismos institucionales, en sus respectivos contextos. Al respecto dirá que:

A pesar de [las] diferencias [contextuales], los feminismos institucionales tienen algo en común: el decidido abandono de la apuesta por situarse fuera del sistema y por no aceptar sino cambios radicales. Un resultado notable de estas políticas ha sido el hecho, realmente impensable hace sólo dos décadas, de que mujeres declaradamente feministas lleguen a ocupar importantes puestos en los partidos políticos y en el Estado. Ahora bien, no puede pensarse que este abandono de la «demonización» del poder no reciba duras críticas desde otros sectores del feminismo, y no haya supuesto incluso un cambio lento y difícil para todo un colectivo que, aparte de su vocación radical, ha sido «socializado en el no poder» (De Miguel, 1995: 38).

Estas tendencias teóricas beben hoy en día de las experiencias del feminismo activista de base (que replican los procesos de empoderamiento individual y sórico típico de «grupos de autoconciencia» de las feministas radicales) y se apoyan también en la incorporación gradual de las mujeres a las instituciones políticas (en el caso de las mujeres feministas, en alianza o imbricadas en partidos de izquierdas) y académicas (como las universidades, donde han proliferado las investigaciones sobre género).

El aspecto de la sororidad o «pacto entre mujeres» (Lagarde, 2006), cobra especial relevancia a estas alturas de nuestra argumentación, en tanto que esta se erige como una estrategia de acción y resistencia que parte desde la conciencia colectiva de la mujer como sujeto político y que le permite actuar desde un sentido unitario (desde la unidad que nos proporciona la condición del género) sin dejar de lado las especificidades identitarias de cada caso (y que vienen dadas por otras condiciones 
como la clase social, que también se ven afectadas por el condicionante de la feminidad).

Precisamente las características del feminismo en su doble vertiente, activista de base e institucionalizado, son las que nos interesan en este punto. Son útiles para nuestro propósito de transformación de las estructuras de poder social a través de experiencias en las que no interviene la violencia (aunque sí la resistencia) y en las que se trabaja por que cristalicen garantías de paz positiva desde la perspectiva de género (Confortini, 2006). Así, parece que, con todo, podemos poner claramente en diálogo la experiencia feminista institucionalizada con la transformación pacífica de conflictos desde la perspectiva de los Estudios para la Paz.

El conflicto interno, pues, se puede interpretar como una continua oportunidad para la integración de perspectivas de mujeres socializadas en esas diferentes situaciones de «no poder» que en sus experiencias vitales han sabido localizar los espacios desde los que resistir o subvertir violencias para desmontar el imaginario y el orden patriarcal. Los grupos de autoconciencia, o el activismo de base en el que muchas políticas y académicas han desarrollado sus principios feministas, han aportado un volumen de saberes que cristalizan en las instituciones de cariz patriarcal y van haciendo efecto, aunque no sin impedimentos, a favor de la igualdad de género.

Y por eso, llegadas pues a este punto, nos interesa poner sobre la mesa la cuestión del legado feminista, la de nuestro particular matrilinaje político. Casi al final de su análisis cinematergráfico, Gámez Fuentes (2004: 225) se pregunta «qué quiere la hija de la madre en términos de una revisión histórica», a lo que precisamente responde que «la demanda filial [pide] que las voces maternas reescriban el pasado en femenino y que expongan sus propias contradicciones, además de su legado disidente para las generaciones democráticas». Así pues, el caso de la institucionalización del feminismo 
español se imbrica casi de manera necesaria en los discursos públicos acerca de la memoria histórica especialmente a raíz de la era Zapatero (en la cual profundizaremos en el siguiente capítulo).

En el contexto actual, sin embargo, esta respuesta resulta algo más problemática por la propia deriva institucional del feminismo, que pareció erigirse en la posición metafórica de lo paternal, del código, de la norma. Las feministas institucionales se presentan, en la esfera simbólica, como la madre fálica y problemática (en lugar de sórica, cuidadosa y facilitadora) para las nuevas generaciones de mujeres. En muchas ocasiones, las feministas históricas de las instituciones, parecen no ser más que un brazo del dominio patriarcal frente a las propuestas de las nuevas generaciones de feministas. Según el discurso académico y político más oficialista del feminismo, parece que los procesos neoliberales de identificación de género o el problema del cuerpo (frente a temas actuales como la regularización de la prostitución o la gestación subrogada) tengan un manual de ideas y remedios prescritos que, inevitablemente, chocan de frente con los usos actuales de la vida y parecen limitar tanto el desarrollo de la vida de las mujeres como la propia construcción social de género.

Lo que parecía que habíamos aprendido de los Estudios para la Paz es que el matrilinaje político debería haberse constituido como referencia del saber pacífica, de aprendizaje testimonial de los usos del poder desde los márgenes. Sin embargo, existe un descompás entre los argumentarios de las feministas históricas (que transluce, a su vez, en la normativa del feminismo de Estado) y el contexto de las nuevas generaciones de jóvenes (inmersas en la era postmoderna de la globalización y la comunicación). Este descompás, como conflicto, está permitiendo que el debate feminista (incluso el más mainstream) esté adquiriendo matices muy enriquecedores en un plazo muy corto de 
tiempo. No obstante, también deja patente una falta de reconocimiento mutuo entre generaciones, falta de escucha; falta la mirada solidaria.

El principal miedo por parte de las históricas en el ámbito académico y de partido, es del que habla actualmente De Miguel (2015) y que tiene que ver con el refuerzo de las mitologías de la feminidad en la era del neoliberalismo, en el que las normas del género se tiñen de libertad de elección mercantilista. Las feministas históricas parecen vivir con el fantasma del olvido, aunque más se habla de ellas (sin ni siquiera haber muerto), y no perciben la carga de esta mochila generacional con la que las más jóvenes hoy emprenden sus proyectos de vida individual, social y política.

El feminismo sigue así estancado, en algunos casos, en un juego de poder generacional (del que no se salvan, hay que decir, ninguna de las tendencias políticas históricas en crisis) que requiere de sororidad y de un reconocimiento claro de los escenarios de violencia cultural, estructural y directa contra todo lo no-masculino. El peligro de este posicionamiento fálico es que las «hijas» lleguen a renegar de las «madres» como fuente de habla impidiendo así el ejercicio de imaginación mnemónica y que ni unas ni otras entiendan que las históricas tienen la experiencia pero las jóvenes padecen igualmente en sus carnes y en la actualidad los condicionantes de género propios de su tiempo.

Con todo esto, podemos llegar a intuir y enmarcar el punto en el que el feminismo se encuentra en nuestro contexto espacial y temporal. Obviamente, como sistema de pensamiento crítico -tanto académico como político-, no es ajeno a las problemáticas actuales, de nuevo internas y externas, que se le presentan. Empezando por las últimas, el feminismo tiene que lidiar con un nuevo paradigma político de crisis de las dos tradicionales corrientes ideológicas que han configurado el discurso y la praxis pública desde la transición. En este plano, la izquierda a la que se ha asociado 
históricamente el movimiento feminista en España, se fragmenta y se recompone una vez más en la historia para dar respuesta a las problemáticas sociales que la crisis económica ha provocado en el funcionamiento efectivo del Estado del Bienestar. Se abre así, pues, un nuevo período transicional que invita a repensar los marcos de construcción de la democracia (como también veremos en el siguiente capítulo).

Así, la mochila feminista en la era postmoderna en el contexto español se presenta cargada de esas cuentas pendientes con las históricas, con las portadoras de memoria silenciada (en el franquismo) e invisibilizada (desde la transición de los setenta y hasta la presente "re-transición"). Esto para las jóvenes supone, por ende, cargar con las mochilas vindicativas de las generaciones de las madres y (bis-) abuelas para, por una parte, articular los objetivos de la lucha con perspectiva histórica y, por otra, situar al sujeto de esa lucha respecto a las vindicaciones feministas históricas y actuales, que a su vez redundan en las primeras. ¿Por qué, si no, casi un siglo después de conseguir el sufragio universal femenino todavía nos miramos en las sufragistas de la II República al hablar de cuotas? O, ¿por qué recurrimos a los relatos de vida de la resistencia femenina como modelo de superación de las crisis políticas de cualquier tipo? Y finalmente, ¿por qué recordamos a las Constituyentes ${ }^{18}$ cuando avistamos un nuevo cambio en la composición de las estructuras políticas del Estado?

Amelia Valcárcel nos aporta la perspectiva de las históricas al concluir su comunicación titulada «La memoria colectiva y los retos del feminismo»:

Pienso que cada tiempo cubre su etapa y nosotras, que vivimos de lo que otras y otros nos consiguieron, tenemos que cubrir la nuestra. Tenemos por

\footnotetext{
${ }^{18}$ Con este nombre se conoce popularmente a las mujeres que participaron en la redacción de la Constitución española del 1978, cuyo testimonio se recoge en el documental Las Constituyentes (Olivia Acosta: 2012).
} 
delante el reto general de la paridad que implica resolver varios desafíos parciales: La formación de una voluntad común bien articulada que sabe de sí, de su memoria y de los fines que persigue. La iluminación de los mecanismos sexistas -cuando no ginófobos- de la sociedad civil, el mercado y la política. La elaboración común de una agenda de mínimos que evite pérdidas de lo ya conseguido y refuerce el asentamiento de logros. Y la resolución del déficit cualitativo que, en el momento presente, es una vergüenza para la razón (Valcárcel, 2001: 88-89).

El paso necesario para la emancipación generacional de las feministas actuales pasa por la reparación del sistema democrático a las históricas del feminismo. Esto es, por el reconocimiento de la aportación del feminismo en la resistencia a la estructuración del Estado democrático. Nos referimos con ello, claro, a la Transición democrática, presentada al público (a la opinión pública a través de la opinión publicada) como un proceso de perdón y hermanamiento de las «dos Españas» pero que se configuró en base al recurso del olvido, en favor de la experiencia estética (Gámez Fuentes, 2004: 24) de normalidad democrática y en detrimento de la rendición de cuentas con las víctimas del franquismo. En esta línea, Gámez Fuentes recurre a las teorías psicoanalistas de Vilarós (1998) para apuntar que «como todo lo que se intenta reprimir o borrar, ese pasado retornará a lo largo de la democracia a través de fisuras en diversas manifestaciones culturales».

En el caso de Gámez Fuentes, la autora se refiere precisamente a las manifestaciones culturales (cinematográficas) de la propia transición. El fenómeno que nos interesa estudiar ahora es el que se produce, como venimos diciendo, en los productos de la cultura popular televisiva que nos presentan continuamente personajes femeninos a en escenarios de una memoria común reconocible por las audiencias que se da durante el período de mainstreamización del feminismo en la época socialista de Zapatero. Como veremos en el siguiente capítulo, se trata de un período en que la 
cuestión de la recuperación de la memoria histórica toma también especial relevancia política y en la que el PSOE parece decidirse a saldar institucionalmente la deuda política de la izquierda con los sectores feministas presentes en la resistencia antifranquista y en el desafío del establecimiento de normalidad democrática en base a la inclusión de la diferencia que implica todavía el ser mujer. 


\section{Marco histórico}

El presente capítulo lo dedicaremos a localizar el contexto de producción, emisión y recepción de las series que forman parte de nuestro cuerpo de análisis. Debemos tener en cuenta, desde el principio, que nuestro objetivo concretamente es realizar una historización de los núcleos discursivos que nos servirán para realizar nuestro análisis. Esto es, más que enumerar una serie de hitos relevantes, les daremos a estos una profundidad teórica que enmarcará el sentido cultural de tales hechos. Este es un paso ineludible en nuestro trabajo, si atendemos a la perspectiva de los Estudios Culturales, que consideran precisamente las expresiones o «prácticas» de la cultura de masas un resultado de las «conjeturas y tensiones sociales» (Gámez Fuentes, 2002: 32) presentes en un contexto histórico-político en particular. Así pues, los ejes que desarrollaremos a continuación sobre la presencia de las cuestiones entorno a la mujer y la memoria en el debate político del momento contribuirán a dar legitimidad a la perspectiva de análisis que hemos empezado a configurar en nuestro marco teórico así como a completar nuestro marco de interpretación.

Como ya hemos especificado anteriormente ${ }^{16}$, las series que analizaremos empezaron a emitirse en 2008 (caso de La Señora) y han ido sucediéndose hasta la actualidad (año 2017, tercera temporada de El Ministerio del Tiempo). Si partimos de la premisa de que la sucesión de las tramas desde La Señora a 14 de abril. La República (2008-2011) bebió directamente del estado de discusión institucionalizada sobre mujer, violencia y memoria en la era socialista de Zapatero (2004-2011) y que el cambio de tendencia que supuso para el debate el cambio gobierno del Partido Popular también se

\footnotetext{
${ }^{16}$ Ver apartado 2 de Metodología.
} 
sintomatizó progresivamente en las trama de Isabel (2012-2014) y El Ministerio del Tiempo (2015-2017), es menester situar este apartado en ese contexto y ver qué influencias históricas configuraron las bases de las perspectivas ideológicas que ahí se reflejan.

Así pues, en primer lugar, nos interesará presentar el panorama general en el que se inició y desarrolló el gobierno del PSOE en el Estado español entre los años 2004 y 2011 y qué sentido histórico-político se le ha adscrito desde la Academia tanto al conjunto de las medidas legislativas adoptadas por el gabinete Zapatero en torno al papel de la mujer en la democracia, como a la centralidad de la recuperación de la memoria histórica. Para tal fin, describiremos los escenarios en los que se aprobaron las leyes para la Igualdad de Género y contra la Violencia de Género, así como la ley de Memoria Histórica. Pero antes, y debido a la temática de esta tesis, que se centra en los discursos audiovisuales sobre, precisamente, mujer y memoria en los relatos televisivos de la cadena pública española, deberemos recuperar la normativa promovida en esta época dedicada a la mejora de la calidad del sector audiovisual y que tuvo especial aplicación en lo que respecta la protección del derecho a la información y el entretenimiento de calidad a través de los canales de radiotelevisión pública.

\section{1. La televisión pública en la era Zapatero: servicio público de calidad}

En junio de 2006, tras dos años de gobierno socialista, ve la luz la Ley de Radio y Televisión de Titularidad Estatal (BOE: 2006). Si recordamos lo que ya señalábamos en el apartado de Metodología, dicha ley especifica que los canales de la 
RTVE tienen por objeto «satisfacer necesidades de información, cultura, educación y entretenimiento de la sociedad española; difundir su identidad y diversidad culturales» (art. 2). También cita, entre sus deberes, el promover el conocimiento de los principios constitucionales (art. 1, apartado a.) y de la historia (art. 3, apartado i.), así como la cohesión territorial (art. 3, apartado e.). De la misma manera, se habla del deber de «fomentar la protección y salvaguarda de la igualdad entre hombre y mujer, evitando toda discriminación entre ellos» (art. 3, apartado k.). Los productos del medio público se definirán, entonces, por articular discursos en pro de la identidad unitaria, de la difusión de los hitos históricos que a esta responden por fomentar la igualdad de género.

Estos parámetros se verían complementados con la aprobación de la Ley de financiación de la Corporación de Radio y Televisión Española (BOE: 2009), que supondría el fin de los ingresos obtenidos a través la publicidad comercial, reforzando así la independencia económica y política del ente ${ }^{17}$. Finalmente, la Ley General de la Comunicación Audiovisual (BOE: 2010) constituye el paso final de la reforma del sector audiovisual del gobierno Zapatero, emprendida ya en la primera de sus dos legislaturas como presidente del Gobierno con la aprobación de las dos leyes anteriores.

Esta última Ley se presenta como norma básica con la finalidad de que el sector privado y el público tengan fijados los principios mínimos que deben inspirar la presencia en el sector audiovisual de organismos prestadores del servicio público de radio, televisión y servicios interactivos. Dichos principios se inspiran en las directrices comunitarias para la garantía y la protección de derecho a la información y a un entretenimiento de calidad. En este sentido, la norma aspira a promover una sociedad

17 Ver: http://www.rtve.es/noticias/20090729/senado-aprueba-definitivamente-ley-suprime-publicidadtve/286994.shtml [último acceso: 14/04/2018] 
más incluyente y equitativa $\mathrm{y}$, específicamente en lo referente a la prevención y eliminación de discriminaciones de género, en el marco de lo establecido en materia de publicidad y medios de comunicación en la Ley Orgánica 1/2004, de 28 de diciembre, de Medidas de Protección integral contra la Violencia de Género y la Ley Orgánica 3/2007, de 22 de marzo, para la igualdad efectiva de hombres y mujeres. En concreto, desde el punto de vista de transversalidad del género, resulta interesante recuperar el artículo 4, en el que se señala el «derecho a recibir una comunicación audiovisual plural» y que contiene los siguientes puntos:

1. Todos tienen el derecho a que la comunicación audiovisual se preste a través de una pluralidad de medios con diferentes ámbitos de cobertura. Esta prestación plural debe asegurar una comunicación audiovisual cuya programación incluya distintos géneros y atienda a los diversos intereses de la sociedad, especialmente cuando se realice a través de prestadores de titularidad pública.

2. La comunicación audiovisual nunca podrá incitar al odio o a la discriminación por razón de género o cualquier circunstancia personal o social y debe ser respetuosa con la dignidad humana y los valores constitucionales, con especial atención a la erradicación de conductas favorecedoras de situaciones de desigualdad de las mujeres.

Toda esta normativa surgió especialmente ante la necesidad de dotar al sector audiovisual (tanto público como privado) de unos parámetros comunes desde los que proteger ese derecho ciudadano a gozar de una comunicación de calidad, en conexión con los valores cívicos de los que venimos hablando a colación de la ley de medios públicos y coincidiría con el fenómeno que nos proponemos estudiar en esta 
tesis: el protagonismo de las mujeres en los argumentos de ficción en el prime time de La 1 de TVE.

\subsubsection{La introducción de la agenda política en la ficción pública: género con memoria}

Tal y como indicábamos en el apartado de Metodología, el tema que hemos tomado para el desarrollo de la tesis ya fue detectado por Palacio (2007: 76), a quien le resultaba «llamativo» que la normativa desarrollada durante la era Zapatero respecto a la igualdad traspasara el papel para plasmarse tempranamente en el ejercicio real de la televisión pública estatal. Concretamente, el autor se refería a la coincidencia en el «tiempo histótico» del fenómeno de proliferación de protagonistas femeninas en las series de TVE con la situación de «vanguardia» política en Europa respecto a la «paridad».

Así, coincidiremos con Palacio en que la idiosincrasia de los productos que nos ocupan también responde a las lógicas inspiradas por la nueva Ley General del Audiovisual (2010), que favoreció la aparición mujeres como protagonistas de distintos programas televisivos de ficción en diverso formato. En esta línea, encontraremos tanto biopics en forma de TV-movies o miniseries dedicadas a personajes femeninos de relevancia (vinculados tanto al terreno de la política como de la cultura popular) para el imaginario nacional (Gámez Fuentes, 2014) como series de ficción que según Menéndez Menéndez supondrían (2014: 64-65):

[...] la respuesta a un nuevo rumbo político en la sociedad española pero también resultado de la influencia de los dramas norteamericanos que, justo en esa época, ofrecían productos de enorme éxito, protagonizados por 
grupos de mujeres y que rompían no sólo con la escasez de papeles femeninos en la ficción seriada sino con la calidad de dichos papeles, al depositar en ellas todo el peso narrativo.

Entre ellas, muchas presentarán un carácter historicista que se inspirará en hechos y personajes no necesariamente reales, aunque también los hay, y que se emitirán tanto en la televisión pública como en los canales privados. Como apunta Padilla Castillo: «Estas historias, aunque ambientadas en otro tiempo, se acercan al momento actual del espectador, haciendo sentirnos que este hecho se repite y aún está pasando. [...] Ahonda en la identidad común y nos cuenta de dónde viene la democracia, la realeza, uno u otro gobierno [...]» (Padilla Castillo, 2012: 39). Se trata de toda una tendencia que oscila entre el carácter revisionista de la historia y la recreación nostálgica de tiempos pasados. Entre las primeras, podríamos clasificar a las escogidas como objeto de estudio de esta tesis. Y como ejemplo de la segunda tendencia nombrada, se encontrarían series del estilo de la ya emblemática Cuéntame cómo paso ${ }^{18}$ $(\text { La } 1,2001-\text { actualidad })^{19}$.

Ya en el apartado de Metodología hemos justificado esta distinción a la hora de justificar los criterios de inclusión de unos productos mediáticos en lugar de otros para nuestro ejercicio de análisis. Así, atendiendo al tiempo y espacio en el que realizamos nuestra aportación, consideramos que los casos que centran nuestra atención van más allá de la cuestión de la nostalgia y reproducen cuestiones traumáticas como una práctica cuasi-exploratoria del pasado común que contribuye en cierta manera al

\footnotetext{
18 Web oficial de la serie, que cuenta, al cierre de esta tesis, con 19 temporadas: http://www.rtve.es/television/cuentame [último acceso: 14/04/2018]

${ }^{19}$ Ver: Cobalán, Ana (2009) y Rueda Laffond, José Carlos y Amparo Guerra Gómez (2009).
} 
diagnóstico y tratamiento de una democracia moderna en crisis como la española. Esta es una crisis de carácter económico, territorial, generacional, democrático y de valores que el feminismo, además, amenaza con acabar de descomponer. Es una crisis que precisamente empezó a fraguarse durante la era Zapatero y que acabó dinamitando su proyecto político, factor que motiva definitivamente la necesidad de la revisión y contextualización de su mandato en las próximas páginas.

\subsection{Reconocimiento y concepto de víctima en la era Zapatero}

Como estamos viendo, el escenario socio-político que propició la llegada del PSOE de Zapatero al gobierno central del Estado favoreció la reintroducción firme de los temas de género y memoria. Pero, además, estas categorías se presentaban cargadas de un sentido de justicia reparativa que también estaba muy presente en la agenda política. Para comprender esta premisa desde la que partimos, debemos primero recuperar una serie de episodios que favorecieron la victoria del $\mathrm{PSOE}^{20}$ en las elecciones generales del 14 de marzo de 2004 y situarnos en ese contexto.

\subsubsection{El revulsivo para la memoria}

Mucho se ha escrito sobre cómo la manipulación de la información oficial por parte el gabinete del PP de José María Aznar sobre los atentados terroristas en la estación de Atocha de Madrid (11 de marzo 2004, sólo tres días antes de que el país acudiera a las urnas) jugó un papel clave en la victoria de un candidato socialista casi

\footnotetext{
20 Ver: https://elpais.com/diario/2004/03/15/espana/1079305201_850215.html [último acceso: $14 / 04 / 2018]$
} 
desconocido para la opinión pública (Field, 2011), en el que ni su propio partido confiaba para ganar las elecciones. Se podría decir que, a efectos de política orgánica del PSOE, Zapatero iba a ser un candidato de transición en la oposición. No obstante, el curso de los acontecimientos que se iban a producir no pudo ser previsto por nadie y la atribución falsa e intencionada a ETA del atentado del 11 de marzo en Atocha por parte del ejecutivo del Partido Popular tornó las cartas en su contra. Estos hechos propiciaron una demanda de rendición de cuentas institucional no solo por parte de los grupos de la oposición, sino también por la sociedad civil que ya había participado en las masivas manifestaciones contra la guerra de Irak en 2003.

Este ambiente de reivindicación por parte de la opinión pública, y de empatía con las víctimas del atentado que favoreció la victoria socialista en las elecciones, se prolongó durante el gobierno de Zapatero y sentó de alguna manera las bases para recuperar el debate sobre la rendición de cuentas con las víctimas de la Guerra Civil española que plasmó la Ley de Memoria Histórica. Hasta ese momento, es decir, durante las tres décadas anteriores de democracia, las únicas víctimas que recibieron una intensa cobertura en la arena pública (política y mediática) fueron las de los ataques de ETA, ya que la ley de Amnistía de 1977 pareció funcionar como un punto final en el reconocimiento de las víctimas ideológicas o políticas del Estado dictatorial, contribuyendo así lo que ha sido académica y políticamente considerado como una «amnesia» o «desmemoria» nacional (Yeste, 2010; Labany, 2008; Bernecker: 2003).

La de Zapatero sería la segunda etapa en la que el ejecutivo central era gobernado por el PSOE en el período democrático de monarquía parlamentaria, que se inicia con la muerte del dictador Francisco Franco en 1975. Este año ha pasado a formar 
parte del imaginario democrático español y especialmente del de los colectivos agrupados en organizaciones activistas, sindicatos y partidos de izquierdas, como el PSOE, que tras años de represión franquista y de actuaciones desde la retaguardia, interpretaron la muerte del dictador como un el símbolo del fin de una etapa oscura de nuestra historia. Ese pasado nada tendría que ver, al menos en principio, con la democracia moderna que llegaba sin remedio y del progreso del que toda la ciudadanía tenía que ser partícipe y beneficiaria. Así, la fecha del 20 de noviembre del ' 75 supondrá un hito para los demócratas en España, junto con la del 6 de diciembre de 1978, fecha de aprobación de la Constitución, texto sacralizado por las generaciones más antiguas de políticos y líderes de opinión más conservadores del Estado, que sin embargo ha sido cuestionado por las voces progresistas de lo que en la actualidad ya conocemos como la «nueva política» ${ }^{21}$.

Con todo, el contexto sociopolítico del momento se erigía como el apropiado para empezar a hablar de democracia, gracias a la nueva Ley de Memoria Histórica, no sólo en términos de paz positiva (que se había configurado sobre la base del perdón, el silencio y el olvido), sino también en términos de reparación y justicia

\footnotetext{
${ }^{21}$ Esta fórmula ha sido ampliamente utilizada por los medios de comunicación españoles para denominar a los nuevos partidos que han entrado en la arena pública estatal a partir del $15 \mathrm{M}$ rompiendo -en principio- la tendencia bipartidista y de gobierno de turno protagonizada por PSOE y PP. Estos son, concretamente, Podemos y Cuidadanos (ver: http://www.elmundo.es/espana/2016/11/13/58275aa5268e3e22468b45be.html [último acceso: 21/05/2018]). En nuestro texto, cuando hemos hablado de la tendencia más progresista de esa nueva política y de sus críticas al sistema político estatal, nos hemos referido al caso de Podemos y al planteamiento de este partido respecto a la Transición democrática y al «Régimen del 78». Concretamente, la organización política se posiciona entre las voces que critican el sistema democrático español por haber perpetuado en el poder a los mismos grupos sociales que lo ostentaron durante la dictadura de Franco a través de un sistema bipartidista y neoliberal, cuya gestión derivaría no solo en una crsis financiera sino en una crisis política que reclama una «nueva transición» (Para más información al respecto, ver: http://www.laopinioncoruna.es/elementosWeb/gestionCajas/MMP/File/2017//Plan_2020.pdf [último acceso: $21 / 05 / 2018]$ )
} 
para todos. Por un lado, como dice Golob (2008), la promoción de la recuperación de la memoria histórica en España coincidió con un movimiento internacional que impulsó una serie de estándares globales para cualquier democracia después de una transición, que incluía la libre investigación del pasado y la rendición de cuentas del Estado. Como resultado, la comunidad internacional (ONU, Amnistía Internacional, etc.) pidió insistentemente a España que se adhiriera a estas normas, cosa que suponía de alguna manera la ruptura de la Ley de Amnistía y, como consecuencia, el fin de la impunidad de los perpetradores del régimen franquista.

Por otro lado, nos encontramos con el factor generacional. En una publicación financiada por el Ministerio de Cultura en el año 2009, que versa precisamente sobre acciones enmarcadas en la Ley de la Memoria Histórica para la preservación del patrimonio cultural, el historiador Julio Aróstegui dirá sobre esta cuestión que esta «en su fondo, responde al espíritu de una nueva generación [cursiva original], la que con propiedad ha sido llamada más de una vez de "los nietos de la guerra", que no vivieron ésta pero que guardan de ella una "memoria heredada" y que tampoco participaron de forma activa en el proceso de la Transición» (Aróstergui, 2009: 58). En esta línea, apunta que:

La Ley, con más o menos acierto, intenta cumplir con esa Memoria en un grado mucho más decidido que lo hizo la Transición, sin olvidos ni falsas reconciliaciones. De ahí que se haya dicho con acierto, según creemos, que el verdadero espíritu del texto refleja el sentimiento de buena parte de una nueva generación que no basa la reconciliación en el pensamiento transicional de los años setenta sino en la búsqueda de una legitimidad histórica como la que poseía la República subvertida por una sublevación ilegítima. Los fundamentos de la democracia se consolidan así y no por las necesarias transacciones obligadas en un proceso de superación de viejas 
tragedias, sino de la legitimidad otorgada por un régimen libremente elegido. (Aróstegui, 2009: 54)

Esta afirmación nos resulta especialmente interesante a la hora de analizar las series que forman parte de nuestro corpus, ya que estas no reconstruyen la memoria de los años de dictadura y represión, como venía haciendo, por ejemplo, el cine. Por el contrario, exploran los antecedentes sociopolíticos que dieron lugar a la instauración de la II República, como es el caso de La Señora y de, obviamente, 14 de abril. La República, así como otros acontecimientos y personajes que forman parte de los mitos asociados a la Historia de España que sirven de referencia para la democracia del presente. En este segundo caso, encontraríamos los relatos de los hermanos Olivares: Isabel y El Ministerio del Tiempo.

Otro aspecto que cabría tener en cuenta, desde un punto de vista más práctico o logístico, sería el de la prosperidad económica que todavía se disfrutaba en el Estado español en el momento de la promulgación de esta ley, como consecuencia de la burbuja inmobiliaria promovida en los noventa y que explotaría en los últimos años de la era Zapatero (2008). La prosperidad de las arcas estatales -aunque esta estuviese sostenida por la especulación en el sector inmobiliario y financiero o la liberalización del sector energético (Fernández Navarrete, 2016: 121-127), parecía haber generado un espacio económico que permitía a la clase política apostar por cuestiones de reconocimiento y reparación, aunque eso supusiera reavivar algunos de los temas que habían sido silenciados o marginados durante las tres décadas anteriores.

Al menos, eso es a lo que apunta el posterior discurso de la austeridad generado a partir de la crisis financiera de 2008 para justificar los recortes en políticas de bienestar ejecutados por el equipo del siguiente gobierno de Rajoy. Este mismo 
argumento también fue usado para justificar los recortes en la financiación de las acciones contra la violencia de género ${ }^{22}$ y por la igualdad entre mujeres y hombres ${ }^{23}$, así como en los destinados a las medidas de justicia reparativa amparadas por la ley de Memoria Histórica ${ }^{24}$. Este razonamiento daría a entender que no fue solamente la ciudadanía quien «vivió por encima de sus posibilidades» ${ }^{25}$, sino que también lo hizo la administración, financiando medidas de este carácter.

\subsubsection{El reconocimiento a las víctimas políticas en la era $\mathrm{ZP}$}

Sin duda, el foco de la última etapa de gobierno socialista estatal se centró en los derechos sociales a favor de la igualdad. Una igualdad que fue más allá de los principios de «redistribución» usuales en la concepción del Estado de Bienestar para ir por la senda del «reconocimiento». En este punto nos interesa recuperar las reflexiones de Fraser (2008) sobre ambos tipos de «reivindicaciones de justicia». La autora esgrime que, aunque se presenten en principio como «polarizados» o disasociados el uno del

\footnotetext{
${ }^{22}$ En abril de 2012, secretario de Estado de Servicios Sociales e Igualdad, Juan Manuel Moreno, anunciaba el recorte del $70 \%$ en campañas de sensibilización contra la violencia de género, apuntando que «El Gobierno anterior hacía campañas a bombo y platillo»: https://elpais.com/sociedad/2012/04/05/actualidad/1333638624_808957.html [último acceso: 21/05/2018]

${ }^{23}$ Tras dos años de gobierno, el Partido Popular había reducido casi a la mitad los presupuestos para igualdad y alrededor de una tercera parte los dedicados a la violencia de género: https://www.20minutos.es/noticia/2008182/0/dos-anos-rajoy/balance-programa/gobierno/ [último acceso: $21 / 05 / 2018]$

24 Ver: https://politica.elpais.com/politica/2013/10/05/actualidad/1380997260_542677.html [último acceso: 21/05/2018]

${ }^{25}$ Esta expresión la emitiría ya el que fuera ministro de Fomento y portavoz del Gobierno del último período de Zapatero, el gallego José Blanco (http://www.psoe.es/media-content/2015/09/603784000000482131.pdf [Última consulta: 21/05/2018]), y poco después sería adoptada por los populares en el ejecutivo (https://www.youtube.com/watch?v=EZvDXRcukrw [último acceso: 21/05/2018]).
} 
otro en la discusión filosófica, se deben complementar a la hora de articular un programa político con tintes de justicia reparativa.

Siguiendo a Fraser, ambos conceptos dejan de ser antagónicos en la esfera pública (al contrario que en la discusión filosófica), precisamente porque es la propia sociedad civil quien llama la atención de las instituciones sobre las especificidades identitarias $\mathrm{y}$, por tanto, sobre las necesidades de los distintos colectivos que la componen. Integrar estas necesidades en la agenda política, es decir, reconocerlas (y favorecer así estrategias de acción positiva a partir de un marco normativo en el que cristalicen las demandas de reconocimiento de las connotaciones respectivas a la identidad que justifican la desigualdad) sería el resultado deseable de aunar ambas perspectivas de justicia. Podríamos decir que se trataría de una justicia que, a partir de ahora (momento presente), garantice igualdad de condiciones ante la ley, sin perder de vista que se deben corregir las desigualdades sociales tangenciales (reconociéndolas previamente).

Sostenemos, en esta línea, que el programa político de Zapatero, que supuso la aprobación de leyes como la de Memoria Histórica, la ley contra la Violencia de Género, la ley Igualdad o la de Matrimonio Igualitario contemplaba esta «concepción bidimensional de la justicia» integrando el «reconocimiento de la diferencia» en la consecución de políticas para la igualdad social, no solo desde y para el presente sino también desde la pretensión de que el estado rinda las cuentas que no rindió en el pasado. Así pues, en el caso que nos ocupa, la idea de reconocimiento se podría vincular fácilmente con la «accountability» y «responsibility» de Butler (2005) cuando lo aplicamos desde la perspectiva de la justicia reparativa. 
Así pues, la aprobación de ley de Memoria Histórica en 2010 fue un solo hito entre toda la extensa legislación implementada en diversos ámbitos para la ampliación de los derechos de la ciudadanía, entre los que se encuentra el de igualdad entre mujeres y hombres y que contemplaría no solo la aplicación de la perspectiva de género en los usos de la administración en el presente, sino que tendría un claro carácter genealógico y reflexivo en torno al concepto de violencia y de víctima. Yusta afirma que:

La recuperación de la memoria histórica consistirá pues, para sus promotores, en contar lo que supuestamente nunca ha sido contado y que modificará el sentido último de todo el relato. Una recuperación que no sólo es palabra sino también acto. [...] Para sus defensores, esta recuperación de la memoria histórica es, como decimos, la reintegración en la narración histórica y en la memoria colectiva del relato y la experiencia de los vencidos y las víctimas. Se plantea como una cuestión de justicia, de dignidad y de reparación, semejante a las formuladas, en otros países, por colectivos que tienen en común el hablar desde una posición de víctimas y de perdedores, de excluidos del relato histórico «oficial» [...]. (Yusta, 2008: 110)

La puesta en práctica de esta ley, como acto, implicaría pues el reconocimiento de las víctimas y de las violencias del pasado e invitaría a una repensar las condiciones sobre las cuales se asigna o legitima la condición de víctima en el presente. Debemos tener en cuenta que en el momento en que se aprueba la normativa sobre la memoria histórica la ley contra la Violencia de Género ya lleva más de un lustro implantada y, por tanto, la condición de víctima ya había sido definida en el discurso público desde otros parámetros. No será disparatado, entonces, que las reflexiones realizadas desde los marcos del feminismo y al respecto de la otorgación del 
sentido político de la víctima quiera aunar el sentido político de la diversidad de las damnificadas por la dictadura, por el terrorismo de ETA y por la violencia de género. Esta ha sido precisamente la deriva discursiva que han tomado, por ejemplo, las vindicaciones feministas para enmarcar el asunto de la violencia de género ${ }^{26}$ como un problema público de actualidad que supera en impacto al de las víctimas del terrorismo etarra (Bandrés, 2011: 21).

Lo que ponen de manifiesto estas estrategias políticas y discursivas de la época de Zapatero es precisamente que lo que ha diferenciado a lo largo de las décadas a un tipo de víctimas de las otras ha sido la presencia o no su reconocimiento como tales en los discursos públicos. Es decir, lo que diferenciaba a las víctimas de ETA (y desde el $11 \mathrm{M}$, las víctimas del terrorismo islamista), de las de la Guerra Civil y la represión franquista o de las víctimas de violencia de género (entendida aquí, desde los tres parámetros de Galtung ${ }^{27}$ ) era básicamente la legitimidad que las instituciones del Estado democrático les habían adscrito, o no, y si eso les convertía en sujetos con derecho a reparación pública.

Por eso, venimos sosteniendo que, en esa primera década de los años 2000 , la emergencia del socialismo supondría una oportunidad para el entonces principal partido de izquierda de rendir cuentas con la ciudadanía en general, y con sus votantes y militancia en particular, sobre una cuestión pendiente desde la transición democrática de los setenta. Siguiendo con la reflexión de Aróstegui (2009) en torno a la ley de Memoria

\footnotetext{
${ }^{26}$ Ver Lucía Etxenike (El País, 30/11/2009, País Vasco) citada en Moreno Benítez, Damián (2010): «De "violencia doméstica" a "terrorismo machista": el uso argumentativo de las denominaciones en la prensa» en Discurso \& Sociedad, 4(4), 893-917. Disponible en: https://goo.gl/9JMZPf [último acceso: 21/05/2018]

${ }^{27}$ Entenderíamos así la violencia de género como un sistema triangular en el que no solo existe la violencia directa, sino que esta resulta sostenida por las estructuras de poder y de la cultura.
} 
Histórica, que recuperábamos en páginas anteriores, consideramos que este tipo de normativas transmiten la necesidad de reconstruir los cimientos de la democracia desde el reconocimiento y la legitimación de la verdad de las víctimas. Se trata de dejar de silenciar unas memorias que resultaban molestas para el relato de paz transicional en el que, aparentemente, todos tuvieron cabida, pero en el que no todas las personas se vieron reconocidas ni moralmente reparadas.

Así pues, la dirección del reconocimiento implícito en la ley es respecto al pasado y hacia las personas que fueron víctimas de un «alzamiento ilegítimo» (en palabras de Aróstegui, 200: 51) y de la represión que vino con la implantación de un régimen totalitarista; un régimen, por tanto, represivo que aniquilaba toda forma de subversión pero que, tras la ley de Amnistía y el paso por el proceso de la Transición democrática, tuvo que dar cabida a los grupos de izquierda que durante aquellos años habían desafiado el orden establecido desde la clandestinidad. En este reconocimiento, por tanto, debe incluirse el legado de las activistas feministas (muchas, en la doble militancia del partido socialista) como parte de esos nuevos cimientos democráticos.

Así pues, las octava y novena legislaturas de la democracia (2004-2011; último período de gobierno del PSOE hasta la moción de censura a Rajoy, llevada a cabo pocos días antes del cierre de esta tesis) nos resultarán esenciales para la compresión y el conocimiento profundo de la genealogía feminista en España y la articulación histórica del movimiento en el territorio estatal. En este punto de convergencia entre las cuestiones de memoria y género, que nos evoca el peso de la lucha del movimiento feminista como base para la democracia y resitúa en el relato oficial a las mujeres como agentes activos en las transformaciones sociales, enmarcamos las propuestas de mainstreaming de género de Zapatero. 
Entre ellas, la implementación de la ley de 2004 contra la Violencia de Género (la más tempranas de las medidas con perspectiva de género) y las campañas institucionales impulsadas desde la administración central vienen a dar cuenta de que el Estado es responsable de combatir y acabar con el sufrimiento de la mitad de su población como parte de la garantía del bienestar a sus ciudadanas. Se trata, además, de una ley pionera en Europa, «por su diagnóstico de la violencia como un problema estructural de desigualdad de género» que «respond[ía] a una petición del movimiento feminista español que se movilizó desde finales de los años noventa para que la lucha contra la violencia de género entrara en la agenda política de manera prioritaria (Lombardo y León, 2014: 20). Este problema de la desigualdad de género, entendida como un tipo de violencia estructural y cultural, se le combatiría unos años más tarde de forma transversal con la promoción de la ley de Igualdad (2007) y la creación del Ministerio de Igualdad.

\subsection{El feminismo institucional y el socialismo en España}

Al comienzo de la segunda legislatura de Zapatero (2008), se estrenó el Ministerio de Igualdad, que tuvo como principal misión el desarrollo de propuestas históricas del movimiento feminista para trabajar contra el problema sistémico de una cultura patriarcal, expresada en diversos escenarios de las estructuras sociales. Entramos así en un período de reconocimiento y reparación y protección oficial de las damnificadas del presente: las mujeres víctimas y supervivientes de la violencia de género entendida, desde nuestro marco de interpretación, a partir de la tríada de 
Galtung $^{28}$. La aplicación de la perspectiva de género en las políticas públicas de una manera transversal (mediante la aplicación del mainstreaming de género) constituye el eje que articula la generación de un estado de debate público paralelo que inspira las acciones feministas, alentadas por las instituciones gubernamentales y académicas y las organizaciones de la sociedad civil, y que todavía se están desarrollando en la actualidad.

Como acabamos de señalar, uno de los primeros signos que anunciaron el carácter transversal de la perspectiva de género en las políticas de Zapatero (quien se autodenominó en su momento «feminista» ${ }^{29}$ ) fue la aprobación de la ley contra la Violencia de Género (BOE, 2004), que vino seguida por la ley de Matrimonio Igualitario (BOE, 2005) y por la ley de Igualdad (BOE, 2007). Esta última «fija el principio de mainstreaming o transversalidad de un enfoque de género en las políticas públicas, y establece las unidades de género como estructuras que dentro de cada ministerio se encargarán de aplicar dicho enfoque» (Lombardo y León, 2014: 20). En línea con este planteamiento feminista, Zapatero creó al comienzo de su segundo mandato (abril de 2008) el Ministerio de Igualdad, dirigido por Bibiana Aído Almagro, la ministra -además- más joven en la historia del país. Este ministerio se hizo cargo del anterior Ministerio de Trabajo y Asuntos Sociales.

Como síntoma del momento encontramos las fotografías oficiales que podemos ver a continuación, tomadas al inicio del segundo mandato presidencial de

\footnotetext{
${ }^{28}$ Desde este punto de vista, las mujeres no seríamos solamente consideradas supervivientes de situación de maltrato en el seno de una relación de pareja, sino que al entender la violencia patriarcal como sistémica, estaríamos construyendo una noción de víctima/superviviente que pondría de relevancia la resistencia femenina ante las situaciones de violencia estructural y simbólica a las que se nos somete a diario.

29 Aquí, la entrevista: http://www.joanabonet.com/2011/08/jose-luis-rodriguez-zapatero-viaje-a-ny-2/ [último acceso: 21/05/2018]
} 
Zapatero (abril de 2008), ampliamente publicadas en los medios de comunicación, nacionales e internacionales. 


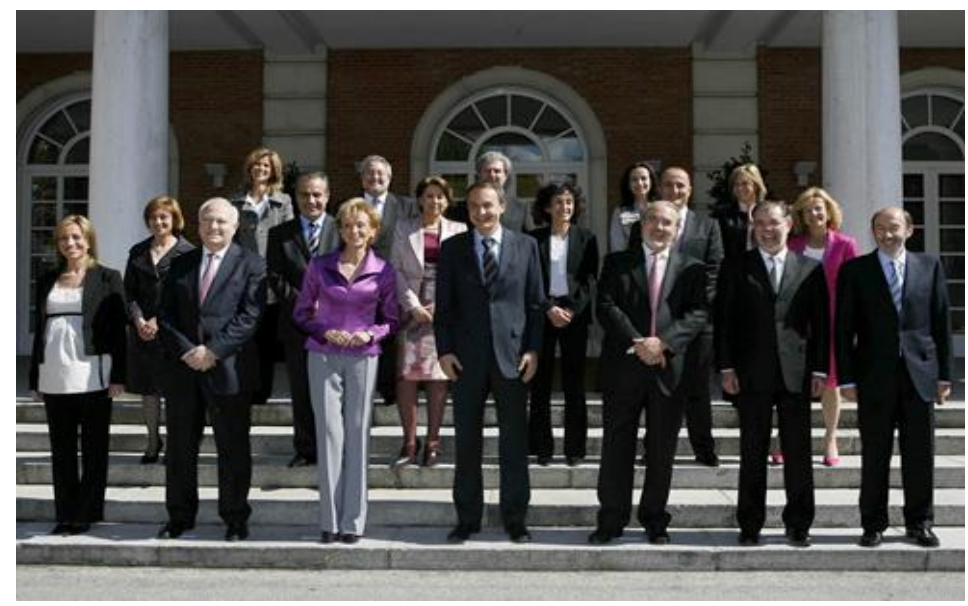

Imagen 2: Foto de familia del Gobierno de José Luis Rodríguez Zapatero, tras las Elecciones Generales de 2008. Palacio de La Moncloa, Madrid - 14/04/2008. Fuente: http://www.lamoncloa.gob.es/gobierno/gobiernosporlegislatu $\mathrm{ras} /$ Paginas/IXLegislatura.aspx?galf1 er $=0 \&$ galf2 $\mathrm{r}=2$ [último acceso: $21 / 05 / 20181$

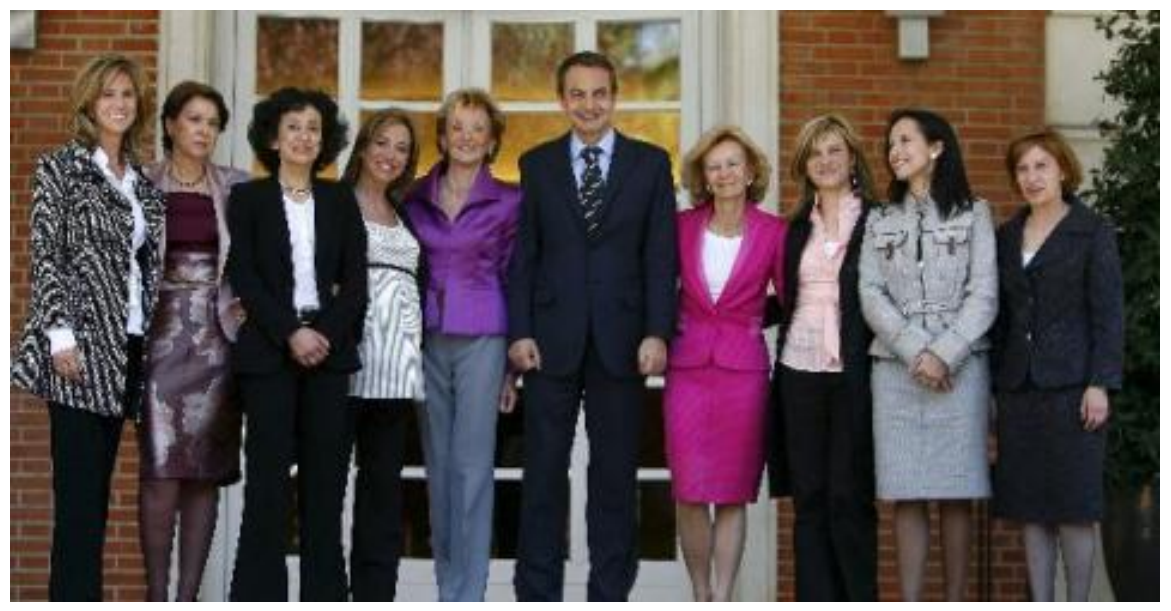

Imagen 3: Primera foto de Zapatero con sus 9 ministras en Moncloa - 14/04/2008. Fuente: Diario Público (http://www.publico.es/actualidad/foto-familia-moncloa-yprimera.html) [último acceso: 21/05/2018] 
Estas representaron la visibilización y consolidación del feminismo de Estado en España al reflejar una mayoría femenina en el ejecutivo parlamentario por primera vez en la historia de la política española. Además, cabe recordar que las ministras ahí retratadas se pusieron al frente de carteras tradicionalmente masculinas como la de Defensa (sostenida por la socialista catalana Carme Chacón) o la Vicepresidencia del Gobierno (de María Teresa Fernández de la Vega), además de ministerios históricamente feminizados como Educación o Asuntos Sociales. De hecho, esas dos legislaturas marcaron el clímax de lo que la filósofa Ana de Miguel (1995: 4143) denomina «feminismo institucional», que implicó la asimilación por parte de las administraciones políticas de los valores de la segunda ola del movimiento por la igualdad de género.

Sin embargo, recordemos que los primeros pasos para la institucionalización del feminismo español fueron llevados bajo la presidencia del primer gobierno socialista en el Estado, encabezado por Felipe González (1982-1996) e impulsados además por la entrada del país en la UE en el 1986 (Lombardo y León, 2014: 23). En 1983 se fundó el Instituto de la Mujer y sus equivalentes en las Comunidades Autónomas y en los años noventa el PSOE incorporó el feminismo en las instituciones estatales promoviendo institutos de investigación feministas y organizaciones de consultoría de género. Se argumenta, empero, que los derechos legales alcanzados por los gobiernos del PSOE llevaron a una desmovilización de los movimientos feministas de base (Gámez Fuentes, 2015; Marugán, et al., 2013).

Efectivamente, la victoria del PSOE en las generales de 1982 supuso una oportunidad para que las reivindicaciones de organizaciones sociales históricas, como el 
caso de las feministas, cristalizaran en la legislación, provocando una sensación de conformidad que desactivaría el activismo durante la década. Más tarde, en la década de los noventa, el Partido Socialista acabaría de institucionalizar el feminismo, promoviendo institutos de investigación sobre cuestiones de mujer y género; unos avances que frenó la entrada en el gobierno del Partido Popular en 1996 (etapa de mayoría absoluta de José María Aznar) y que no se retomaron y consolidaron hasta el regreso al poder del PSOE en 2004. En las páginas que siguen, veremos cuál había sido el legado del feminismo en la democracia que retoma y mainstreamiza el gabinete de Zapatero a partir de esta fecha a colación, de nuevo, de las directrices europeas al respecto.

\subsubsection{EI legado feminista para la democracia}

Cuando hablamos de democracia en nuestro contexto, resulta obligado hablar de la Transición y del consenso conseguido por los «padres de la Constitución» para formular el texto que sentaba los cimientos del nuevo sistema político. Aquellos hombres que fueron capaces de dejar sus diferencias por un fin de mayor envergadura (la convivencia democrática tras la dictadura) tienen su espacio conmemorativo en los medios de comunicación cada seis de diciembre. Muy poco se dice, sin embargo, acerca de las mujeres (27 congresistas y senadoras) que formaban parte de las negociaciones y los acuerdos para la igualdad de la mujer en democracia entre los bastidores de la doble militancia (Castillo Mateu, 2018) ${ }^{30}$.

30 De este menester se ocupa el documental Las Constituyentes (Olivia Acosta: 2012), una pieza en la queda patente que, como dice Amelia Valcárcel, «el feminismo es un hijo no querido de la Ilustración» (2001:8). Esta máxima trasladada al contexto de la democracia española reciente supondría afirmar que el 
Gracias a la presión de la militancia feminista de la izquierda y a las mujeres que contribuyeron a la redacción de la Constitución Española de 1978, se hicieron constar los siguientes derechos y principios a los que todavía recurrimos para esgrimir la viabilidad de las leyes de igualdad. Por una parte, el artículo 9.2 establece el principio de igualdad material o sustancial, el artículo 14 de la ley fundamental del Estado hace referencia explícita al principio de igualdad y no discriminación, y el 15 dice que «todos» [sic] tienen derecho a la vida y a la integridad física y moral ${ }^{31}$. El artículo 32 hablará del derecho a contraer matrimonio con plena igualdad jurídica., el 35.1, del derecho al trabajo sin discriminación por razón sexo. Y el artículo 57.1 CE, se referirá a la protección integral de los poderes públicos a las madres.

A pesar de este trabajo de inclusión de los intereses feministas en el texto constitucional de la democracia y de que las mujeres habían tenido ya su protagonismo en la lucha antifranquista de los años cincuenta y sesenta, los grupos de izquierda a los que se adscribían — entre ellos el Partido Comunista (PCE), que vivió a finales de la dictadura la escisión de lo que sería más tarde el Partido Feminista (PFE), liderado por Lidia Falcón-consideraron siempre su lucha, la de ellas, como tangencial (Francés, 2015: 22). Llegados los setenta y con la transición en marcha, cualquier reacción política que cristalizara durante la reconstrucción de la democracia del Estado parecía desviar el foco de atención del objetivo importante (recuperar los derechos perdidos durante el franquismo) por meras «cuestiones personales» (Gámez Fuentes, 2015). Esto muestra que tampoco los sectores más progresistas eran sensibles al lema del feminismo

feminismo ha sido la madre no reconocida de la izquierda en la transición democrática de los setenta o el vientre de alquiler del $15 \mathrm{M}$ y de la nueva izquierda. ()

${ }^{31}$ Este artículo ha resultado, desde la transición y hasta nuestros días, la referencia para esgrimir argumentos a favor o en contra de las modificaciones de la ley del aborto. 
radical que proclamaba que «lo personal es político» ni conscientes de que la lucha de las mujeres no partía de una perspectiva política por el beneficio de las personas de género no masculino, sino que implicaba la aplicación de una mirada diferente desde la que construir un sistema democrático que beneficiara a toda la población.

Aunque la lucha por la igualdad de género efectiva (y con eso nos referimos a la implantación formal en las estructuras del Estado mediante el desarrollo de políticas y legislación garantistas, así como a la asimilación cultural de la perspectiva de género) fue relegada en favor de la gran misión de la transición democrática (una misión sobre la que todavía se proyectan sombras), no se puede decir que el movimiento feminista se mantuviera impasible ante las oportunidades de la transición democrática. Así, se reconocen tres fases de eclosión del feminismo de la segunda ola en España en este período histórico. Estas se definen en base a su expansión organizativa (1975-1979), a su escisión interna (1979-1982) y a su fragmentación y desintegración (1982-1985). Este último proceso marcaría la institucionalización de la militancia (De Grado, 2004: 26 y Larumbe, 2005: 12).

Siguiendo el recorrido cronológico nos encontramos con la celebración de las I Jornadas Nacionales por la Liberación de la Mujer en 1975, que coinciden con la celebración del Año Internacional de la Mujer de las Naciones Unidas (Gould Levine, 2004: 59). Este hito funcionó como catalizador de las demandas de las feministas y supuso un primer paso para la discusión (semipública) variada sobre la mujer respecto a temas como la familia, el divorcio, los anticonceptivos y el aborto (Vega, 2007); o respecto al trabajo, la sociedad, la educación y el mundo rural. No obstante, el encuentro no se salvó de abordar la polémica ideológica sobre la relación de la lucha feminista con la lucha política en general. De allí, las feministas salieron sin consensos, 
pero con posiciones claras respecto a los retos para la igualdad de su sujeto político en el escenario de transición democrática (Moreno, 1977; Gould Levine, 2004: 59).

Así, la celebración de las jornadas inspiraría gran diversidad de acciones de vindicación feminista que nos permiten vislumbrar que los éxitos legislativos del movimiento feminista conseguidos a posteriori no serían el producto de las políticas institucionales per se, sino de las acciones de los grupos de base (Vega, 2007). En esta línea, la agenda reformista feminista vendría marcada por las reclamaciones de amnistía para prisioneras por discriminaciones de carácter misógino en Código Penal (1977) y por las medidas contra desigualdad laboral, así como la planificación familiar legalización de los anticonceptivos- o la despenalización del adulterio y del aborto (1978). En 1981 vendría la legislación sobre el divorcio en base a la igualdad de responsabilidades en la patria potestad y la legalización del Partido Feminista de Lidia Falcón (Gould Levine, 2004: 61), cuatro años después de la legalización del Partido Comunista Español.

En este momento ya se puede contabilizar la celebración de dos encuentros feministas más de carácter estatal, además del de Madrid en 1975 (I Jornadas Nacionales por la Liberación de la Mujer) tenemos: les Jornades Catalanes de la Dona (1976) en Barcelona y las II Jornadas Estatales de la Mujer (1979) en Granada, suponiendo estas últimas la apertura del movimiento a partir de la constatación de las dificultades encontradas entre las mujeres comprometidas con la doble militancia (en partidos y sindicatos) y las militantes feministas independientes de trascender las diferencias ideológicas intrínsecas al movimiento (Díaz, 2011). Es aquí donde encontramos la escisión de las feministas de la igualdad (feminismo ilustrado), quienes, con la victoria de Felipe González en 1982, verían iniciada esa tercera fase de 
progresiva institucionalización del feminismo tras décadas de invisibilización de las mujeres en esa doble militancia.

En este contexto, desde la esfera del Estado, se crearían entes como el Instituto Nacional de la Mujer (y sus réplicas en las Comunidades Autónomas) en 1983, se promulgaría una ley del aborto (conocida como "ley de supuestos") en $1985^{32}$, y se aprobaría un Plan para la Igualdad de Oportunidades de las Mujeres, en 1987, dirigido a facilitar su acceso a puestos de poder (cuerpo militar, finanzas y gobierno) (Gould Levine, 2004: 63). No obstante, a pesar de la incorporación de algunas demandas feministas por parte del PSOE en las instituciones (a través del reconocimiento de derechos de las mujeres mediante o la promoción de los institutos de investigación y consultorías de género), ya hemos mencionado que, desde la Academia, este período se ha leído en términos de desmovilización del feminismo de base (De Miguel 1995; Cruz y Zecchi, 2004; Gámez Fuentes, 2015), de la misma manera que las propias protagonistas vivieron con desencanto aquella década.

Lidia Falcón, en su descripción de esta primera fase de institucionalización del feminismo de mediados de los ochenta, destacará los siguientes factores: el condicionamiento de las políticas de subvenciones del Estado posterior a la Transición, la progresiva institucionalización de las tareas de las que se habían ocupado los grupos feministas hasta ese momento (que entonces quedaron en manos de ayuntamientos, autonomías, Seguridad Social, etc.) y «el desánimo o cansancio que acomete a algunas asociaciones de mujeres que creen alcanzados los principales objetivos de la lucha» (Falcón, 2000: 17). De la misma manera, sigue la activista, habrá muchas «líderes» del

\footnotetext{
${ }^{32}$ Ver: BOE $n^{\circ} 166,12 / 07 / 1985$, p. 22041-22041: Ley Orgánica 9/1985, de 5 de julio, de reforma del artículo 417 bis del Código Penal. Disponible en: https://www.boe.es/buscar/doc.php?id=BOE-A-198514138 [último acceso: 21/05/2018]
} 
movimiento feminista durante la dictadura que, posteriormente, abandonarán la militancia para formar parte exclusivamente de las organizaciones de la resistencia que se insertan en el sistema de partidos debido a sus «ambiciones políticas».

Los avances en temas de género cesaron a mediados de los noventa, con la victoria del Partido Popular (PP) en 1996 y la presidencia de José María Aznar. Lo mismo puede decirse de la etapa de Gobierno del PP de Mariano Rajoy (2011-2015), que, como si de un bucle se tratase, vino a borrar la agenda feminista de la esfera pública tras la segunda época de apogeo del feminismo institucionalizado en el Estado español durante el gobierno de Zapatero (2004-2011), comenzando con la merma de los presupuestos del Estado para a las víctimas de violencia de género y siguiendo con la polémica propuesta para reformar la Ley del Aborto (que terminó con la renuncia del ministro de Justicia, Alberto Ruiz-Gallardón). No obstante, cabe señalar aquí que esta propuesta fue la que motivó un revulsivo del activismo y la sororidad feministas tras ese segundo período de apogeo del feminismo de Estado.

\subsubsection{La sociedad formalmente igualitaria}

Es necesario, antes de continuar con nuestra exposición del contexto histórico, detenernos en los claroscuros que la imbricación del discurso y la lucha feminista ha provocado en la sociedad una vez que el feminismo se ha ido institucionalizando, ya que eso nos servirá para dar cuenta de la complejidad del marco político en el que se inserta nuestro trabajo.

La discusión en la esfera pública alrededor de la igualdad, sobre la que se está incidiendo en la socialización de las nuevas generaciones, radica en los debates 
tradicionales del movimiento feminista que, por un lado, defienden/cuestionan la integración de las vindicaciones políticas de las subalternas en la agenda de las estructuras tradicionales de representación institucional y, por otro, sigue «maridando» ${ }^{33}$ la dicotomía igualdad/diferencia ${ }^{34}$ en los espacios privilegiados de pensamiento y debate. Así, por una parte, nos interesa centrarnos principalmente en el discurso feminista que ha entrado en las agendas de las instituciones y a partir del cual se construido ese marco en nuestra «sociedad formalmente igualitaria» (De Miguel, 2015). Por otra, resulta imperativo vislumbrar las derivas por las cuales el discurso feminista de base encuentra motivos y motivaciones para recoger y replantear debates en torno al sujeto del feminismo y respuestas a las problemáticas que sugiere la coyuntura actual y que tienen que ver con la capacitación respecto a la vida pública.

La agenda feminista más oficial sigue reclamando la visibilización del papel de las mujeres en los espacios de representación y liderazgo. Así, desde los propios partidos políticos, alentados por la implementación de ley de cuotas socialista (Uribe, 2013), se incide en la necesidad de participación de la mujer en los espacios de organización y de decisión política, siguiendo el rastro de la agenda de la doble militancia feminista histórica. En esta línea, las secciones feministas de los partidos se encargan, más allá de trabajar por los objetivos de las organizaciones a las que pertenecen, de transformar la estructura interna patriarcal a través de la concienciación del colectivo militante en general, con especial atención a la sensibilización de las secciones de jóvenes. En esta línea, apelan a la necesidad de la presencia de mujeres en

\footnotetext{
${ }^{33}$ Parafraseamos la alusión de Mercedes de Grado (2004: 44) a la conciliación de las propuestas teóricas del feminismo teórico de la igualdad y de la diferencia (De Grado, 2004: 35-43)

34 Ver De Miguel, Ana (1995): Los feminismos a través de la historia. Disponible en: https://goo.gl/PzCVJB [último acceso: 21/05/2018]
} 
la política y de los liderazgos femeninos, ya que todavía se percibe como problemática la ausencia de mujeres en los órganos de decisión de las estructuras sociales.

Se incide por ello en la importancia de que las fuerzas políticas tengan la voluntad de llevar a cabo políticas integradoras basadas en el feminismo y que articulen desde la perspectiva de la igualdad de género, consecuentemente, todas las políticas transformadoras y no solo acciones puntuales para salir del paso ante la opinión pública o los grupos de presión feministas (si es que existen tales lobbies). Así, los programas electorales (especialmente, desde la izquierda) ${ }^{35}$ recogen propuestas para la renovación de la legislación en base a criterios trasversales de impacto de género y desde una perspectiva de solidaridad en asuntos directamente relacionados con la crianza y los cuidados (como por ejemplo, los permisos por maternidad y paternidad y la dependencia), además de incluir medidas para la protección y acogida en los casos de violencia de género.

Volviendo al tema de las cuotas, parece ser que este aspecto de la normativa socialista por la igualdad de género ha calado sospechosamente bien en la presentación pública de las nuevas -y no tanto- fuerzas políticas, que se han acogido a la corriente de opinión igualitaria, aunque a veces interpretada desde el marco del neoliberalismo ${ }^{36}$. Sin entrar ahora en esta discusión, sí que nos resulta interesante en este momento ver como en esta suerte de retorno al desencanto con los avances del feminismo de Estado

\footnotetext{
${ }^{35}$ Véase, por ejemplo, el caso del PSOE (programa disponible en: https://goo.gl/h8h3q8), Podemos (programa disponible en: https://goo.gl/SrPZfh), incluso de los partidos nacionalistes periféricos como Compromís (programa disponible en: https://goo.gl/Nzn3yM) [último acceso: 19/06/2018]

${ }^{36}$ En su obra más reciente, Ana de Miguel (Neoliberalismo sexual. El mito de la libre elección, 2015: cap. 2) señala -entre otros frentes abiertos para el feminismo- los peligros de la confusión entre el discurso por el empoderamiento femenino y la fagocitación del deseo de feminidad neoliberal a través de mecanismos de consumo que perpetúan las construcciones desiguales del género (pp. 309-310).
} 
socialista, nos encontramos de nuevo con las influencias que este ha ido posando sobre el imaginario colectivo (radicalmente patriarcal, cabe decir). Por eso, resulta curiosa la reflexión de Larumbe (2005) sobre los logros del movimiento tras la transición democrática y que puede leerse perfectamente desde nuestro contexto político presente. Dice:

El feminismo ha terminado por influir en los programas de todos los partidos políticos sobre todo en los de izquierdas, aunque, incluso, entre los partidos de derechas podemos apreciar el curioso fenómeno de la criptomnesia que llega a producir la influencia minoritaria cuando ésta es exitosa y que de forma breve puede explicarse así: el individuo puede guardar algo en la memoria y olvidar que esa idea la ha escuchado o recibido de otra persona. Con el paso del tiempo, el sujeto no sólo termina por asumirla, sino que cree ser padre de la misma. (Larumbe, 2005: 24) [La cursiva es nuestra]

Bien sea por la causa que señala Larumbe - por la firme convicción de los partidos, por un impulso oportunista o por una cuestión simplemente de ley-la cuestión de las cuotas de representación presente en la agenda feminista institucional parece haber calado incluso en los partidos más conservadores (Uribe, 2013: 192). Así, no nos resulta tampoco extraño que sean nombres femeninos los que a día de hoy ocupen los titulares de los medios de comunicación como portavoces de su partido, aunque siguiendo una línea de liderazgo particularmente tacherista. Sería el caso de Isabel Bonig (presidenta del Partido Popular de la Comunidad Valenciana), Cristina Cifuentes (expresidenta del PP de Madrid) ${ }^{37}$, Susana Díaz (presidenta de Andalucía, del Partido Socialista) ${ }^{38}$, o Inés Arrimadas (líder de Ciudadanos en Catalunya).

\footnotetext{
${ }^{37}$ Ambas, además, por estar implicadas en casos de corrupción: https://www.levante-emv.com/comunitatvalenciana/2018/06/12/gurtel-pago-actos-rajoy-bonig/1730626.html [último acceso: 21/05/2018]
} 
Pero precisamente esta cuestión es la que genera paradojas en el debate feminista. Parece que la mainstreamización de la perspectiva de género en la política ha tenido buenos resultados, al menos en apariencia. Los partidos se preocupan por incluir la cuestión de la igualdad entre mujeres y hombres en su discurso y sus programas, y también tienen en cuenta el sistema de cuotas de género a la hora de configurar sus listas (las 1lamadas «listas cremallera»). A pesar de ello, sigue habiendo muy pocas mujeres como cabeza de lista de sus partidos, especialmente cuanto más relevantes son para la composición de las cámaras (Uribe, 2013; Delgado, 2010). Así, aunque se alcance a cumplir las cuotas y el reparto de escaños o de cargos sea igualitario, las mujeres siguen ocupando predominantemente los segundos lugares y, cuanto mayor es la distribución de votos entre partidos y más diversidad de opciones políticas están representadas en las cámaras, más masculinizadas están, ya que los primeros puestos habrán sido asignados a hombres.

Otra cuestión que genera debate en el contexto político de formalización de la igualdad es precisamente el de los tipos de liderazgo femeninos. Es decir, el feminismo se pregunta ${ }^{39}$ si efectivamente la incorporación de la mujer a los espacios de decisión implica una feminización de la mirada que rige esas decisiones. Ya De Beauvoir señalaba que:

En el momento en que las mujeres empiezan a tomar parte en la elaboración del mundo, ese mundo es todavía un mundo que pertenece a

http://www.publico.es/politica/master-cifuentes-jueza-imputa-cifuentes-caso-master.html [último acceso: $21 / 05 / 2018]$

${ }^{38}$ En este artículo, María Castejón reflexiona sobre las paradojas que arrojan al debate el tipo de liderazgos ejercidos por mujeres en los partidos tradicionales, fijándose en el caso de la actual presidenta de Andalucía: https://www.eldiario.es/pikara/Mujerismos-mujer-medida-todas-cosas_6 386771328.html [último acceso: 21/05/2018] 
los hombres; ellos no lo dudan, y ellas dudan apenas. Negarse a ser Alteridad, rechazar la complicidad con el hombre, sería para ellas renunciar a todas las ventajas que les puede procurar la alianza con la casta superior. (Beauvoir, 1998: 55)

La filósofa de mediados del s. XX apuntaba que, inevitablemente, las mujeres, por nuestra situación de género, no tenemos opción más que negociar con los hombres en estos espacios de poder masculinizados, aunque desde el feminismo se sigue optando por perfiles de políticas que verdaderamente apuesten por feminizar la política, es decir, gobernar desde la perspectiva de género ${ }^{40}$, desde el cuidado a la diversidad y la inclusión de la diferencia.

\subsection{La llegada de la crisis, del 15-M a las calles y del PP al gobierno}

La ampliación de los derechos civiles llevada a cabo durante el gobierno Zapatero (2004-2011) fue reducida con la entrada del Partido Popular en el gobierno central a base de recortes del gasto público, lo cual fue, a su vez, consecuencia de la aplicación de las políticas de austeridad ya iniciadas por los socialistas con la intención de contrarrestar los efectos financieros de la crisis económica del $2008^{41}$. La reacción del electorado poco se hizo esperar y la convocatoria anticipada de elecciones en

\footnotetext{
${ }^{40}$ En el siguiente artículo colocado en Opendemocracy.net, se comentan los ejes de gobernabilidad municipal y regional que caracterizan a políticas como Manuela Carmena (actual alcaldesa de Madrid), Ada Nicoulau (actual alcaldesa de Barcelona) o Mónica Oltra (actual vicepresidenta de la Generalitat Valenciana) y que supondrían un distanciamiento al modelo neoliberal de liderazgo: https://www.opendemocracy.net/uk/austerity-media/mar-jos-g-mez-fuentes-laura-castillo-mateu/spainno-country-for-old-men-politics

${ }^{41}$ Durante la campaña de las generales de 2011, Mariano Rajoy, como candidato presidencial por el Partido Popular, anunció que «metería la tijera» a todas las partidas presupuestarias necesarias para complir con los objetivos de dèficit establecidos por la UE: http://www.europapress.es/nacional/noticiarajoy-le-voy-meter-tijera-todo-pensiones-sanidad-educacion-20111104105210.html [último acceso: $21 / 05 / 2018]$
} 
noviembre de 2011 reflejó un giro conservador de los votos que daría la victoria a Mariano Rajoy y supondría una nueva mayoría absoluta para el PP. Con ella, se puso fin a toda nueva inversión o esfuerzo por dar continuidad a las políticas con perspectiva de género (Paleo y Alonso, 2015) y de recuperación de la memoria histórica ${ }^{42}$.

De esta manera, como ya dijimos, se borró la agenda feminista, comenzando con la retirada de fondos estatales para ayudar a las víctimas de la violencia de género. Por si la retirada de financiación por la erradicación de la violencia de género no resulta lo suficiente demostrativa de la tendencia ideológica del gobierno de Rajoy, podemos fácilmente recuperar el intento de reforma integral de la ley del aborto que, como observamos, no llegó a aplicarse en su totalidad. Más bien terminó con la renuncia del entonces ministro de Justicia, Alberto Ruiz Gallardón, tras las protestas masivas del movimiento feminista que, a lo largo y ancho del Estado, se manifestó en la marcha violeta conocida como El Tren de la Libertad (Castillo Mateu, 2015) ${ }^{43}$. Se trató de una marcha cuya estética (los lemas, el tono desenfadado y lúdico de la marcha, la música, la elección de un color significativo para la causa -en este caso, el violeta feminista) evocaba el ambiente del movimiento anti-austeridad y las manifestaciones que tres años antes se organizaron en torno al hito del 15 de marzo de 2011.

Recordemos que estas protestas ciudadanas masivas acabaron acelerando todos los procesos electorales a falta de un año para la convocatoria de elecciones generales. Este despertar de la sociedad civil también vino acompañada del surgimiento de nuevas organizaciones, como Podemos, que tomaron forma de partido y se erigieron $42 \quad$ Ver: $\quad$ https://www.eldiario.es/sociedad/Gobierno-vuelve-ningunear-MemoriaHistorica_0_629237898.html [último acceso: 14/04/2018]

${ }^{43}$ Los testimonios de las organizadoras y asistentes a la marcha quedaron recogidos en un documental de producción cooperativa titulado Yo decido. El tren de la libertad. Disponible online en: https://vimeo.com/99974636 [último acceso: 14/04/2018] 
como representantes de ese espíritu de transformación que motivó que las generaciones más jóvenes y mejor preparadas de la historia participaran de la reflexión en las plazas y calles de las ciudades. Resulta curioso que tanto este nuevo partido encabezado por Pablo Iglesias, como el que más tarde sería nuevo representante del PSOE, Pedro Sánchez, destacaran en las sucesivas campañas electorales la necesidad de representar una «segunda transición» ${ }^{44}$. El sentido popular que cobraba esta expresión era precisamente el de la necesidad de regenerar el sistema democrático hacia la garantía y de recuperar los derechos sociales (perdidos o dañados a causa de las políticas de austeridad) y la soberanía popular, en lugar de complacer los requisitos del sistema económico mundial.

Las constantes referencias a esta tan esperada «segunda transición» por parte los líderes de la izquierda en el nuevo milenio, desde el presidente Zapatero a los líderes de las izquierdas, resultan de alguna manera repetitivos, continuados. Parece ser que, a pesar de los intentos de Zapatero por recuperar y reparar la memoria histórica y de los cambios experimentados en la esfera representativa, las nuevas generaciones de ciudadanos y ciudadanas todavía necesitan reparar el trauma del olvido transicional. Es decir, a pesar de que el deseo común fue el de establecer la normalidad democrática lo más pronto posible durante la Transición, la política de silencio (respecto a la perpetuación de los sectores de poder franquista en las instituciones) y del olvido forzado no resultó adecuada y, entrado el nuevo siglo, las generaciones de nietos y biznietos de la población damnificada necesitan del saneamiento de las heridas familiares para poder reapropiarse de los espacios políticos con legitimidad.

44 Ver: https://politica.elpais.com/politica/2014/07/16/actualidad/1405522678_081334.html [último acceso: $14 / 04 / 2018]$ 
Una de las disfunciones, precisamente de la transición democrática, de las que la llamada «nueva política» ha demostrado adolecer, se hizo ya patente en la acampada del 15M, en la Puerta del Sol de Madrid. El movimiento de los indignados congregó a todo tipo de miembros de la sociedad civil organizada en el tercer sector, y -obviamente- esa representación contó también con grupos de feministas y una pancarta con el eslogan «La revolución será feminista o no será» (Gámez Fuentes, 2015); un lema que podría considerarse del todo adecuado y en consonancia con las aspiraciones del movimiento, ya que demandaba atención de los políticos sobre la protección de los derechos de una parte importante de la ciudadanía (la mitad) y se mostraba en contra de los recortes impuestos por las administraciones del Estado que perjudicaran las garantías sociales de ese sector. No obstante, de acuerdo con el artículo de Gámez Fuentes, el feminismo fue percibido como un intruso en la plaza y las feministas fueron acusadas de querer fragmentar la lucha:

The different committees [...] had to deal with manifestations of structural violence in the form of lack of representation in committees and assemblies, patronising behaviours (when setting out their arguments) and sexist stereotyping (mainly having to do with women's demands being considered not universal or "personal caprices"). [...] The conflictual relationships experienced by feminist groups within their respective camps was enhanced on occasion by the mainstream media, who framed women's demands as a source of confrontation. [...] feminism in general, [...] was accused of pursuing the privilege status of women over men (Gámez Fuentes, 2015: $360)$.

Traemos a colación este episodio porque resulta representativo del momento de nueva (quién sabe si segunda o tercera) transición y el todavía denostado papel del movimiento feminista en España que sigue encontrándose con problemas similares a los 
que se le planteaban en la transición democrática. Así pueden leerse algunos paralelismos históricos que son sintomáticos de una suerte de espiral de eterno retorno, en el que parece haber caído también el activismo feminista en la configuración de la política en este país. Parece que nunca es un buen momento para darle cabida, ya que hacerlo ya no supone solamente incorporar a las mujeres al debate y a la acción de la esfera pública, sino que implica también un cambio de paradigma que muchos parecen temer y que otros parecen no querer comprender.

La filósofa Ana de Miguel (2015) se preguntaría aquí cómo es que se sigue reproduciendo la desigualdad en sociedades formalmente igualitarias. Una pregunta a la que los y las defensoras del feminismo intentan dar respuesta, apelados y apeladas por una suerte de voz del patriarcado que se reproduce en forma de duda hacia la causa desde muchos frentes, de nuevo, desde lo más personal a lo político. En efecto, en el caso español, la autoconciencia de la ciudadanía, en términos generales, apoya con firmeza el valor de la igualdad entre hombres y mujeres. La opinión pública y publicada no discrepa ante cuestión de, independientemente del género, tener las mismas oportunidades. Podemos decir que se considera un valor de progreso y una cuestión de justicia. Se apela incluso a la Constitución de 1978 para defender que tenemos todas las personas los mismos derechos y este aspecto nos confiere además un carácter de sociedad empoderada, moderna y progresista respecto a otras sociedades. Las instituciones públicas presentan a la sociedad española como una sociedad comprometida con la igualdad que, más allá de la mera declaración de intenciones, había dado un paso público y político hacia su concreción mediante el desarrollo y ejecución de una legislación y de medidas activas por la igualdad. 
No obstante, a la vista queda que los sectores progresistas de este país todavía siguen en el proceso de salir de algunos «armarios» ${ }^{45}$, entre los que se encuentra precisamente el espacio simbólico del machismo o de la cultura patriarcal. A pesar de ello, y teniendo en cuenta los backlashes a los que se ha enfrentado el movimiento feminista, a pesar de la pedagogía institucional que de él se ha hecho, tampoco estaría de más reconocer (en la línea de las declaraciones que hizo el socialista Pedro Zerolo en la entrevista que referenciamos a pie de la página anterior) la «valentía» con la que el gobierno de Zapatero «salió de armarios» y afrontó algunos tabúes que habían quedado en el imaginario de la sociedad española desde la transición, en especial en el de las militantes feministas de la izquierda y las víctimas del franquismo y sus descendientes. La valentía precisamente se manifestó a través de una voluntad de rendición de cuentas (accountability en palabras de Butler, 2009) que cristalizó en un marco normativo muy centrado en la reparación y en esa pedagogía formal (oficial) e informal (en el plano del entretenimiento y las industrias culturales). De hecho, Zerolo sentenciaba que la premisa de la «valentía» resultaba indispensable para «enfocar» el ejercicio político. En esta línea, decía: «la valentía es el secreto de la libertad y de la igualdad [...] cuando la izquierda ha sido valiente en este país [...] ha acertado siempre y ha contado con el

\footnotetext{
${ }^{45}$ En referencia a las declaraciones del socialista y activista LGTBI Pedro Zerolo con las periodistas Gemma Nierga y Pepa Bueno (ambas al frente del magazine matinal Hoy por Hoy), donde el militante apuntó la necesidad de «visibilizar» y de «construir referentes» en todo tipo de activismo, algo que aprendió, decía, del movimiento de autodeterminación femenina: «lo privado es público, sobre todo cuando eres un servidor público [...] tengo que ser transparente en todo lo que hago y la ciudadanía tiene derecho a saber cómo soy», dijo.

En la entrevista radiofónica a la que nos referimos, Zerolo usó esta expresión popular para traer a colación las resistencias que el tema de la igualdad encuentra en algunos militantes de izquierdas, herederos de una tradición socialista muy enmarcada en la heteronormatividad. No obstante, nos resulta útil recurrir a este modismo para poner de relieve las paradojas inherentes al discurso universalista con las que se han topado los partidos progresistas en este país, en concreto y en este caso el PSOE. Es decir, cuando existe conflicto entre lo deseable en la práctica y lo presumible del ideario.
} 
apoyo de la inmensa mayoría de la ciudadanía española en todas y cada una de las leyes que han supuesto un revulsivo».

\subsection{Temas pendientes: la cuestión territorial y el tabú de los nacionalismos}

Antes de cerrar el capítulo que dedicamos a enmarcar históricamente los productos culturales que analizaremos después, es menester para el caso que nos ocupa revisar cómo la ruptura del centralismo geopolítico ha resultado también un «armario» del que todavía le cuesta salir al núcleo duro del PSOE. No es casual (por generar de nuevo un paralelismo con el momento presente) que Pedro Sánchez, actual secretario general del partido, se mostrara en la precampaña de las generales con la bandera monárquica de fondo.

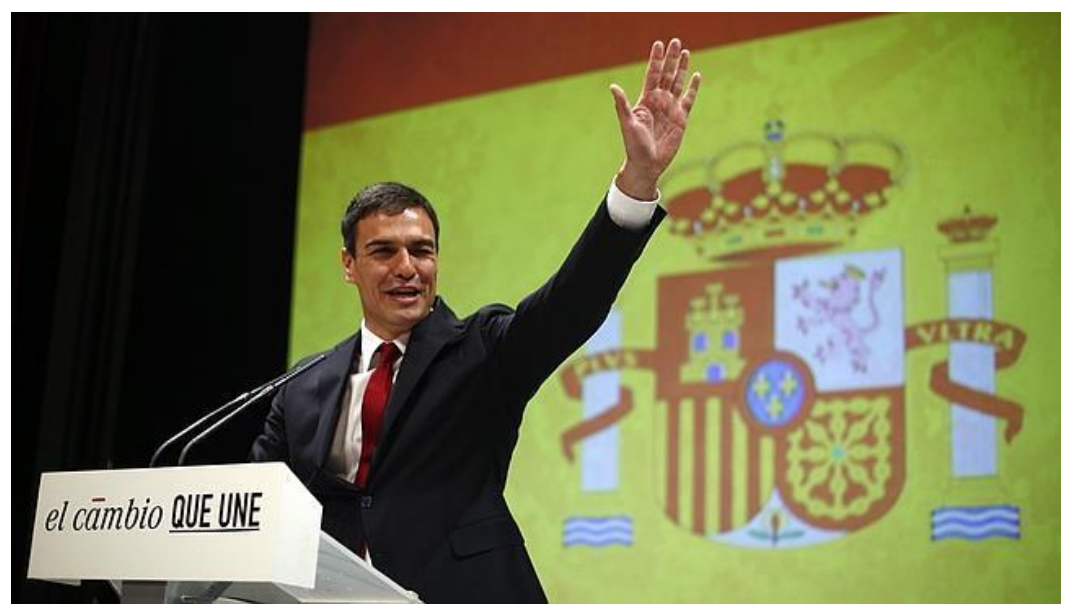

Imagen 4: Foto de Pedro Sánchez, secretario general del PSOE, frente a la bandera constitucional en su acto de presentación como candidato presidencial a las elecciones generales -21/06/2015. Fuente: http://www.abc.es/fotonoticias/fotos-espana/20150623/pedro-sanchezdelante-bandera-1621352066455.html [último acceso: 21/05/2018] 
Nos va bien aquí recurrir a la metáfora del armario del españolismo centralista (a colación de los comentarios anteriores del socialista Pedro Zerolo a las que hacíamos referencia) que algunos sectores del PSOE vienen reproduciendo hasta la actualidad. Esto, en un partido que parece no recordar que su ensamblaje territorial es de corte federalista en el contexto del Estado cuando desde Cataluña se pedía apoyo al gobierno central para ampliar las demandas de autonomía tras los recortes que sufrió el Estatut de 2005 por parte del Tribunal Constitucional. El PSC sigue resintiéndose en las elecciones a pesar de haber sido históricamente, junto al Partido Socialista de Andalucía, la principal potencia del socialismo en el Estado. La deriva política hacia el independentismo, consolidada tras las elecciones del 27S del 2015 hizo que el PSOE volviera a replantear una reforma constitucional de cariz federalista de cara a las elecciones generales del 20D de 2015. Un proyecto, el territorial, que, como el feminismo, ha quedado relegado a un segundo plano por causas mayores desde la transición.

No obstante, al cierre de esta tesis, el proceso de independencia en Catalunya ha cobrado la suficiente relevancia política internacional como para que sea una necesidad imperiosa la de establecer un diálogo entre la capital del Estado y Cataluña. Así, en lugar de optar por posar ante banderas y con lemas por la unidad, Pedro Sánchez, ahora como presidente del gobierno (tras haber conseguido los apoyos necesarios para sacar adelante una moción de censura contra la presidencia de Mariano Rajoy) ha nombrado como Ministra de Administraciones Territoriales a la federalista 
catalana Meritxell Batet ${ }^{46}$. Esta elección de quien será la encargada de establecer el diálogo con los actores políticos catalanes simboliza a priori un paso atrás en las políticas de unidad unilateral y desigual por parte del estado, al frente de las cuales se había posicionado el partido socialista de Sánchez.

Teniendo en cuenta los puntos anteriores podemos ver cómo, a grandes rasgos, en la configuración de la identidad política española de la democracia interseccionan dos cuestiones. Por un lado, la unidad territorial del estado y, por el otro, la cuestión del silenciamiento de las víctimas de la Guerra Civil y de la dictadura (ya sean estas formuladas desde parámetros de reconocimiento o de negación). Vemos además como, durante la época Zapatero, se introduce de manera transversal la cuestión del género y que esta invitará, cuanto menos, a repensar los ejes anteriores. Además, se establecerán durante estos años las recomendaciones desde las que los medios de titularidad pública, en su función de servicio a la ciudadanía, deben aproximarse a estos temas. En este escenario es en el que se insertan los productos culturales que analizaremos en el siguiente capítulo.

46 Ver: https://www.eldiario.es/catalunya/politica/Batet-ministra_0 7777623073.html [último acceso: $14 / 04 / 2018]$ 


\section{Análisis}

El análisis que emprendemos con este capítulo ya se inició de modo exploratorio en el Trabajo Final del Máster en Estudios Internacionales de Paz, Conflictos y Desarrollo, en el cual se realizó una lectura del capítulo especial Isabel: la reina, un compendio de las escenas más relevantes de las tres temporadas de la serie Isabel, desde el paradigma de la comunicación para la paz. Esta se llevó a cabo teniendo en cuenta los conocimientos adquiridos en el campo de los Estudios de Paz. Más concretamente, nuestra aproximación se realizó desde el marco de la Comunicación para el Cambio Social con perspectiva de género, el cual se corresponde con la línea de investigación del programa de doctorado que se escogió finalmente para desarrollar la presente tesis doctoral.

En ese momento ya empezamos a intuir cómo la mirada televisiva se interesa por la memoria, desde un punto de vista centralista del Estado, mientras que también se imbrica en estas narrativas la perspectiva de género institucionalizada. Como ya apuntábamos en nuestro apartado de metodología, la perspectiva de género presente en el análisis también viene sugerida por la propia temática de las series y el hecho de que todas estén protagonizadas por mujeres. Nuestra lectura, además, sigue partiendo de una concepción del producto televisivo-serie como un elemento que forma parte del contínuum discursivo que es la cultura. También hemos indicado anteriormente que nos interesan las series de televisión en tanto que, como producto de la cultura popular, reproducen a nivel discursivo los debates públicos, las tensiones políticas y sociales de un contexto o momento histórico concreto. De la misma manera, contribuyen a resituar los ejes desde los que se conciben las problemáticas sociales que sintomatizan.

Esta concepción culturalista de los productos mediáticos es de la que 
también partimos en el presente trabajo. La diferencia esta vez radica en el recorrido cronológico del análisis. Esto es, si en su momento se consideró la serie Isabel como representativa del cambio de tendencia en las políticas de reconocimiento de género, las otras tres series escogidas nos ayudarán a dibujar un escenario discursivo más amplio respecto al feminismo, su mainstreamización durante la época del gobierno Zapatero y el posterior backlash conservador que colea todavía hoy, tras un período de mayoría absoluta del PP y la costosa mayoría simple tras la repetición de las últimas elecciones generales.

Antes de empezar con el desarrollo del análisis, debemos explicar cuál va a ser la estructura según la cual organizaremos los contenidos de este apartado. El groso lo dividiremos en tres partes principales. El primero, será introductorio y en él observaremos las características generales que asemejan a las protagonistas de las series que analizaremos. Es decir, en lo que nos interesaremos primero será en la idea de feminidad o el prototipo de mujer con el que la narración nos invita a empatizar. En segundo lugar, indagaremos en el paradigma de empoderamiento de la mujer y las categorías respecto a las cuales se representa en las series La Señora, 14 de abril. La República e Isabel. En este caso, veremos las especificidades de cada serie, su vínculo con el discurso del feminismo institucional, así como las contradicciones subyacentes al texto que invitan a abrir una lectura respecto al debate sobre los planteamientos del feminismo de izquierdas y su desarrollo en un contexto de democracia neoliberal. Así pues, indagaremos en aspectos como la representación de la violencia y la victimización, la sororidad y los afectos o las paradojas que plantea el modelo de empoderamiento institucional respecto a la socialización femenina y la situación contextual de las mujeres. 
En este sentido cabe apuntar que las tres primeras series en las que nos fijaremos, agotan en la pequeña pantalla el período de gobierno del socialismo. La serie Isabel, de hecho, da un salto ideológico importante en su segunda temporada a la hora de respresentar los debates respecto a la mainstreamización del feminismo, la promoción de la igualdad de género y su no correspondencia con la realidad vivida por parte de las mujeres. Este período, que coincide institucionalmente con la época Rajoy, se caracteriza por el reaccionismo misógino de la opinión pública, los retrocesos en las políticas de igualdad y los recortes en los recursos contra la violencia de género. Sin embargo, sería un error no destacar la reactivación y la reorganización del movimiento feminista, tanto dentro de la militancia de partidos de izquierda como fuera. Esta reactivación supondrá de unos años a acá la complejización de los debates feministas, que se sitúan en tendencias de la tercera ola, la postfeminista, evidenciando un claro descompás entre el discurso que toma protagonismo en las calles y el reproducido institucionalmente.

Con esto en mente leeremos a los personajes femeninos de El Ministerio del Tiempo, una serie que parece partir de la asimilación de los discursos públicos sobre la igualdad de género que plantea conflictos más complejos para el debate que resultan al interseccionar las cuestiones de género y memoria. Esto es, se superaría el carácter pedagógico que se aprecia en las series anteriores (que implicaría la deconstrucción discursiva de la racionalidad patriarcal a través de los problemas planteados a las protagonistas a nivel personal y relacional) para plantear un nivel de debate en el que ya no solo se trata de recuperar e incluir la voz y las experiencias de las mujeres en las instituciones como objetivo último, sino de preguntarse por las consecuencias políticas de tal misión. 
Las últimas páginas de este capítulo estarán dedicadas a la discusión de los resultados del análisis. En ella contrastaremos precisamente el tratamiento que hacen las distintas series de las cuestiones de la agenda feminista y las implicaciones de la ambientación historicista de las mismas.

Así pues, a continuación, pasaremos a introducir las series y los personajes que centran nuestra atención a la hora de realizar el análisis discursivo. Como venimos diciendo, nos interesan especialmente las protagonistas de los relatos. No obstante, la construcción de las subjetividades y el devenir de tales mujeres no sería tal sin el acompañamiento de una retahíla de personajes femeninos en los que también repararemos en el análisis. De entrada podríamos decir que, exceptuando el caso de Isabel, y debido al carácter mitológico que la narración no deja de otorgar a la figura de la reina católica (revisaremos más adelante el por qué), nuestras protagonistas se acercan poco o nada al prototipo de heroína súper capaz (esa superwoman que puede con todo y todo lo puede sola). Más bien, los relatos optan por presentarnos a mujeres que si pueden es porque resisten unidas, porque se apoyan, porque se saben vulnerables y se protegen.

Teniendo esto en mente, realizaremos el recorrido por las series escogidas en orden cronológico y analizaremos a sus personajes femeninos principales y a estos otros que consideramos relevantes por su aportación al recorrido vital de las protagonistas. Para abordar el estudio de su caracterización, además, nos serviremos de intertextos o referencias externas que suman carga significante a los personajes. Con esto nos referimos, por ejemplo, a la aparición de la actriz en otros productos de la cultura o a la relación figurativa con mujeres de la esfera pública que alimentan el imaginario popular y que condicionarían la relación de las audiencias con el personaje, así como la lectura de sus acciones. 


\subsection{Reconstruyendo el modelo de feminidad del feminismo institucional socialista}

Empezamos nuestra tarea ocupándonos de dos series que sitúan el tiempo de la diégesis entre las décadas de los años veinte y treinta del siglo XX respectivamente y que comparten creadora, Virginia Yagüe, actual vicepresidenta de CIMA (Asociación de Mujeres Cineastas y de Medios Audiovisuales ${ }^{49}$ ). La primera de ellas, La Señora, fue un encargo de la productora Diagonal, que quería una historia protagonizada por una mujer en los años veinte, tal y como señala Cascajosa en su artículo dedicado a la cineasta (2017: 392).

De entrada, en LS nos encontramos ante la complicada historia de amor que comparten la protagonista, Victoria (una joven burguesa interpretada por Adriana Ugarte), y Ángel (Rodolfo Sancho), el hijo de una familia proletaria al que obligan a ordenarse sacerdote para salvar a su madre y hermano de la miseria, impidiendo así el deseo de los jóvenes de formalizar su amor. Sin embargo, en el trabajo de Cascajosa (2017) encontramos interesantes aportaciones que vendrían a complejizar la lectura de la narración de la vida de Victoria y a confirmar algunas de las sospechas que vertíamos en forma de hipótesis sobre los relatos televisivos en los que nos estamos fijando.

Entre otros aspectos, Cascajosa destaca como LS sigue la estela de su serie

\footnotetext{
${ }^{49}$ CIMA nace en 2006, con el objetivo de «fomentar una presencia igualitaria de las cineastas y profesionales» del sector audiovisual «contribuyendo a una representación equilibrada y realista de la mujer dentro de los contenidos», tal y como se explicita en su página web: https://cimamujerescineastas.es/que-es-cima/ [última consulta 14/04/2018] Como podemos apreciar, esta definición de su misión como asociación profesional responde a la asimilación de la crítica fílmica feminista acerca de la estereotipación de personajes femeninos creados a partir del imaginario masculino dominante y la necesidad de romper y transgredir la carga simbólica tradicional.
} 
predecesora de sobremesa, Amar en Tiempos Revueltos ${ }^{50}$, en tanto que ambas usan como trasfondo una historia amorosa entre jóvenes de diferente clase social sobre la que adscriben las luchas personales de cierto prototipo de mujer que experienciará y se enfrentará a los conflictos políticos del espacio y tiempo histórico recreado en la diégesis. Para el caso, Cascajosa dirá (2017: 394):

[...] un acercamiento a La Señora no estaría completo sin incidir en un aspecto sobresaliente: su carácter como serie que se presentaba a los espectadores como un melodrama, pero que con el paso de los capítulos se fue convirtiendo cada más en una serie política, una vez que la vinculación emocional de los espectadores con los protagonistas estaba asentada y existía un mayor margen de maniobra.

Así pues, LS no será concebida como un melodrama al uso en el que se narrarán las venturas y desventuras amorosas de Victoria (que también), sino que los episodios la vida de la protagonista son concebidos para ser leídos desde un prisma político que tiene en cuenta el contexto histórico en el que se ambienta el relato. Yagüe, citada en Cascajosa (2017: 393), incide en este sentido en que le interesaba especialmente «contar el arco de crecimiento y de madurez de una mujer» porque considera «que es el relato referencial que más pobremente se ha abordado y sobre el que hay mucho que contar. Cómo las mujeres nos constituimos como individuos y nos reivindicamos desde una zona plena». En este arco de crecimiento se ve implicada, entre otros personajes en los que nos detendremos más adelante, una de las protagonistas de la secuela de la serie, 14 de abril. La República, Encarna Alcántara

\footnotetext{
${ }^{50}$ La primera temporada de la telenovela Amar en Tiempos Revueltos (La 1 de TVE: 2005-2006), presenta muchas similitudes argumentales, además, con la serie Temps de Silenci (TV3: 2001-2002) con la que comparte productora (también, Diagonal) y personal creativo (entre los que encontramos a Rodolf Sirera). La serie catalana se emitió justo un año antes del inicio de la gobierno tripartito de Catalunya que fue liderado por Pasqual Maragall (PSC) entre los años 2003 y 2006.
} 
(Lucía Jiménez ${ }^{51}$ ), junto a la que trabajará para sacar adelante a su familia y el legado empresarial que hereda de su padre.

El personaje de Encarna servirá para hilar los argumentos de LS y 14ALR. Esta segunda serie, sin embargo, presentará un discurso político más explícito y muy vinculado al feminismo institucional de la era del feminismo socialista que nos ocupa. Si volvemos al texto de Cascajosa (2017: 396), en él se hace una referencia a una curiosa expresión de un portavoz del Partido Popular acerca de este tipo de relatos audiovisuales que caracterizó la época previa a su entrada en el gobierno, que decía: «Los diálogos encajarían como un guante en un mitin de Zapatero». No en vano, una de las cuestiones más relevantes en 14ALR es la referencia a la militancia feminista socialista que luchó por el sufragio femenino tras la implantación de la II República española. De hecho, la propia Virginia Yagüe, confirmará que las figuras de Clara Campoamor y la Pasionaria servirán de inspiración para embastar la caracterización de Encarna (Cascajosa, 2017: 395).

De nuevo, en 14ALR, los intríngulis amorosos servirán de excusa para mostrar en pantalla los conflictos histórico-políticos del tiempo representado. Si en el caso de LS, estos tenían que ver con el auge de la burguesía industrial y la lucha de

51 Lucía Jiménez forma parte de la cantera de actores y actrices que dieron el salto a la fama gracias a la telenovela juvenil Al Salir de Clase (Telecinco, 1997-2002). Transcurridos 20 años desde su estreno, sus caracteres forman parte ya del imaginario no solo televisivo, sino también del cinematográfico español e internacional. Este sería el caso de la actriz Elsa Pataky. Otra de las actrices revelación de esa cantera fue Pilar López de Ayala, recordada por su papel protagonista en Juana la loca (Vicente Aranda, 2001), que le valió el Goya a mejor actriz en el 2002. Entre el helenco de aquel programa de sobremesa encontramos también al propio Rodolfo Sancho (Ángel en La Señora) cuyas apariciones en papeles protagonistas en las series y telenovelas de ficción históricas de RTVE han sido constantes en los últimos años. Ya en $\mathrm{Al}$ Salir de Clase, su aparición junto a la de Carmen Morales, sugerían una simbólica renovación o modernización continuista del imaginario tardofranquista al que pertenecieron el padre del primero (Sancho Gracia, recordado especialmente por su papel de Curro Jiménez) y de la madre de la segunda (la actriz y cantante Rocío https://verne.elpais.com/verne/2017/08/21/articulo/1503303905 876921.html_[última consulta 14/04/2018] 
clases, en el de 14ALR se reproducirán las tensiones surgidas a raíz de la implantación de la II República española y tendrán que ver, como decíamos, con la consecución de una democracia inclusiva desde una perspectiva no solo de clase, sino también de género y que, además, vendrá fuertemente marcada por los intereses políticos internacionales.

Madrid se elige como espacio de la diégesis y la ciudad se representa como el centro administrativo donde se materializarán institucionalmente los cambios del nuevo régimen republicano. Además, este nuevo entorno urbano en el que se desarrolla la acción se presenta como un espacio apto para la exploración y la autorrealización, también para las mujeres. A diferencia de Victoria, a la que sitúan en un pequeño núcleo rural que ahoga sus deseos, Encarna encuentra en la gran ciudad la oportunidad de crecer y ampliar sus perspectivas en lo personal, en lo afectivo y en lo político.

En resumen, en las dos series nos encontramos con personajes femeninos que representan una feminidad posible en los años previos a la Guerra Civil y que encarnan conflictos incardinados en su condición de mujer. Estos conflictos, además, trascienden el tiempo histórico en el que se desarrolla el relato y se vinculan al debate político de su emisión y lo hacen en dos direcciones, como ahora veremos. Por una parte, recreando los debates en torno a la igualdad y a la violencia de género y, por otra, aludiendo a la memoria del feminismo socialista como promotor (en el pasado) y garante (actual) de los derechos de las mujeres. 


\subsubsection{Las mujeres de la memoria democrática: Victoria Márquez ( La Señora) y Encarna Alcántara (14 de abril. La República)}

\subsubsection{Victoria, de señorita rebelde a empresaria minera}

Victoria Márquez, protagonista La Señora, fue pues la primera chica a la que la audiencia de La 1 de TVE acompañó en su proceso de crecimiento y empoderamiento, personal y colectivo. A Victoria la conocemos siendo una adolescente, o como dice su presentación en la página web oficial de la serie ${ }^{52}$, «una señorita» $\mathrm{y}$ «de provincias», (en el dosier de la serie ${ }^{53}$ se habla textualmente de «un lugar imaginario del norte», pero ya en el capítulo piloto nos sitúan en el año «1920 en una ciudad de Asturias...»). Victoria pertenece a una familia burguesa acomodada y queda «huérfana de madre desde muy niña». También, sigue su presentación oficial, «ha desarrollado una personalidad independiente y decidida que la convierte en una mujer adelantada a su tiempo ${ }^{54} \gg$. Seguramente porque, al quedar tanto ella como su hermano mayor, Pablo, bajo el único amparo de su padre, el empresario minero Ricardo Márquez (Alberto Jiménez), el orden del género se impusiera de manera un tanto difusa a pesar, valga decir, de la incansable tarea de la ama de llaves de la casa Márquez, Vicenta (Ana Wagener), de la que también hablaremos en las próximas páginas.

\footnotetext{
${ }^{52}$ Descripción del personaje accesible aquí: http://www.rtve.es/television/20090113/victoria-marquezinterpretada-adriana-ugarte/219514.shtml [última consulta 14/04/2018]

53 Ir a la página cuatro del dosier: http://www.rtve.es/archivos/70-9021FICHERO/LaSenora08DosierPDF.pdf [última consulta 14/04/2018]

${ }^{54}$ Esta fórmula, la de "mujer adelantada a su tiempo", también se utilizará en la promoción de la serie Isabel, como veremos más adelante.
} 


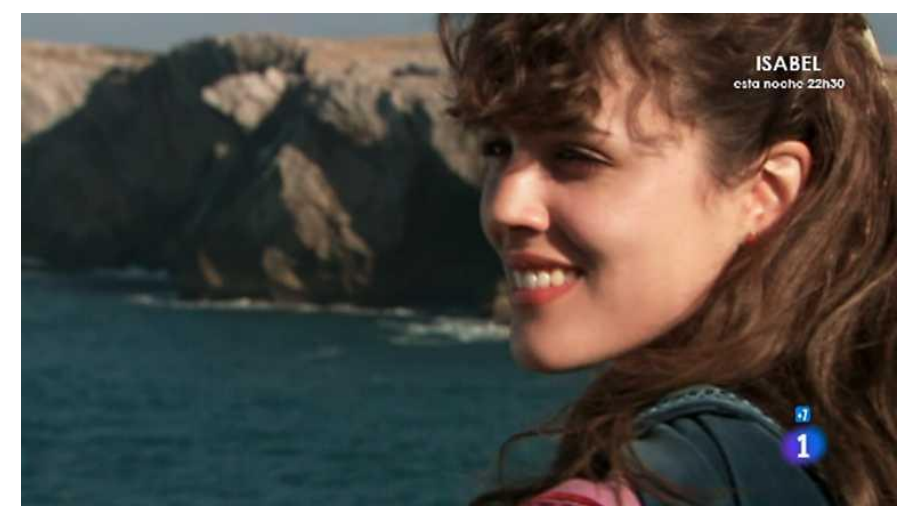

Imagen 5: Fotograma promocional de La Señora (temporada 1). Victoria Márquzez adolescente en el acantilado donde conoce a Ángel y donde vuelve siempre a meditar cuando se le presentan dificultades vitales. Fuente: http://www.rtve.es/alacarta/videos/la-senora/senoracapitulo-37/661017/ [última consulta 14/04/2018]

Ya en el capítulo piloto (1X01) conocemos el carácter espontáneo y atrevido de Victoria, el cual combina con la ternura que inspira su aspecto angelical. En el fotograma anterior, apreciamos su pelo largo ondulado, su sonrisa inocente y su mirada confiada. La capa que viste se confunde con el tono del mar, dando cuenta de la consonancia entre su naturalidad y la del paisaje. La imagen pertenece a la secuencia en la que la protagonista y su hermano Pablo (Alberto Ferreiro) se escapan de casa, huyendo de la lección de su institutriz inglesa, para, aprovechando la brisa de los acantilados, ir a volar la cometa que les regaló su padre. Así pues, ya desde el primer momento, la audiencia es sabedora de la dificultad de la joven para adaptarse a las normas. Ella lo corroborará tras disculparse con su padre por lo ocurrido e insistirle en que «no puedo estar en estas cuatro paredes porque me ahogo».

Es precisamente desde ese halo de inocencia despreocupada, de su actitud desenfadada, incluso juguetona, desde el cual vemos a la Victoria adolescente enfrentarse al mundo y a su primer amor, Ángel. Resulta curioso, de hecho, el contraste 
que se da entre la mirada de este personaje masculino hacia la joven burguesa y la visión de la madre del mismo. Nos situamos de nuevo en el capítulo piloto, tras haberse producido el primer encuentro entre los enamorados. Ángel conoce a Victoria porque esta arriesga su vida en unos acantilados por salvar el juguete que su padre les había regalado a ella y a su hermano. Este motivo le vale a Ángel para calificar de valiente a la protagonista cuando de vuelta a casa le cuenta la anécdota a su progenitora. Sin embargo, esta (Amalia -Pepa López-, un personaje caracterizado cual mujer humilde y piadosa) le corrige: «esa niña anda por ahí como si fuera una salvaje. Por mucha criada que tenga, se nota que no tiene madre». De este comentario se desprenden dos cuestiones: una, que la construcción de género es transversal y se reproduce, por tanto, en cualquier clase social; y la otra, que Victoria no cumple con las expectativas de una mujer de su estatus debido a falta de una figura femenina que le sirviera de referencia de lo que debería «llegar a ser», utilizando la expresión de Beauvoir (1949).

Será precisamente ese carácter poco adecuado (y el consiguiente apego a Ángel, pertenenciente a una clase social inferior) el que se intentará corregir enviándola a un internado inglés, donde recibirá la formación adecuada para una mujercita de su clase, a pesar de su resistencia inicial. Sin embargo, esta decisión familiar (tomada y ejecutada por el padre) no resulta satisfactoria para la figura de autoridad moral de la casa y promotora del internamiento (encarnada en personaje de Vicenta, el ama de llaves de la casa Márquez) ya que, lejos de corregir la actitud de Victoria, su traslado al extranjero solo conlleva la corroboración de su personalidad decidida y de su amor a Ángel, como señal de desobediencia. Así, la protagonista parece acercarse al prototipo de «chica rara» que, según señala Gámez Fuentes (2004: 92), se aparta del modelo de mujer huérfana (de madre, para nuestro caso) débil y desprotegida para reproducir un 
tipo de feminidad «inconformis[ta] contra las normas de convivencia que le son impuestas».

De hecho, como vemos en la web de la serie, la presentación del personaje de Victoria continúa exponiendo que «las circunstancias y su fuerte carácter la llevarán a ponerse al frente de los negocios familiares, algo poco habitual en la época». Resulta cierto que su manera de ser, por la que su padre sentía predilección, hizo que este dejara constancia en su testamento de la necesidad de que Victoria refrendara las decisiones de su hermano al frente de la mina que heredarían tras su muerte. De alguna manera, esta decisión del padre, que rompería con los esquemas patriarcales de transmisión del patrimonio, viene a decirnos que la joven está capacitada para llevar a cabo una tarea de tal importancia que, a pesar de que la norma social conmine a asignarla a su hijo varón, también podría ser llevada a cabo por una mujer de su talante. Ese temperamento que la define, más que servirle para llevar a cabo las cuestiones de mera gestión, le será útil para poder tratar con otros hombres de negocios y con los obreros del sindicato de la mina, que continuamente la menospreciarán por ser mujer.

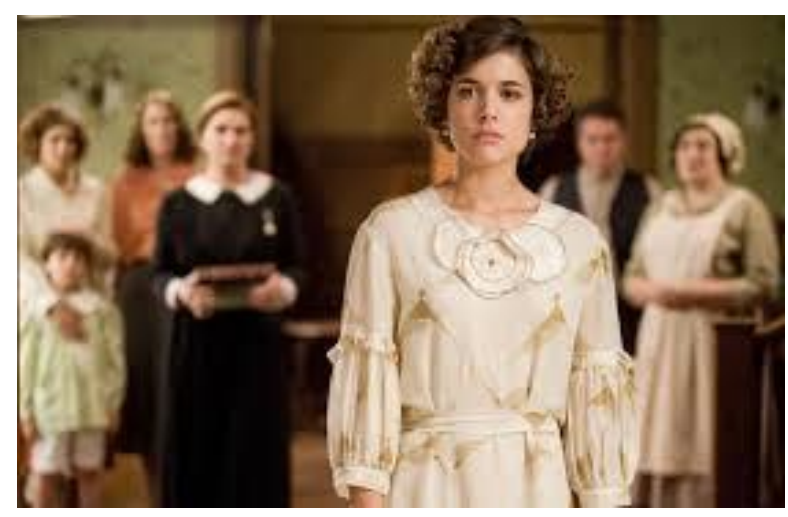

Imagen 6: Victoria Márquez adulta con el servicio de la casa Márquez, su cuñada Encarna y su sobrino, en segundo plano en fotograma promocional de La Señora (temporada 3). Fuente: http://www.rtve.es/alacarta/videos/lasenora/senora-capitulo-37/661017/[última consulta 14/04/2018] 
Su fortaleza y su capacidad para tomar decisiones firmes y arriesgadas no la salvarán, sin embargo, del dolor ni de la desaprobación de otras mujeres a su alrededor, entre ellas, la ya nombrada, Vicenta, la responsable de servicio de la casa Márquez. De ella, se dice ${ }^{55}$ que «si la casa funciona es gracias a la disciplina, en ocasiones férrea, que esta pulcra mujer impone con firmeza desde hace años. Para ella, Victoria y Pablo son como sus hijos y, en ocasiones, es excesivamente protectora con ellos». Podemos ver en estas líneas cómo Vicenta habita, casi de manera necesaria, la figura de ama de casa y madre ante la ausencia de la progenitora, a la que nunca llegamos a conocer. Desde esa posición de autoridad se asegurará de mantener el orden de género y clase, sin perder la «vinculación emotiva» (Chicharro, 2009: 63) con sus «señoritos».

En la imagen que sigue, puede apreciarse la muestra de apoyo cariñoso que comparten Victoria y Vicenta, quien sostiene las manos a la primera, tras la accidentada muerte del padre, Ricardo Márquez. Este gesto nos permite apreciar que es, precisamente, Vicenta la proveedora de cuidados en esta relación desigual pero interdependiente entre señora y sirvienta, entre las que existe una especie de familiaridad que aprovisiona de amparo y consejo a la joven burguesa. Destaca en este sentido la escena de ese mismo capítulo $(2 \times 01)$ en la que la jefa de servicio amenaza a su señora con dejar la casa, tras haber dejado entrar por la puerta principal a su pobre (en sentido literal) pretendiente mientras la joven está de luto.

55 Descripción del personaje de Vicenta en la web oficial de la serie: http://www.rtve.es/television/20090130/vicenta-ana-wagener/226926.shtml [última consulta 14/04/2018] 


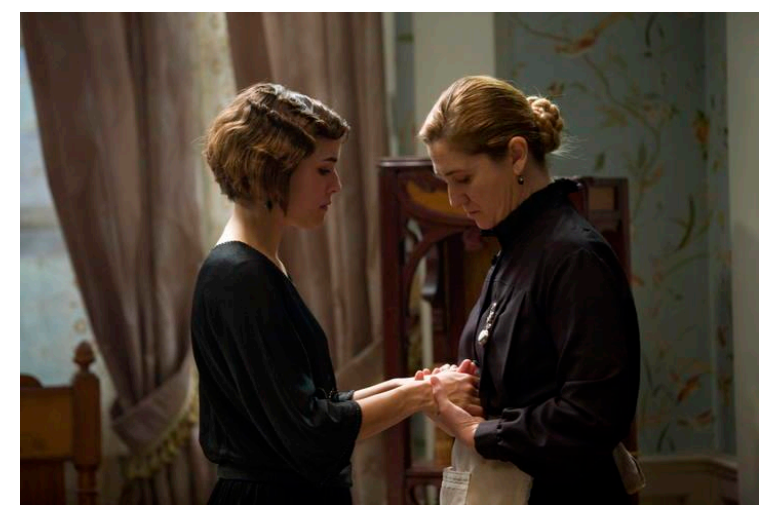

Imagen 7: Vicenta (derecha) sostiene las manos de Victoria el día del entierro del padre de la joven (temporada 1). Fuente: http://www.rtve.es/fotogalerias/senora-capitulos2-3-imagenes/30112/seorala1 t03c0308m05/51 [última consulta 14/04/2018]

Al respecto de este interesante personaje, pueden comentarse algunos aspectos que complementarían el análisis de Chicharro (2009) sobre la representación de las relaciones de clase en LS. Según la autora «la docilidad y la dominación se tiñen de afectividad, con lo cual se establecen conexiones de empatía y complicidad entre débiles y poderosos, ello representa entonces las posibilidades de una entente cordiale entre grupos disímiles» (Chicharro, 2009: 60). Podríamos decir que la lectura de Chicharro situaría la relación entre Victoria y, en este caso, Vicenta, en un espacio de tolerancia de la otredad que se presentaría en cierto modo edulcorado por necesidades del guión. Sin embargo, nosotras preferimos aproximarnos desde la perspectiva de la «paz imperfecta» de Muñoz (2001). Así entenderíamos que el conflicto de clase entre una y otra mujer se representa como una relación de interdependiente que transforma por ella misma el conflicto por medios pacíficos y que se traduciría en negociaciones y afectos de tipo altruista, entre otros (Comins, Paris y Martínez Guzmán, 2011: 98). 


\subsubsection{Encarna, la activista socialista sufragista}

Así como Vicenta ocupará, respecto de Victoria, la posición de la madre ausente, el personaje de Encarna irá desarrollando una relación fraternal con la protagonista de LS a medida que avanza la serie, especialmente tras el deceso del hermano de la protagonista. La figura de Encarna aparece inicialmente en LS vinculada a una «familia muy humilde», aunque la propia serie $^{56}$ ya nos la presenta como «una mujer de acción». Sus orígenes y su carácter activo e implicado le llevan a simpatizar con las ideologías de izquierdas y a participar de la lucha obrera con los mineros del pueblo. No obstante, la lucha de Encarna adquiere un evidente tinte feminista desde el momento en que muestra especial preocupación por la educación de las mujeres obreras, así como por su salud.

De hecho, Encarna fundará una escuela de mujeres en la que enseñará a leer y a contar a compañeras de la fábrica tras la jornada laboral y a la que también invitará a las trabajadoras del burdel del pueblo (1x05). A causa de las desavenencias con su patrón, motivadas por el desagrado de este hacia la iniciativa de la activista, el aula acabará cerrándose. Más tarde, Encarna acabará trabajando en un ambulatorio habilitado por el legítimo heredero de la mina, Pablo Márquez, con el que además tendrá un hijo ${ }^{57}$. Este lazo familiar será el que llevará a Encarna, tras la muerte de Pablo, a gestionar codo con codo con Victoria la explotación minera que, finalmente, decidirán

\footnotetext{
56 Descripción del personaje de Encarna en la web oficial de la serie: $\underline{\text { http://www.rtve.es/television/20090202/encarna-lucia-jimenez/227647.shtml [última consulta }}$ 14/04/2018]

57 Tras enterarse de que Encarna espera un hijo, fruto de un encuentro esporádico en el dispensario médico en el que ella trabaja (y que el propio Pablo monta y subvenciona para "liberarla" de sus labores como sirvienta), el señorito decide declararle su amor y pedirle matrimonio. No obstante, y en consonancia con los devenires que caracterizan al género del melodrama, él muere accidentalmente el mismo día de la boda. Esto no evitará, sin embargo, que Encarna se instale en la casa Márquez.
} 
colectivizar tras las negociaciones con los representantes sindicales de la misma.

Ese doble activismo de Encarna, marcado por su ideología feminista de izquierdas y por su apoyo a la II República (que ya se muestra en los últimos capítulos de LS), se toma como línea de continuidad para el argumento de 14ALR. En este caso, el personaje adquiere relevancia en la capital del estado como militante del Partido Socialista Obrero Español (PSOE) y en el desarrollo del proyecto progresista republicano. En concreto, Encarna dedicará sus esfuerzos a recabar apoyos al sufragio femenino entre los camaradas socialistas para su posterior aprobación en el Congreso de los Diputados (cámara legislativa). Además, sus servicios son también requeridos por el Ministerio de Agricultura para la gestión burocrática de la Reforma Agraria, en beneficio de los campesinos.

La evolución del carácter de Encarna resulta bastante notorio a lo largo de los episodios de LS y se consolida con su acción en el argumento de 14ALR. En LS, empieza siendo una joven inocente e impulsiva al estilo de Victoria Márquez, pero con un sentido de la justicia que ya se desarrolla de manera muy consciente desde su juventud y que viene motivado y condicionado por su origen proletario y el contacto con la miseria. Esta diferencia de caracteres también se aprecia en el aspecto visual de cada una. Si nos fijamos, el personaje de Encarna, tiene un físico algo más rudo que el de la señorita Márquez, aunque podríamos decir que ambas comparten un aire andrógino que se acentúa con la caracterización de época (pelos cortos, vestidos de corte recto, etc.) Como vemos en la fotografía, las facciones de Encarna son más marcadas, más angulosas, su espalda es más cuadrada, todo su cuerpo parece más fuerte y robusto que el de Victoria, que tiene un aspecto más delicado, es más delgada y su faz se ve más redondeada y rosada que la de su cuñada. 


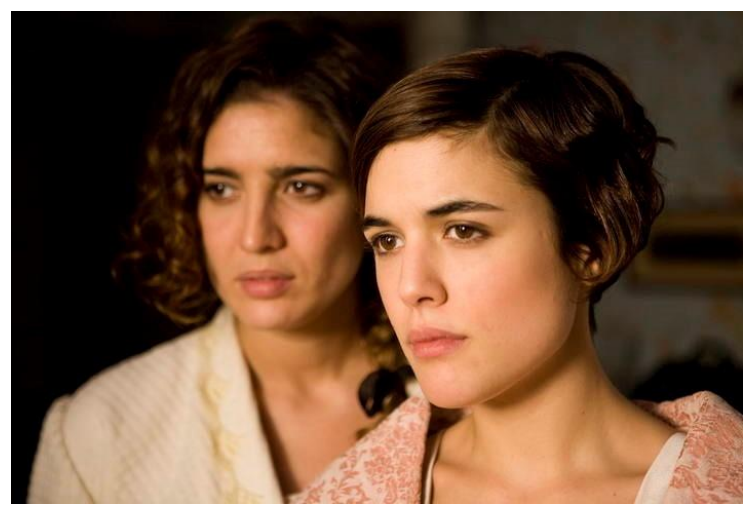

Imagen 8: Victoria (derecha), en casa Márquez, espera junto a Encarna (izquierda) noticias sobre la viabilidad económica de la mina (capítulo 25, temporada 2). Fuente: http://www.rtve.es/fotogalerias/senora-capitulo25-imagenes/37672/seorala2t25c0309m39/39 [última consulta 14/04/2018]

Podría incluso decirse que el tipo de cuerpo de Encarna se parece más al de Vicenta, aspecto que vincularía la forma al fondo. El significante nos connota la pertenencia de ambas a la clase trabajadora, la que solo «vale» por su «fuerza» de trabajo. La fuerza de trabajo de ambas se invierte particularmente en las tareas de cuidados, aunque cada una los procure en una dirección opuesta, dejando patente de nuevo sus intereses. Mientras Vicenta dedicará su vida a asegurar el bienestar de una familia de la nueva burguesía y a perpetuar su poder, Encarna se empleará a fondo en mitigar los efectos de las desigualdades y asegurar el derecho al acceso a servicios de primera necesidad (educación y sanidad).

Precisamente el hecho de que ambas pertenezcan a la misma clase social y la actitud de auto odio ${ }^{58}$ que se esconde bajo la rigidez de los protocolos sociales que

\footnotetext{
${ }^{58}$ El término «auto odio» lo tomamos de la sociolingïstica de la lengua catalana y viene a nombrar la actitud negativa de los habitantes de un territorio a su lengua madre. Esta se produce como efecto de la asimilación cultural, tras un fenómeno de colonización o dominio por parte de un grupo social con un idioma diferente y que tendría como consecuencia el uso de la lengua invasora, por parte del pueblo,
} 
Vicenta perpetúa (al más puro estilo de madre fálica) provocan el rechazo inicial de esta hacia Encarna como esposa del señorito (2x04). Resulta significativo, de hecho, el contraste entre la actitud de Vicenta en el capítulo piloto de LS y la que tendrá una vez la joven obrera se convierta en prometida de Pablo. Cabe decir que, en ese primer capítulo, Encarna pasa una prueba supervisada por Vicenta para trabajar sirviendo en la casa Márquez durante la fiesta de bienvenida de Victoria, tras su estancia en el internado. El ama de llaves dice textualmente a Encarna que parece «más espabilada que las otras» y la premia sirviendo en el salón principal. Con este gesto, el ama de llaves parece reconocerse en la aspirante; por el contrario, a Vicenta le costará reconocer a Encarna en su nueva situación de consorte. Sin embargo, con el transcurso del tiempo diegético y el salto al spin off 14ALR, la audiencia será testigo del acercamiento entre ambas mujeres, que comparten la crianza de Pedro, el hijo de la joven activista y Pablo. Así, los reproches irán dejando espacio a los cuidados que Vicenta nunca deja de procurar al pequeño (y, por extensión, a Encarna), del que también se encargará cuando encierren a su madre en la cárcel por su vinculación con la causa republicana (LS, capítulo 3x05) o cuando su partido la destine a Madrid (14ALR, capítulo 1x01), en un ejercicio de sororidad entre mujeres al que nos referiremos más adelante.

Justamente, su traslado a la capital, en 14ALR, ofrece al personaje de Encarna una nueva dimensión que explorar en el terreno de los afectos como nuevo espacio para la subversión política. Esta posibilidad se la ofrece el personaje de Amparo (Marta Belaustegui), quien, desde la primera vez que escucha hablar a Encarna (1x01), se siente atraída por la vehemencia de sus palabras. A Amparo la conocemos como

como signo de progreso y buena situación social (ver Ninyoles, 2017). En nuestro caso, la hemos querido utilizar para definir la actitud de negación de la propia clase social mediante el halago y la perpetuación de los usos y costumbres (violencia simbólica) de la clase social dominante. 
regente de un local de estilo cabaretesco, que resulta ser una tapadera para su actividad como agente de la revolución rusa. Allí la veremos cantar, servir copas o traficar con armas para la causa soviética o con drogas opiáceas que calman el dolor y sueltan la lengua a militares que planifican golpes contra el Estado republicano.

Así, si el personaje de Vicenta actúa como contraste respecto a personajes como el de Victoria y, especialmente, como el de Encarna en el plano de lo moderno, lo nuevo y lo transgresor, la aparición de Amparo provoca el efecto contrario. Al lado de ella, Encarna vuelve a verse como esa joven ingenua que se deja preñar por el señorito, al que, en principio, tampoco iba a reclamarle sus obligaciones como padre. Con todo, haciendo gala de su valentía y de su espíritu transformador, Encarna se sube al tren de Amparo, con quien explora la posibilidad de conocerse personal, erótica y políticamente desde otros prismas, y quien le manifiesta su amor acompañándola en sus momentos bajos y protegiéndola ante maniobras políticas.

El personaje de Amparo, que en cualquier otro relato sesgado por la mirada patriarcal hubiese funcionado según el prototipo de mujer fatal, contribuye en este caso a dar profundidad al de Encarna, en tanto que la primera se presenta como un desafío constante a lo personal y lo político de la segunda. Este factor contribuye a complejizar la psicología de Encarna y, con ello, la mirada con perspectiva de género a la Historia, en la línea de lo que plantea Scott (1990). Es decir, la evolución de la relación entre ambas que va desde la camaradería hacia los cuidados y que acabará implicando el terreno amoroso y de la sexualidad, desprende unas lecturas políticas muy enriquecedoras a la hora de repensar el relato histórico respecto al sujeto político de la lucha y las estrategias de empoderamiento feminista. 


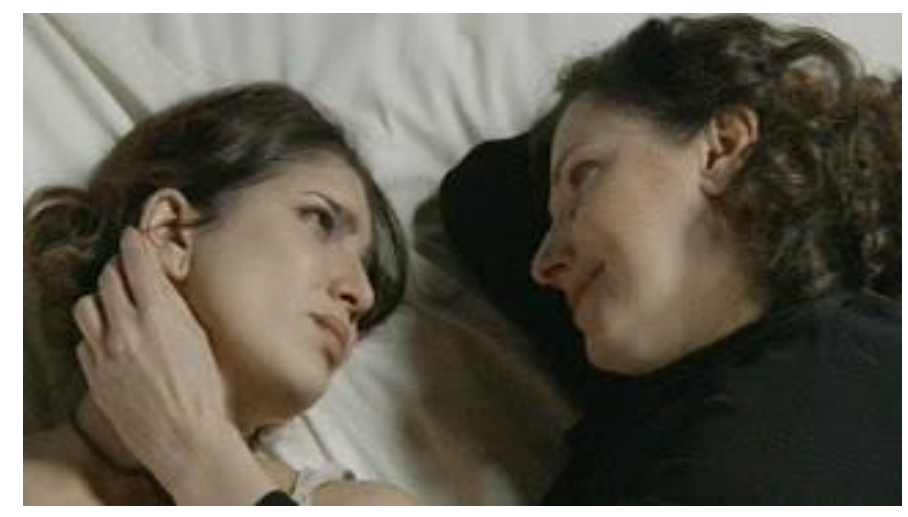

Imagen 9: Amparo (derecha) acaricia a Encarna (izquierda) en 14ALR (capítulo 11 de la temporada 1). Fuente: http://www.rtve.es/alacarta/videos/14-de-abril-larepublica/14-abril-republica-amparo-encarna-mascerca/1061695/ [última consulta 14/04/2018]

Así, la irrupción de la homosexualidad femenina en el relato de Encarna funcionará como metáfora de su tendencia militante que la situaría en el terreno del «lesbianismo político» (Amorós, 2000: 20). Narrativamente, puede verse que aquí existe una «elección consciente [...] como efecto de una consigna ideológica feminista en el sentido de que la práctica de la heterosexualidad sería una forma no deseable de alianza con el enemigo, no la simple orientación del deseo sexual hacia otras mujeres» que nos sitúa en el culmen ideológico de la militante socialista mientras que el tiempo extradiegético con el que dialoga el relato coincide con el culmen de la institucionalización del feminismo en el estado español. 


\subsubsection{El giro conservador y la complejización del discurso feminista en la cultura popular}

Ya en nuestro marco histórico apuntábamos a cómo la experiencia vivida por la Comisión de Feminismos Sol en la acampada del 15M de 2011 había marcado un punto de inflexión en el debate público feminista, especialmente en lo que respecta a las resistencias patriarcales dentro de los movimientos y partidos progresistas, a priori, compatibles con las demandas de igualdad (Gámez Fuentes, 2015; Gámez Fuentes y Rivas Machota, 2012). También, como decíamos, estos acontecimientos coinciden con los últimos coletazos de la era Zapatero, quien convocaría elecciones anticipadas pocos meses después de las acampadas debido a las presiones internas (de partido) y externas (UE) que «agotaron» ${ }^{59}$ su proyecto político como consecuencia de la imposición de recortes. Así pues, aunque en principio fuesen causas excepcionales y externas (crisis internacional) las que motivaron el fin precipitado del mandato socialista, el relato promovido por la derecha sobre el fracaso de la gestión económica de Zapatero se extendió, de alguna manera, al resto de su programa y contribuyó a alimentar la idea populista según la cual los gobiernos de derecha crean riqueza y los de izquierda la distribuyen alegremente.

Siguiendo esta lógica, las políticas de acción positiva por la igualdad de género, que ya fueron objeto de crítica en el momento de su implantación (por diestros y siniestros), se convertirían en un blanco fácil en el discurso de la austeridad ${ }^{60}$, dada la

\footnotetext{
${ }^{59}$ La crónica del diario El País relata explicitamente que Zapatero se vio «obligado a renunciar a parte de sus principios para cumplir con exigencias de los mercados y de la Unión Europea, con recortes sociales que no estaban en su proyecto»: https://politica.elpais.com/politica/2011/07/29/actualidad/1311929850 613039.html [última consulta: 14/04/2018]

${ }^{60}$ En el apartado del Marco Histórico ya hemos hecho referencia al fin de la paridad del gobierno Zapatero y del propio Ministerio de Igualdad, que no tuvo que esperar a la llegada de la derecha, sino que, por el contrario, fue el propio Rodríguez Zapatero quien lo convirtió, dos años después de su creación, en
} 
tendencia liberal a dar (interesadamente) por hecho que la igualdad formal entre hombres y mujeres existe de base y que esta clase de medidas resultan nocivas desde un punto de vista meritocrático (Monereo, 2007: 2-3). Así pues, ajenos a cualquier crítica feminista sobre los límites de la universalidad ilustrada y apoyándose en la condición de no permanencia (Urteaga, 2009: 198) de las mal llamadas políticas de «discriminación positiva», la tendencia de pensamiento neoliberal sobre la igualdad de las mujeres se fue imponiendo poco a poco en el halo de lo que fuere el feminismo institucional de la época socialista y fue sintomatizándose en los productos de la cultura popular objeto de nuestro análisis, como veremos a continuación.

En esta línea, en los años subsiguientes nos encontramos con dos productos televisivos en los que las protagonistas se caracterizan teniendo en cuenta el binomio mujer-institución y que atenderán las cuestiones de la libertad e igualdad femeninas desde el punto de vista del legado común, el gobierno y la gestión de lo público: Isabel y El Ministerio del Tiempo.

\begin{tabular}{lccccc}
\hline una & secretaría & de & Estado. & Más & detalles \\
https://elpais.com/elpais/2010/10/20/actualidad/1287562624_850215.html & [última consulta: & 14/04/2018]
\end{tabular}




\subsubsection{Isabel, el ideal de mujer con poder}

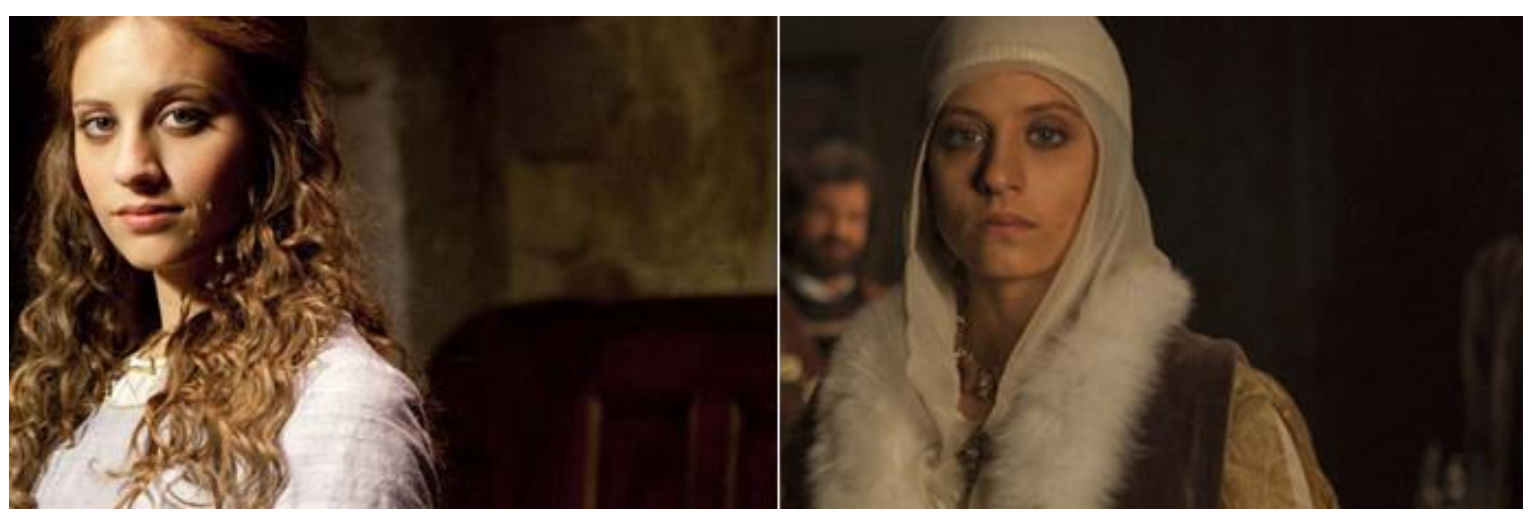

Imagen 10: Contraste del aspecto entre la Isabel joven de la primera temporada (izquierda) y el mismo personaje envejecido (derecha). Fuente: https://www.huffingtonpost.es/2014/10/09/isabel-premionacional-television_n_5957078.html_ [última consulta 14/04/2018]

Como podemos apreciar en la imagen que precede (izquierda) del personaje

de Isabel, existen paralelismos entre la imagen de Lolita infantil ${ }^{61}$ de la figura de la futura reina con la de la protagonista de LS, ya que se sigue con la caracterización inocente mediante los tirabuzones, el pelo, los ojos claros, la sonrisa dulce y la vestimenta muy clara, en tonos blancos y beige. Esta luminosidad se va oscureciendo en la serie a medida que avanza la trama. De hecho, el relato nos invita a acompañar a la

\footnotetext{
${ }^{61}$ Michelle Jenner fue la actriz elegida para encarnar el papel de Isabel I de Castilla en la serie. Esta joven actriz (barcelonesa, nacida en 1986), que prestó su imagen angelical a la representación de la monarca, ganó popularidad a nivel estatal con su interpretación de otro papel protagonista en la pequeña pantalla, concretamente en la serie Los hombres de Paco. En este caso era Sara, una joven pícara con cierto complejo de Electra a la que los estudios le interesaban algo menos que su meta amorosa, que no era otra que el chico protagonista de la serie. Años antes, todavía más joven, se la había podido ver en la exitosa telenovela El cor de la ciutat de (TV3). Además, su carrera en el mundo del doblaje la llevó a poner voz al personaje de Hermione Granger en Harry Potter, a la que daba vida la actriz Emma Watson en su período de infantil y hasta la adolescencia. En el audiovisual español, es cada vez más común que las actrices y los actores relevantes se hagan su propio hueco en el panorama a través de su aparición en los productos televisivos. Su popularidad en la «pequeña pantalla» es la que les catapultará (o no) posteriormente hacia el ámbito del cine. Esta es una de las muchas estrategias comerciales con las que ha probado suerte el cine español para salir de su eterna crisis: la creación de un star system propio y de proximidad (ya sea asociado al ámbito estatal como al regional) que funcione como gancho para atraer público (los y las fans de las series y de sus protagonistas) a las salas.
} 
protagonista en su padecer ya desde muy joven. Este empieza en el momento de la separación forzada de su madre enferma (1x01) y la posterior muerte de su hermano menor, Alfonso (1x04). Hasta aquí, podemos reconocer claras similitudes con el personaje de Victoria Márquez de La Señora, personaje también marcado por la ausencia materna, así como la de su hermano.

Parece como si las experiencias vitales dejaran marca en su vestimenta, que progresivamente va incorporando los bordados (una vez desposada, en el capítulo 1x09) y los tonos dorados y arena (que nos recuerdan su vínculo con el territorio de Castilla), para dar paso a los velos de la segunda temporada, que parecen recoger y reconfortar a la reina en momentos turbios (el aborto, las infidelidades del rey Fernando o el desasosiego de las guerras). La tercera temporada presenta una imagen de Isabel más deteriorada, con la piel apagada y manchada, con la mirada ojerosa, vestida de riguroso negro, como muestra del luto de la madre, pero que recupera el blanco roto del tejido de lienzo cuando se acerca al final de su vida y se entrega a su fe.

Ya en los primeros capítulos de la primera temporada de la serie, se hace especial referencia a la preparación intelectual de la infanta a manos de su consejero Gonzalo Chacón. Muestra de ello es, por ejemplo, la escena en la que juega con él una partida de ajedrez antes de que su madre la lleve a rezar (1x01). Este inicio ya nos da una pista clave de la que será su caracterización: una joven con formación, perspicaz en la estrategia, pero fiel a sus deberes como hija y también a las tradiciones. Muestra de ello es el diálogo que mantiene con su instructor durante esa partida de ajedrez, en la que la joven infanta dice: «Hay algo que no entiendo de este juego: ser reina es algo muy importante, ¿verdad?». «Lo es», responde Chacón. «Y entonces, ¿por qué se puede mover solo de cuadro en cuadro, si hasta los alfiles y las torres tienen más lustre y movimiento?». 
Esta pregunta que expresa la protagonista ya augura la paradoja que se planteará especialmente durante esa primera temporada de la serie, que tiene que ver con las limitaciones que experimenta una mujer a lo largo de su vida, a pesar de, en este caso, detentar el poder de pleno derecho y demostrar su capacitación (De Miguel, 2015). De hecho, la pérdida progresiva de brillantez del personaje va acompañada del desgaste que le produce su proceso de empoderamiento político y la carrera de obstáculos en la que parece convertirse el ejercicio del poder real, marcado fuertemente además por su condición de mujer católica. La resignación de Isabel y su sentido del deber configuran una parte muy importante de la caracterización moral del personaje. De hecho, son estos los rasgos que le permiten sobreponerse al dolor que le genera la pérdida de sus seres queridos $(1 \mathrm{x} 05)$.

No obstante, este afán por cumplir con las expectativas que, por jerarquía, se le asignan no le impedirá negarse a contraer matrimonio con el rey de Portugal e imponer su derecho a casarse con quien ella deseara, lo que le costaría un enfrentamiento civil con su hermanastro tras la dolorosa pérdida de su hermano Alfonso (1x06), quien le precedía en la línea sucesoria al trono. Ante los posibles pactos matrimoniales que el hermanastro pudiera negociar para alejar a Isabel de Castilla del reino tras el pacto de la paz entre ambas partes (atendiendo a que la reconciliación se sostenía con la condición de ella fuera la sucesora legítima de Enrique IV), los consejeros de la infanta, entre ellos su fiel Chacón, apuestan por Fernando de Aragón como candidato a desposar.

La narración nos invita, pues, a ver a la protagonista en su faceta de reina (como una mujer con poder en lo público), y nos interesará especialmente cómo este personaje encarna la idea de un nuevo estado-nación. Al tratarse de una figura femenina, nos resultará crucial atender al plano de lo personal, es decir, a la evolución 
de su personalidad en relación a su esposo y a la crianza. Aquí se cumpliría entonces la máxima «lo personal es político» (Hanisch, 1969) ya que, al tratarse de una monarca, las alianzas matrimoniales se mimetizan con el devenir del estado y desvelan su sentido político más esencial, pues la unión estratégica entre los desposados no tiene otro fin que el de preservar el patrimonio compartido.

Resulta destacable una frase de Isabel cuando los consejeros del rey dudan de su capacidad para ejercer como cabeza de la corona por su condición de mujer: «como esposa, obedeceré a mi marido; como madre, cuidaré de mis hijos; pero como reina, no rendiré obediencia a nadie» (1x06). La frase destaca por sí misma el talante que regirá el proyecto y el modo de vida de la joven mujer, una vez desposada con Fernando, quien también resultará beneficiado con este matrimonio estratégico. La sostenibilidad política de la Corona de Aragón necesitaba imperiosamente establecer pactos territoriales y económicos que evitaran una potencial invasión de Francia. Más beneficioso, si cabe, resultaría desposar a Isabel después de que esta consiguiera, tras una noble negociación, que su hermanastro firmase el pacto de Guisando, según el cual ella figuraría finalmente como primera heredera del reino de Castilla en detrimento de su hija Juana. «Soportó, tras su boda, maledicencias y limitaciones económicas. Tuvo que manejar la diplomacia con una dureza de carácter capaz de poner firmes a un ejército (y a su propio marido, si hacía falta). Y todo, por una obsesión: ser reina.» ${ }^{62}$

\footnotetext{
${ }^{62}$ Fragmento de la sinopsis de la primera temporada en la web oficial de la serie. Disponible en: http://www.rtve.es/television/isabel-la-catolica/la-serie/ [última consulta 14/04/2018]
} 


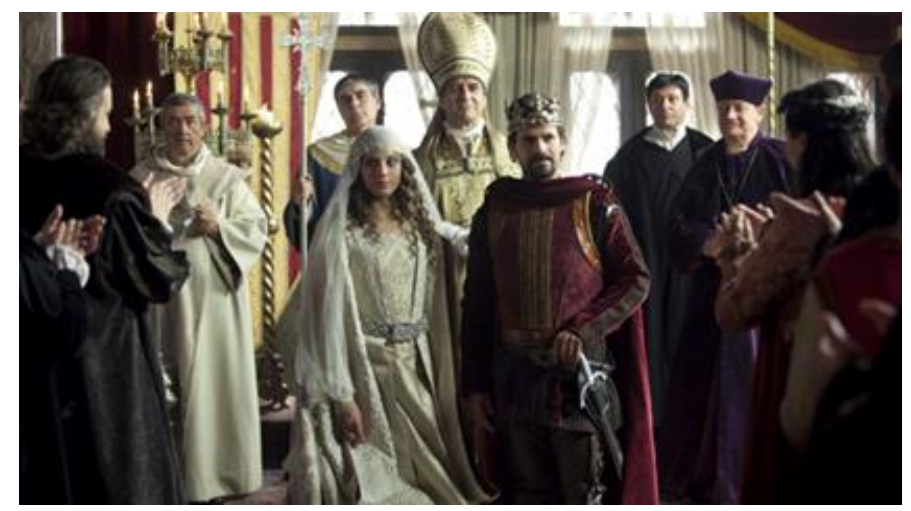

Imagen 11: Infanta Isabel (izquierda) desposa al príncipe Fernando (derecha) (capítulo 9 de la temporada 1). Fuente: http://www.rtve.es/alacarta/videos/isabel/isabel-bodaisabel-fernando/1558786/ [última consulta 14/04/2018]

Como se puede ver, el carácter estricto de Isabel figura como uno de sus principales rasgos, tanto en el ámbito público (en el despliegue de sus habilidades políticas como monarca) como en el privado (en el asunto matrimonial). Nos viene bien recuperar estas líneas porque es en esta temporada en la que más se destacan los rasgos personales de Isabel, los que condicionarán sus decisiones como mujer, reina y madre y, por tanto, sobre los que se asentará el desarrollo de la trama. En el capítulo siete de la primera temporada (1x07), uno de los hombres de la corte de Isabel, Gutierre de Cárdenas, enviado a conocer a su futurible marido, se la describe de la siguiente manera:

Es elegante pero modesta; es austera, es poco amiga de lujos ni de joyas; muy cristiana y devota; nunca habla por hablar, es muy consciente de los deberes que por una le corresponden; y es fuerte, fuerte de carácter. Nunca he conocido a una mujer, y apenas algún hombre, que tenga su fortaleza. Es una mujer excepcional.

Esta es la contestación que recibe Fernando a la pregunta de si Isabel es rubia o morena. «Solo quiero saber cómo es mi futura esposa», esgrime. Y es que al 
pretendiente se le presenta como un joven mujeriego, en contraposición a la imagen de rectitud que desprende la infanta. Tanto en esta como en posteriores temporadas los affaires amorosos de Fernando de Aragón en sus viajes y campañas militares y la existencia de descendientes bastardos causan más de una decepción a Isabel de Castilla. Toda una metáfora de la relación entre el estado español y los deseos de independencia emergentes en Cataluña durante las legislaturas socialistas, que también se verá sintomatizada en la representación de las disputas de poder matrimonial entre ambos miembros. En estas, los argumentos de Isabel suelen ganar en sensatez a los de su marido, cuya ambición política queda en muchas ocasiones castrada por la regente. Muestra del sesgo centralista será la escena (1x13) en la que la infanta (ya desposada con el príncipe gracias al visto bueno del Papa de Roma) le dice a Chacón: «él mandará en Aragón, pero quien manda en Castilla soy yo».

\subsubsection{Amelia: la paradoja de la mujer en la institución}

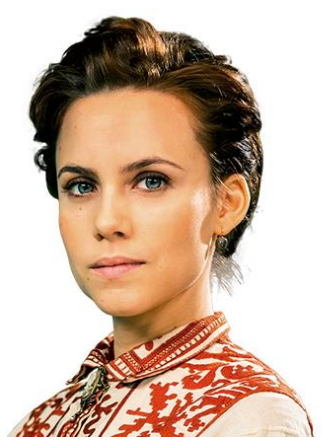

Imagen 12: Amelia en la foto de su «ficha de agente» de EMDT. Fuente: http://www.rtve.es/television/ministeriodel-tiempo/personajes/ [última consulta $14 / 04 / 2018]$ 
Amelia Folch (Aura Garrido), es la más reciente de nuestras protagonistas y es la líder de la patrulla más emblemática de EMDT, la que ya en la primera temporada conformaban ella misma y otros dos personajes masculinos: Julián Martínez (Rodolfo Sancho) y Alonso de Entrerríos (Nacho Fresneda). Como podemos apreciar en la «información destacada» de la «ficha de agente» que extraemos de la página web oficial de la serie ${ }^{63}$, Amelia es una joven barcelonesa, bilingüe, de finales del siglo XIX (1880) «inteligente, inquieta, aplicada y estudiosa» pero que «no acepta las reglas del juego de su época». No en vano, es «una de las primeras [mujeres] universitarias» del estado español. No es raro que esta circunstancia inspire pensar en las primeras figuras femeninas que pisaron las instituciones universitarias como es el caso de Elena Maseras, Martina Castells o Dolors Aleu o incluso como la de Concepción Arenal, con la que compartiría su gusto por la literatura (López, 2002; Peña, 2010; Amiguet, 2014; Mellado, 2015).

Como suele ser habitual, los capítulos piloto de las series nos proporcionan abundante información sobre los personajes, de manera que el espectador los pueda situar en el sentido del relato a lo largo de la trama. En este caso, parte de esa información nos viene dada por otro personaje: Salvador Martí (Jaime Blanch), el subsecretario del Ministerio. Este personaje está al mando y se encarga de reclutar, organizar a los agentes de las patrullas y sus misiones, es decir, de garantizar el buen funcionamiento de la institución. «Amelia [...] es el cerebro. Es moderna, inteligente. Ve lo que los demás no ven. Si hubiera nacido en el siglo XXI, sería lo que quisiera». A lo que la jefa de logística, Irene Larra (Cayetana Guillén Cuervo), que había sido

\footnotetext{
${ }^{63}$ Fichas de agente disponibles en: http://www.rtve.es/television/ministerio-del-tiempo/personajes/ Web oficial de la serie: http://www.rtve.es/television/ministerio-del-tiempo/ [última consulta $14 / 04 / 2018]$
} 
precisamente la funcionaria que reclutó a Amelia en su tiempo apunta: «Pues ahora tiene esa posibilidad».

Irene manda llamar a Amelia en medio de una clase magistral sobre Lope de Vega en la universidad. Como buena alumna aplicada, la única mujer de la sala pide la palabra para intervenir y cuestionar las afirmaciones dogmáticas de su profesor, quien tacha públicamente las palabras de Amelia de «tonterías» para pedirle seguidamente que le deje seguir con la clase. Tras esta escena, Amelia acude a la llamada de Irene y al preguntarle quién es, esta le responde: «Alguien que sabe lo mucho que vales», contraponiendo su punto de vista al del profesor. En esa misma conversación, en la que Irene ofrece un espacio de reconocimiento a los anhelos de Amelia, la joven universitaria dice: «Es difícil encontrar a una mujer con la que hablar de arte, política o cosas importantes».

Reconocemos aquí una pincelada del discurso de la igualdad neoliberal, el que valora el acceso de la mujer a las esferas públicas masculinizadas (como la Academia) solo si esta es capaz de apreciar el gusto por la cultura legitimada en estos espacios y que tiene que ver de nuevo con el perfil de poder patriarcal. De hecho, sigue: «A veces pienso que las mujeres somos nuestras peores enemigas. Pero eso tiene que cambiar. Estoy segura [de] que en un futuro las mujeres podrán hacer lo mismo que un hombre». Acto seguido, Irene le invita a brindar por ello y le da de beber de una petaca. Este gesto acaba de proyectar la idea del feminismo de primera y segunda ola en la pantalla, en tanto que las mujeres que se encuentran en el plano son coetáneas de esas etapas del movimiento y proyectan en el futuro la idea del igualitarismo desde los parámetros androcéntricos.

El personaje de Irene, de hecho, tiene de por sí un talante bastante masculinizado. Su ficha de agente nos dice que en su época, los años treinta del siglo 
$\mathrm{XX}$, «a la mujer no se le ofrecía la posibilidad de destacar». Este punto resulta un tanto confuso, teniendo en cuenta cómo se construye el personaje de Encarna en 14ALR. Aunque, bien es cierto que Irene dice nacer exactamente en el año 1930 (1x01) y eso implicaría que en su etapa adulta estuviera sometida a los cánones de feminidad del franquismo. Dejando esta consideración aparte, lo que podemos comprobar es que la institución secreta sí la destaca como «uno [sic] de los mejores agentes del Ministerio», además de calificarla como una «mujer fuerte, independiente y dedicada a su trabajo». También consta en la ficha que su estado civil es «separada», aunque no se habla aquí de que es homosexual, a pesar de que este dato lo da a conocer la narración el mismo momento del reclutamiento de Amelia. Precisamente tras compartir un trago por un futuro igualitario, la estudiante insiste en el desacuerdo con las normas de género de su época y dice no necesitar marido. Esta ocasión la aprovecha Irene para besarla en los labios, aunque Amelia espeta estupefacta: «[...] pero el caso es que me gustan». La escena termina, a pesar del varapalo de la agente, con la siguiente sentencia por su parte: «Tu mundo se te queda pequeño, querida. Y eso sí lo podemos solucionar».

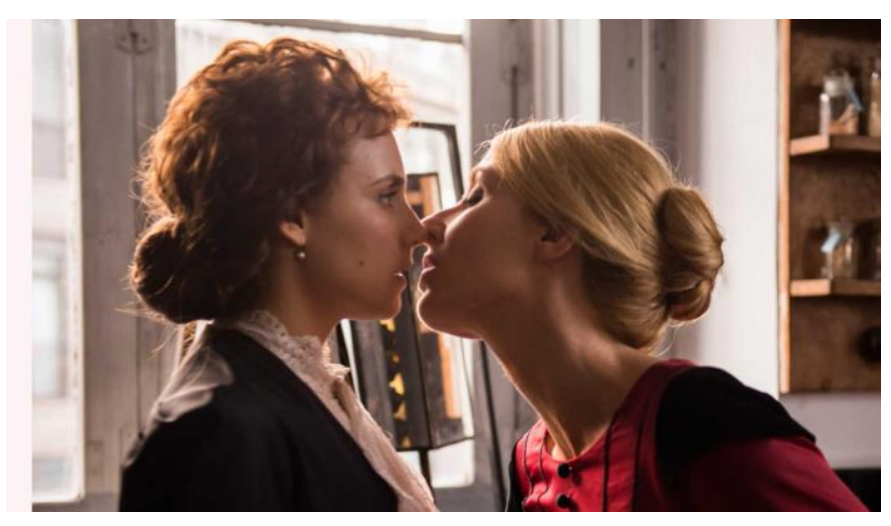

Imagen 13: Irene (derecha) besa a Amelia (izquierda) en el laboratorio de la universidad $(1 \times 13)$ Fuente: http://www.rtve.es/alacarta/videos/programa/mdt-ameliafolch-primera-mujer-universidad-barcelona/2995162/ [última consulta 14/04/2018] 
Como vemos, Amelia es una mujer «adelantada a su época» ${ }^{64}$ (aunque no tanto como las mujeres de principios del siglo XX, como Encarna de 14ALR y la propia Irene de EMDT) y se la caracteriza de forma casi idéntica a la de las protagonistas anteriores: es joven, perspicaz, sensible, con una formación ejemplar (excepcional para el momento, si tenemos en cuenta que nos la presentan en un seminario universitario donde ella es la única mujer oyente) y con una capacidad de liderazgo caracterizada por la sensatez y por el sentido del deber. No obstante, es necesario hacer hincapié en la parte de su descripción en la ficha oficial, porque en ella se apunta que «hasta ahora acataba las normas del Ministerio, pero desde que ha descubierto su futuro sus principios se han tambaleado».

En este tambaleo de principios tiene mucho que ver Lola Mendieta (Natalia Millán), un personaje femenino complejo que el relato va introduciendo en cuentagotas, con datos contradictorios, y cuyo perfil resulta difícil de conocer. En principio, se trata de un personaje desertor, que va proporcionándonos poco a poco información sobre dónde residen sus motivaciones para luchar contra el Ministerio del Tiempo y, aparentemente, contra su causa antifascista. Es, de hecho, el primer encuentro con Amelia (1x03) el que permite, tanto a la audiencia como a la jefa de la patrulla, empezar a desmitificar la institución de la Historia. De hecho, es en el fondo de esta cuestión donde reside, desde nuestra lectura, el conflicto argumental de la serie. Esto es, en las dinámicas institucionales que han mitificado ciertos hitos y nombres a costa del sufrimiento y el silenciamiento de otros en pro de que la historia no cambie, como dice el propio Salvador Martí desde en el primer capítulo de la serie.

\footnotetext{
${ }^{64}$ De nuevo vemos emplear la misma coletilla desde la propia instancia narradora que se ha utilizado anteriormente para describir a los personajes de Victoria Márquez, de LS, y de Isabel la Católica, en Isabel.
} 


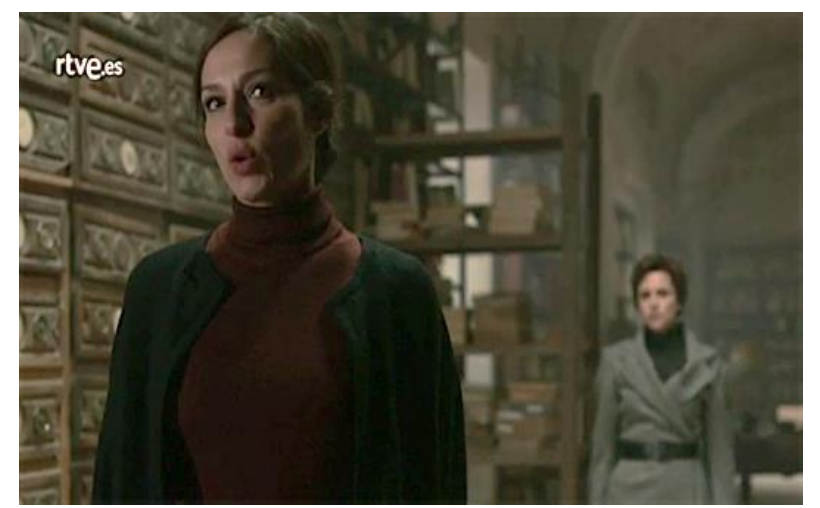

Imagen. Lola Mendieta en primer plano (izquierda) deja paralizada a Amelia (derecha) tras proporcionarle información sobre su futuro $(1 \mathrm{x} 03)$ Fuente: http://www.rtve.es/television/ministerio-deltiempo/capitulos-completos/temporada-1/capitulo-3/ [última consulta 14/04/2018]

\subsection{La representación del empoderamiento femenino y sus límites y de otras estrategias de emancipación}

\subsubsection{La vulnerabilidad y la victimización en La Señora}

Si seguimos el orden cronológico, tal y como venimos haciendo hasta ahora, debemos empezar hablando de La Señora, que se estrenó en televisión en marzo de 2008, el mismo mes en que el socialista Zapatero revalidaría su puesto como presidente del gobierno del Estado, tras cuatro años ya de mandato. La serie se emitiría, pues, coincidiendo con el debate creado en torno a la elección del gabinete paritario y la creación del Ministerio de Igualdad con Bibiana Aído al frente del mismo, la ministra más joven de la historia de la democracia. No resulta extraño, por tanto, que nos encontremos con un discurso sobre el empoderamiento femenino centrado en sujetos 
muy jóvenes pero muy bien formadas, en consonancia con los debates en torno a la igualdad de capacidades entre sexos y los obstáculos para la consecución de metas profesionales y personales en el caso de las mujeres.

En este contexto es en el que se nos presenta a Victoria Márquez. El carácter melodramático en el que se desarrolla el argumento de la serie se recrea en la presencia constante de la muerte (de una madre a la que la audiencia no llega a conocer, así como del padre y del hermano de la protagonista - en los capítulos dos de la primera y cuatro de la segunda temporada, respectivamente), en el duelo (no solo provocado por el fallecimiento de sus familiares, sino también por las bruscas separaciones de su humilde pretendiente, a quien coaccionan para ordenarse sacerdote y apartarse de la joven burguesa) y en la frustración (provocada no solo por las dificultades amorosas y empresariales de Victoria). La circunstancia de la pérdida que caracteriza el desarrollo vital de Victoria proyecta una sensación desamparo en la protagonista que solo parece poder revertirse con los cuidados de los que le provee Ángel (aunque estos no se produzcan en el seno de una pareja sentimental formal).

De hecho, son los vaivenes amorosos entre la pareja y la vulnerabilidad que forjan estos acontecimientos en la figura de Victoria los que desvelan en la pantalla las bondades y maldades de resto de personajes. Particularmente, nos debemos referir aquí al futuro marido de Victoria, el marqués Gonzalo De Castro (Roberto Enríquez), quien, movido por intereses económicos, participará en la planificación de la muerte del padre de la protagonista de la serie. Así pues, el conflicto argumental que se despliega a lo largo de las tres temporadas se moverá entre los esfuerzos del marqués por conquistar y desposar a Victoria (heredera legítima de la mina), como garantía de su dominio empresarial, la lucha personal de Ángel por demostrar a Victoria la fatal verdad que oculta su marido, y la disputa interna de la protagonista. Esta se debate constantemente 
entre su amor al sacerdote y la incredulidad hacia los argumentos del mismo, que vendrá motivada además por el despecho que siente hacia él tras abandonarla en pro (presumiblemente) de su fe religiosa.

En esta encrucijada de emociones e intereses, y debido a la propia idiosincrasia del género, se recurre en abundancia a las expresiones extremas de emociones como la alegría o la tristeza. Aunque lo cierto es que, detrás de tales expresiones, se aprecia un halo de infantilización alrededor de la protagonista que lleva a sentirla en exceso desamparada o sola (a pesar de toda la gente que vive y o sirve en la casa Márquez y que se preocupa por sus bienestar). Esta infantilización, marcada por la aparente soledad y la posición de ignorancia en la que se la coloca, son las que llevan a Victoria a confiar en personas como su marido, el Marqués de Castro. El cinismo y la ambición de este solo son desconocidos por Victoria, ya que tanto los personajes de procedencia humilde (entre ellos, Ángel, el amor platónico de la señorita), como los burgueses (como el propio padre y el hermano de la protagonista), desconfían de él. Lo cierto es que resulta un personaje muy complejo y camaleónico y no será hasta el último capítulo de la serie que Victoria sepa de su falsa identidad y corrobore las sospechas de su hermano y de Ángel sobre la implicación directa del marqués con la muerte de su padre.

El personaje de este usurpador de identidades venido a más parece ser especialmente hábil en la manipulación de las mujeres que aparecen en su camino. A la que conocemos como su primera esposa, Irene de Castro, de quien él heredará el título de marqués, consigue enamorarla hasta tal punto que esta arriesga su salud (física y mental) para darle un heredero que nunca llegaría, tras varios abortos que la llevan finalmente a la muerte. El duelo de Gonzalo por la pérdida de su esposa hará que Victoria, quien acaba de dejar el luto por su padre pero adolece la repentina marcha de 
Ángel al seminario de curas, empatice con una interesada buena voluntad del marqués quien, con la excusa de querer atender a la familia del que fuera su socio, atará en corto a Victoria para disipar cualquier halo de sospecha que lo vincule con el accidente mortal de su progenitor.

Como cualquier maltratador de manual, Gonzalo aprovechará la soledad e inocencia de su víctima para proveerle de atenciones durante su cortejo (1x06-1x11). Cuando consigue prometerse con ella ya la hace sentir culpable por no estar feliz ante la noticia del casamiento y estar más preocupada por el estado del negocio familiar (1x12). Una vez consigue tenerla en matrimonio, infligirá en ella todo tipo de chantajes emocionales con el fin de anular sus iniciativas y decisiones personales y empresariales para manejar, sin la supervisión de la heredera legítima, la mina de los Márquez. De nuevo, acciones de un maltratador prototípico que resultan reconocibles encajan con la descripción oficial de la idea de violencia de género, que quedará definida en el imaginario colectivo extradiegético a partir del establecimiento de un marco hegemónico que ha construido un prototipo de víctima como desprovista de agencia (Gámez Fuentes, 2012; Gámez Fuentes y Núñez Puente, 2013).

Debemos tener en cuenta que en el discurso del feminismo de Estado hasta el momento había tenido un importante peso el tema de la violencia de género. No en vano, la ley contra la violencia de género se aprobó antes de finalizar el 2004 (año en que Zapatero ganaría las primeras elecciones generales), mientras que la ley de igualdad no vería la luz hasta marzo de 2007 (un año antes de que los socialistas ganaran las segundas elecciones consecutivas del siglo XXI). Las críticas actuales a la revictimización de la mujer en los casos de violencia de género y en la representación mediática de esta, nos hacen reflexionar sobre cómo se trata en el relato de LS la vulnerabilidad de Victoria y, en efecto, podemos apreciar cómo la performatividad de la 
vulnerabilidad de la protagonista se acerca a ese paradigma doblemente victimizador.

No ayuda precisamente a replantear tal marco de reconocimiento de la víctima de violencia el papel del «verdadero amor» de la protagonista, Ángel. Debemos tener en cuenta que la liberación por parte de Victoria del yugo de su matrimonio (engañoso e interesado) no se produce hasta que aquel, gracias a su buena posición en la institución eclesiástica, consigue recabar las pruebas que demuestran que Gonzalo fue el asesino de Ricardo Márquez. A Ángel lo podríamos situar en el paradigma del asistencialismo y actuaría del mismo modo que lo hace una autoridad médica que debe ratificar las pruebas de maltrato ante una autoridad jurídica, sin las cuales no habría caso de violencia de género ni razón o motivo para la separación que, en el caso de la serie, pasaría por una nulidad matrimonial que facilitaría la posterior unión de Victoria y Ángel.

\subsubsection{La mujer frente al patriarcado: más allá de la violencia de género}

La misma buena voluntad, que a veces la ciega, hace de Victoria un personaje ideal para representar la transformación de los valores sociales. Debemos tener en cuenta que LS se nos presenta como una historia de la lucha de clases. Como ya habíamos avanzado, el engagement con las audiencias se trabaja precisamente desde el melodrama (Cascajosa, 2017) y la identificación con una chica joven enamorada. De hecho, el motor de la narración es la historia de amor adolescente entre jóvenes de distinta clase social que y que, como ya apuntamos, sigue el modelo de la primera temporada de la telenovela de sobremesa Amar en Tiempos Revueltos (Cascajosa, 2017; Chicharro, 2009). Así, se produce la identificación y la simpatía de la audiencia con una niña inofensiva, preciosa a la vez que correcta; una ecuación que hace de ella un buen partido como esposa y madre. El deseo, proyectado hacia el personaje de Ángel, y el 
deber como esposa del marqués, recrean el conflicto típico del melodrama entre el amor romántico y el valor del matrimonio heteronormativo católico como moneda de cambio y mantenimiento del estatus quo.

La propia Virginia Yagüe, vicedirectora de CIMA (Asociación de Mujeres Cineastas y de Medios Audiovisuales) y creadora de la serie, hacía hincapié ${ }^{65}$ en la importancia narrativa de las paradojas que encarnaban algunas mujeres de los «locos años $20 »$, quienes eran «objeto de burla y de fuerte control moral» si no se sometían al rol de esposa abnegada, y esto por parte tanto de hombres como de mujeres. Así, esta serie pondrá en el foco la diversidad de estructuras del poder patriarcal (el burgués, el caciquil y el eclesiástico), desde una distancia histórica (que no sabemos si hace bien o no a la identificación de la audiencia con la narración o si lo aleja en el tiempo, pero sí sospechamos que resulta menos amenazante). El objetivo es recuperar locus de enunciación marcados por el género y, también, la clase y que nos hablan más de la posibilidad de empoderamiento femenino (a pesar del dolor y de los errores) que de resignación.

En este escenario de violencia cultural y estructural hacia la mujer (Confortini, 2006), Victoria resulta castigada por su elección sentimental. Dentro del hogar, además, sentirá por primera vez el desapego de su hermano mayor por tener que refrendar ella las decisiones de Pablo al frente de la mina, atendiendo a las últimas voluntades de su padre (1x02). Sin embargo, lo que Pablo se toma en un primer momento como una falta de reconocimiento a sus capacidades, el guion lo expresa en forma de reaccionismo misógino a través del personaje de Justo, el mozo de la casa Márquez. Este sentencia (haciendo honor a su nombre de pila) que «el señor se

\footnotetext{
${ }^{65}$ En el reportaje Felices años 20, emitido justo antes del primer capítulo de la serie y que invita a leer el argumento desde la perspectiva de la lucha de clases y de la falta de derechos de las mujeres. Disponible en: http://www.rtve.es/alacarta/videos/la-senora/senora-felices-anos-20/110454/
} 
equivocó y debiera dejarlo todo en manos de su hijo», a lo que Vicenta, el ama de llaves, le contestará que hizo bien, porque ella (Victoria) tenía más cabeza que el señorito (coincidiendo con los continuos viajes de Pablo a Italia y su simpatía por las corrientes fascistas y el embarazo de Encarna). Así pues, como empresaria, Victoria será cuestionada desde el principio por las personas que en teoría la quieren bien y, más tarde, será saboteada por los burgueses y señores de apellido de la comarca que dudan de sus capacidades para hacer negocios.

Ante estas situaciones, los personajes femeninos, como sujetos de no-poder (aunque este poder sea legítimo, como es el caso de la herencia del negocio familiar) solo pueden resistir y apoyarse. En este aspecto, es esencial para Victoria la relación con su cuñada Encarna, con la que contará también para encontrar soluciones sostenibles para la viabilidad de la mina, ante tal saboteo (del que es también partícipe su marido Gonzalo), y evitar su cierre y el consiguiente despido de los obreros. Se produce así una simbiosis entre ellas dos que hace gala del necesario entendimiento entre clases en tiempos de cambio. En su análisis de la serie, Chicharro (2009: 63) habla de la «coexistencia pacífica entre grupos alejados socialmente» ${ }^{66}$ que se da en la casa Márquez en «una suerte de microsociedad armoniosa en la que cada estrato ocupa su lugar asignado socialmente sin atisbo alguno de rebeldía». Teniendo esta apreciación en cuenta, nosotras proponemos añadir una lectura a la que aplicamos el prisma de género y que nos permite apreciar cómo la relación de sororidad entre los personajes femeninos permite que los cuidados en el interior del hogar se transformen en decisiones políticas (en tanto que distribuyen la capacidad de acceso a los medios de producción) que tienen consecuencias positivas en el exterior. Muestra de ello es la escena del último capítulo

\footnotetext{
${ }^{66}$ Lo hace a colación de la relación emotiva que comparten Victoria y Vicenta, pero luego la hace extensible a las relaciones de los señores con el servicio en general. Nosotras lo hacemos extensible a Encarna, en tanto que es acogida también en la casa, a pesar de su origen humilde y sus ideas políticas.
} 
de la primera temporada $(1 \mathrm{x} 13)$ en que Pablo y Victoria, tras hacerse con el control mayoritario de la mina, ordenan el alto al fuego a los guardias civiles que intervenían, por orden del marqués, contra el piquete de obreros y obreras de la mina, entre los que se encuentran Encarna y Ángel, que protestan por la inseguridad de sus condiciones laborales.

Con todo, el desenlace de la serie se nos presenta como una metáfora, cuanto menos, complicada. Cuando Victoria consigue deshacerse del lastre de su matrimonio, reunirse con su amor de la adolescencia y cooperativizar la mina tras las negociaciones con los obreros, muere. Y muere sepultada por las estructuras de la propia mina, tras la asamblea en la que el comité le nombraba responsable de la gestión. Tenemos dos maneras de leer este final. La primera, nos dice que la colaboración entre patronas y obreros acaba por destruir la estructura social y económica existente hasta el momento y, con ello, el privilegio de hombres pero también de ciertas mujeres. U otra, que nos resulta más lógica y que tiene en cuenta a los causantes del derribo y la muerte de La Señora. La mina se viene abajo debido a los explosivos colocados por un cabecilla del sindicato obrero comprado por el propio Marqués de Castro con el fin de dar un escarmiento a los obreros y que «todo sig[uier]a igual». Este hecho nos invita a hacer la lectura inversa: el mantenimiento del poder patriarcal y del pacto exclusivo e interesado entre hombres solo puede tener consecuencias fatales para los intentos de empoderamiento femenino.

\subsubsection{Sororidad y matrilineaje en 14 de abril. La República.}

Como ya hemos mencionado anteriormente, la ficción y el personaje que traemos al análisis forma parte de toda una tendencia de títulos de productos 
audiovisuales emitidos en la televisión estatal que aproximan al gran público la genealogía feminista que subyace a las políticas por la igualdad de género y por la recuperación de las voces de colectivos silenciados. La serie 14ALR hace referencia explícita a esta necesidad de recuperar el legado feminista en diferentes episodios de nuestra historia reciente y a los debates generados alrededor de la institucionalización del feminismo en la era Zapatero.

El primer guiño a este respecto lo encontramos ya en el primer capítulo del spin off, en el discurso que Encarna ofrece a la militancia socialista para conseguir apoyos al sufragio femenino y que éste sea aprobado en el Congreso. En él esgrime, como ejemplo para el proyecto republicano, el esfuerzo de Victoria (protagonista de LS) por colectivizar la mina, poniendo así de relevancia el papel de la mujer en la vida pública y relacionándolo con el reparto de los medios de producción y de la riqueza. Esta referencia intertextual (que tiene efectos tanto intra- como extra-diegéticos, ya que juega con el imaginario compartido entre el personaje de Encarna y la audiencia de la serie anterior y su secuela) conmemora la relación de sororidad entre ambas y la necesidad de mantener vivo el legado femenino para la construcción de un proyecto político que aspira a ser garante de justicia social y de igualdad.

De hecho, las relaciones de sororidad envuelven los círculos relacionales de Encarna e incluso parecen ser estos los que, de alguna manera, posibilitan su éxito en la arena política. Especialmente importantes son los personajes femeninos con los que compartía espacio en LS y a los que se hace referencia en el capítulo 8 (1x08) de 14ALR. En este episodio, Encarna recibe la visita de su hijo Pedro, que viene acompañado por Vicenta, el ama de llaves de la casa Márquez, lugar familiar donde el niño sigue siendo criado con la ayuda de la misma Vicenta y Marcelina, una institutriz republicana, mientras su madre trabaja en Madrid. Con ambas, Encarna mantiene una 
relación familiar, de la misma manera que con otro de los personajes de LS, Ludi, una criada de la casa Márquez con su propia trama en 14ALR. Por cuestión del origen humilde de Encarna y de sus ideales, el trato con estos otros personajes resulta siempre entre iguales. De hecho, son ellas las que la animan a seguir con su proyecto político cuando los remordimientos maternales le hacen querer volver al Norte y estar cerca de su hijo.

En este sentido, se aprecia como la solidaridad entre mujeres resulta básica para la igualdad de género y el beneficio de la sociedad en general. Un ejemplo de esto, lo encontramos ya en el primer capítulo, cuando Ludi se encuentra con Encarna en Madrid y la pone al día de las cosas de casa. «Marcelina decía que lo que usted venía a hacer a Madrid era muy importante y que al final todos nos acabaríamos beneficiando de ello», le dice Ludi mientras la coge de la mano. Y continúa diciendo: «la señora Vicenta dice que la señora Victoria hubiese sido la primera en animarla», acentuando el compromiso con la memoria. De este modo, las relaciones entre mujeres, a pesar de ser de diferentes clases sociales, consiguen representarse lejos de principios antagonistas. Las alianzas políticas, de hecho, llegan a identificar a los varones, o a algunos varones, como objeto de su opresión. Cabe destacar el papel de los militares o del policía que intenta violar a Encarna. Aunque las relaciones entre géneros son complejas en la trama, es importante ver la identificación de sujetos masculinos de opresión que, además, ejercen una opresión de género.

La relación con Amparo, sin embargo, da un paso más allá de la sororidad y adscribe complejidad a las relaciones feministas, además de adquirir más tarde tintes de intimidad que han quedado en el aire a falta de la emisión de la segunda temporada de 14ALR al cierre de esta tesis. Si bien es cierto que su relación tiene un claro componente político derivado de sus respectivas militancias en el Partido Comunista 
(Amparo) y el Socialista (Encarna), esta relación entre las dos funciona como algo más que como una metáfora de las simpatías y las desavenencias de las corrientes feministas y de las izquierdas en la II República. Si bien, se aprecia en primer momento el desencuentro político entre ambas cuando el personaje de Amparo dice que «dar el voto a la mujer sería dárselo a sus confesores» (1x01), reproduciendo así el pensamiento hegemónico sobre el sufragio universal dentro de los círculos obreristas, sus encuentros a lo largo de la temporada representan un entramado complejo de intereses tanto políticos como personales que más que separarlas, las unen.

La escena que describíamos hace referencia directa a los hechos históricos. El debate sobre la «cuestión femenina» en el contexto español estuvo capitalizado por los desacuerdos sobre el sufragio universal, debate que se plasmó en el Congreso de los Diputados de la mano de Victoria Kent y Clara Campoamor (cabe destacar que son dos personajes históricos vinculados al anarquismo, no al socialismo), y cuyos argumentos se reproducen en ese primer capítulo. Las alianzas posteriores entre posicionamientos de mujeres de distintas clases sociales reflejan los debates sobre la jerarquía de luchas políticas (las de las mujeres o las del proletariado) y los modos de generar relaciones de sororidad que, en buena parte, pasan por reconocer los agenciamientos sujetados a las posiciones estructurales.

Como hemos podido ver, podríamos decir que 14ALR sintomatiza como ninguna los debates en torno al feminismo de Estado y su promoción de la memoria de las mujeres. El personaje de Encarna representa a la perfección los debates contemporáneos sobre las capacidades femeninas en política, así como las renuncias personales que la función pública implica en la vida de las mujeres. No obstante, la trama generada alrededor de Encarna y a sus relaciones profesionales, familiares e íntimas con otras mujeres otorgan complejidad a la cuestión de la capacitación y el 
empoderamiento femenino. Este no se entiende en la serie si no es desde la colectividad y para la colectividad. Es decir, Encarna y la sinécdoque de la institucionalización del feminismo en España, no hubiese sido posible sin el apoyo de las mujeres que trabajaron codo a codo con ella en la administración pública y que la quisieron en sus espacios privados de afectos.

En última instancia, la aproximación interseccional al género, la clase y la sexualidad que entreteje la figura de Encarna, evidencia la voluntad de resignificar, de manera épica, a las mujeres republicanas condensando en el personaje el modelo prototípico de 'la mujer nueva' sobrepasando, en el ámbito de la libertad sexual, las producciones de género propias del contexto histórico. Acostumbradas a que los productos de la cultura popular opten por reproducir historias sesgadas por la mirada patriarcal, según la cual las relaciones entre mujeres no existen si no son de rivalidad, esta serie aporta una mirada hacia las relaciones de complicidad y solidaridad entre las mujeres.

\subsubsection{La reconstrucción del mito de la feminidad nacional en Isabel}

El caso de Isabel implica un salto conceptual ya que no se centra tanto en las estrategias de empoderamiento individual y colectivo de una mujer, sino en la traducción de estas en la gestión de lo público. Esto es, se recupera un mito nacional para resignificarlo desde los parámetros del feminismo institucional y vincular la genealogía de la identidad española a estos. Para ello, la serie recuerda los momentos relevantes de la vida de la reina católica: «su juventud, la lucha por el poder con su hermano Enrique IV, su boda con Fernando de Aragón, la conquista de Granada, el descubrimiento de América, sus conflictos por mantener la estabilidad de su reino gracias a los enlaces matrimoniales de sus hijos con los principales reinos europeos para combatir a Francia; la historia de su hija Juana la Loca o su muerte, el 26 de noviembre 
de 1504, con la preocupación de su sucesión en mente» ${ }^{67}$.

El mito femenino, en la serie, se representa en torno a tres ejes: mujerreligiosa, mujer-esposa y mujer-madre. Estos tres componentes se combinarán con su condición de monarca y chocarán con sus aspiraciones como mujer-soberana. El personaje remasterizado de la reina católica resulta una imagen prototípica de la superwoman neoliberal que, por su privilegio en el acceso a las esferas de poder, podría encajar en el paradigma del patriarcado de consentimiento (De Miguel, 2015).

Podríamos decir que la Historia nacional se reconstruye a partir de los códigos actuales según los cuales se entiende el papel de la mujer en la sociedad, su situación y condicionantes (la maternidad, entre ellas) en las estructuras de poder. Esto, además, en un contexto en el que la configuración política del territorio también es motivo de debate en la esfera pública y en la unión matrimonial de los Reyes Católicos representa un hito recurrente en los argumentarios por la unidad del estado-nación. De hecho, la segunda temporada se inicia precisamente con una disputa política entre ambos, en la que Fernando sentencia: «no creáis por ello que dejaré de reclamar mis derechos». A lo que ella responde muy serenamente: «Os concederé hasta donde considere justo. Aunque sea yo quien reine en Castilla, tendréis derechos reales, podréis impartir justicia; cosa que yo nunca podré hacer en Aragón: no lo olvidéis. Escuchad mis propuestas y sumad las vuestras».

«Esto va a ser nuestro matrimonio? ¿Siempre una lucha?», pregunta el marido. A lo que ella responde que no, porque aprenderán a «convivir con la grandeza del otro porque nos necesitamos, porque nos amamos». Esta discusión de los personajes hacen alusión a dos asuntos clave en la agenda política de la época de creación y

\footnotetext{
${ }^{67}$ Sinopsis disponible en la web oficial de la serie: http://www.rtve.es/television/20141206/isabel-isabelreina/1061343.shtml [última consulta 14/04/2018]
} 
emisión de la serie: la cuestión de género y el conflicto territorial. Así, por una parte, estamos viendo cómo una mujer de Estado interpela a un igual, de género masculino, en cuestiones de gobernanza y le invita a sumar esfuerzos a pesar de encontrarse la mujer en situación de inferioridad respecto al territorio que gestiona el hombre (aquí el Reino de Aragón funcionaría como metáfora de tal espacio de influencia de lo masculino). Por la otra, se proyecta una visión romantizada de la unión del estado-nación (ser uno con la grandeza del otro, toda una declaración de intenciones del PSOE hacia el PSC). Esta apuesta por la unidad se representará mediante el consiguiente apoyo de la nobleza castellana a Fernando en la Guerra de Sucesión ${ }^{68}$, que viene acompañado por la noticia del segundo embarazo de Isabel (al que, si es varón, darán el nombre de su abuelo paterno, Juan) y el deseo del matrimonio de que la buena nueva sea preludio de paz para el reino de Castilla.

No obstante, la noticia de que el rey había tenido una hija en Aragón, provoca tal impacto en el ánimo de la reina que causa la pérdida del deseado sucesor, que nació varón pero muerto. Una deslealtad, por parte de Fernando de Aragón, cuyo duelo somatizará la reina de Castilla, para quien el primero reproduce las siguientes palabras de arrepentimiento: «si no podéis perdonar al hombre, perdonad al rey». Esta frase apelaría directamente a la capacidad «femenina» de transformación de conflictos en los espacios de gestión.

La mujer empoderada deseable desde el marco del feminismo institucionalizado, de acuerdo con la caracterización de Isabel en la serie, parece no poder renunciar a sus deberes de esposa fiel devota y madre sacrificada, con las

${ }^{68} \mathrm{El}$ grupo de nobles contrarios a la causa isabelina, promovió el matrimonio entre la Beltraneja y Alfonso V para reclamar los derechos sucesorios de la niña con el apoyo del rey de Portugal, hermano de la madre de la joven desposada, Juana de Avis. 
contradicciones que esto plantea en el plano personal. Unas contradicciones que dan precisamente profundidad al personaje y que proyectan un sentimiento de autocompasión que apelaría a las mujeres de clase media-alta, con estudios universitarios o una sensibilidad política lo suficientemente radical en el fondo como para militar en ella, pero que obligadamente debe ser moderada en la forma para conseguir sus objetivos. Así parecería que la igualdad formal, entendida desde el marco hegemónico, sólo es posible desde la asimilación del poder en términos patriarcales, porque performativizarla supone hacerlo todavía y sin remedio desde los códigos de la cultura patriarcal que configuran nuestro marco ontológico y a través de los cuales nos socializamos y nos relacionamos con el poder o nos instalamos en él.

Al fin y al cabo, la figura de Isabel la católica se resignifica en la pantalla para adaptarse al mito o al prototipo de mujer de la era del feminismo institucionalizado que se abriría en el período Zapatero. Es inevitable, al hilo de esta cuestión, pensar en el perfil de las representantes gubernamentales del Partido Socialista de la época, sin establecer un paralelismo entre la protagonista de la serie y la recientemente fallecida Carme Chacón en su cargo de Ministra de Defensa (una labor que posteriormente realizaría también la militante del PP, Dolores de Cospedal), cuando esta pasaba revista a las tropas del ejército mientras estaba embarazada ${ }^{69}$. Este paralelismo vendría precisamente a colación de la problematización pública de la conciliación (por parte de las mujeres) entre la vida profesional y familiar de las mujeres «empoderadas».

De hecho, la deriva personal de la reina parece adentrarse en el vacío a medida que va cumpliendo objetivos en su vida política. Estos objetivos tienen que ver con el legado que ella dejará como monarca, pero que, al parecer, no ha podido fraguar como madre, a pesar de tener encarrilado el proyecto de unión de los reinos de Castilla

\footnotetext{
${ }^{69} \mathrm{https}: / /$ verne.elpais.com/verne/2017/04/09/articulo/1491764891_617960.html
} 
y Aragón, con la expansión hacia el Reino de Granada y la posterior empresa colonial. Como vemos, el destino no deja de poner a prueba esa fortaleza que caracterizaba a la joven Isabel, que va desgastándose como cualquier mujer trabajadora sin capacidad de conciliación. El sino del personaje de Isabel plantea si existe compatibilidad entre la ostentación del poder y la materialización del feminismo de estado si para tener acceso a la esfera de lo público, a la política, una debe hacerlo asumiendo el sentido de poder patriarcal.

Sin embargo, esta compasión que despierta la figura de la reina en el espacio de lo personal y de los afectos, se desplaza cuando entra en juego la representación de la otredad. A pesar de que la unión matrimonial de los reyes católicos se encuentra sumida en una crisis de confianza de Isabel hacia su esposo, los ya monarcas de Castilla y Aragón inician el proyecto de conquista del Reino de Granada. Esta empresa de expansión territorial con motivación religiosa causará el empobrecimiento de los reinados y hará florecer el lado más cínico del personaje de Isabel de Castilla, quien sentencia: «Asediaremos su ciudad hasta que el emir no tenga nada que llevarse a la boca y se arrastre ante mí suplicando clemencia». A esto se sumará la expulsión y la persecución de los herejes judíos en la península Ibérica y el apoyo a Colón en la empresa de conquista de «las Indias».

Como vemos, el aspecto más familiar y emocional de la protagonista no puede desligarse de la concepción del estado-nación moderno regido por la ideología católica. Este segundo factor, servirá como cauce para el desarrollo del spin-off o serie derivada de Isabel, y que llevó por título Carlos, Rey Emperador, cuyo personaje principal es el nieto de los Reyes Católicos, hijo de su hija Juana I de Castilla (apodada la Loca) y de Felipe I de Castilla (apodado el Hermoso). Por lo que podemos dilucidar, las decisiones creativas optaron por saltarse la figura de Juana en pro dar el 
protagonismo histórico de la secuela a una figura masculina cuyo mayor reconocimiento pasa por haber consolidado empresa colonizadora de su estirpe castellano-aragonesa.

\subsubsection{El cuestionamiento de la legitimidad institucional en Amelia}

El caso de EMDT nos interesa por su misma esencia, ya que nos presenta un repertorio de mujeres funcionarias que trabajan en un organismo secreto del estado cuya misión es proteger la historia para que nada cambie. Es más, lo que se nos da a entender es que desde la unificación de los reinos de Castilla y Aragón, las mujeres mejor preparadas o «adelantadas a su tiempo» han trabajado secretamente en pro del mantenimiento del status quo en la España unificada y católica. De hecho, es en el capítulo $1 \mathrm{x} 04$ donde se da a conocer que el secreto de las puertas del tiempo fue revelado por parte de un judío a la reina Isabel la Católica bajo el compromiso real de proteger a la familia de este de la expulsión a la que ella misma sometió a su pueblo y a la que se hace referencia en la propia serie Isabel, con quien comparten creador: Javier Olivares $^{70}$.

Aquí se nos está aportando una información relevante, ya que podemos deducir que el tipo de mujer que presta servicio a esta administración deberá comulgar con la premisa que rige la misión ministerial iniciada por una monarca blanca occidental, iniciadora del fenómeno conocido como colonización, cuyo ideal supremo consistió en someter a pueblos a la fe católica. Sin embargo, resulta significativo que sean los hallazgos o la información que posee la mejor y más reciente trabajadora del

\footnotetext{
${ }^{70}$ Cabe mencionar además que en ese capítulo se juega con la intertextualidad entre ambas series y se realiza un cameo por parte de Michelle Jenner, recuperando su papel de Isabel la Católica en el mismo set de rodaje de la serie Isabel. El punto cómico lo trae la visita de Rodolfo Sancho, quien llega a la corte de la reina en su papel de Julián, agente de El Ministerio del Tiempo, y no como el rey Fernando de Aragón.
} 
Ministerio, una aplicada universitaria, una mujer ilustrada, lo que lleve a cuestionar tal misión y su propia función como «protectora» de la Historia. Así, la situación de Amelia, precisamente, enlazaría con la premisa de la filósofa Amelia Valcárcel (2001: 8), con la quien curiosamente comparte nombre de pila y quien sostiene que «[el feminismo] es un pensamiento político típicamente ilustrado. [...] Sin embargo de lo dicho no cabe deducir que la Ilustración es de suyo feminista. Es más, pienso que el feminismo es un hijo no querido de la Ilustración». A tenor de la consideración de Valcárcel, sería conveniente preguntarnos sobre cuál es el papel de un personaje femenino como el de Amelia dentro de esa institución de la Historia, qué aporta su mirada y su acción en transcurso de la misma.

Para empezar, destacaremos que a pesar de que procede del siglo XIX, la jefa de la patrulla es reclutada en el tiempo presente. Su carácter aplicado y su amplio conocimiento de la historia y la literatura española la validan para ejercer su cargo. También, el hecho de que no desee reproducir los mandatos de género de su tiempo y que no esté interesada, por ejemplo, en contraer matrimonio. De alguna manera, la imposibilidad de llevar a cabo una vida privada plena o a su gusto, es algo que tienen en común los tres miembros iniciales de la patrulla de Amelia. Sin embargo, es la necesidad de conocer su propia historia, de dotar su vida de relato, la que le da motivos para creer en la bondad de personajes como Lola Mendieta (1x03), a quien los dirigentes del ministerio dan a conocer como una desertora.

Sin embargo, el cara a cara entre Amelia y la ex agente del Ministerio le permite a la primera conocer las motivaciones de la segunda para querer materializar unos presuntos pactos con los mandos nazis, hecho del que se le acusa desde la institución del Tiempo. Lola confiesa a la agente de la patrulla que su propósito es que la guerra termine cuanto antes para no causar las muertes y sufrimiento que, con la 
perspectiva histórica a la que permiten acceder las puertas del Ministerio, sabía que se iba a producir de manera irremediable. Podríamos decir aquí que el móvil de Mendieta representa en la pantalla la propuesta de la nueva agenda de los Estudios para la Paz respecto a la necesidad de recuperar los saberes de las mujeres para hacer las paces desde el cuidado y la protección de la vulnerabilidad de la vida (Martínez Guzmán, 2000; Martínez Guzmán, Comins Mingol y París Albert, 2009).

Es precisamente esta escena de interpelación mutua y reconocimiento entre las dos mujeres la que activa la curiosidad de Amelia y su necesidad de conocer su porvenir a través de las puertas. Este deseo lo comparte con su compañero Julián, quien, a pesar de la prohibición expresa de la institución, querrá usar su privilegio de acceso al tiempo pasado para evitar el accidente que causa la muerte de su pareja (1x08). Para su desgracia, Julián descubrirá que es el propio vehículo que él conduce desde el presente y en compañía de Amelia, el que desencadena el atropello de su mujer en el pasado. De esta circunstancia se desprende una lectura que cuestiona la presumible bondad de la institución. Esto es, ya no estaríamos hablamos de si las intervenciones del Ministerio sobre los hechos del pasado tienen la capacidad de remediar la victimización y el sufrimiento colateral de los hechos traumáticos del pasado. A partir de entonces, sabemos que es posible que tales intervenciones sean las que han causado tales víctimas y tal sufrimiento traumático. O dicho de otra manera, podría ser que la misión de mantener la Historia tal y como nos la han contado, en lugar de favorecer una estabilidad social en el presente (lo que Muñoz -2001- denominaría «paz imperfecta»), lo que esté perpetuando sea una estructura social heredada del medievo y los patrones de violencia que las han sustentado sin que importen las víctimas.

Así pues, la cuestión última que plantearía la serie no quedaría tanto en la posibilidad de conocer la verdad respecto a la Historia común del estado-nación, sino a 
la legitimidad de sus estructuras institucionales en tanto que representantes del pueblo y garantes de la seguridad de las personas. En este sentido, la paradoja que reconcome a Amelia tiene su origen en la comprobación, a través de su experiencia, de la imposibilidad de usar las puertas del ministerio, los mecanismos de la institución, en el cuidado de la vida.

\subsection{Recapitulación y discusión de resultados}

\subsubsection{El modelo de feminidad del feminismo institucional}

Como hemos podido observar en las páginas anteriores, todos los personajes femeninos protagonistas coinciden de alguna manera en sus características: son chicas jóvenes, inteligentes, rebeldes y curiosas a la vez que prudentes y sensatas, cariñosas, familiares y con buena (a veces excepcional) posición social. Sin duda, su apariencia física y juventud inicial (cabe tener en cuenta que los argumentos de las series suelen hacer referencia, de uno u otro modo - como veremos más adelante, a todo el ciclo vital de sus protagonistas) juegan un papel muy importante en los procesos de familiarización con esas protagonistas que empiezan a desplazar del centro de la narración a los personajes masculinos en pleno prime time.

El aspecto de la juventud lo podemos leer desde dos perspectivas. La primera, desde el plano psíquico, esta resulta una metáfora de la ruptura y la subversión y de la posibilidad de evolución, de cambio, de aprendizaje. Es decir, la juventud de estas mujeres les abre infinitas posibilidades respecto a su desarrollo vital y su legado social. En lo que respecta a lo físico, la juventud evoca belleza, fuerza (fortaleza, resistencia) y salud, aspectos que tienen que ver con su capital erótico y reproductivo. Con todo, nuestras protagonistas encarnan una suerte de lolitas del siglo XIX que ya no 
superan la infancia asociada a la feminidad, no solo a través de la liberación sexual, sino también de la intelectual.

Su posición social (vinculada a la burguesía, la nobleza o la aristocracia) les facilita el acceso a una formación avanzada o especializada que subvierte las condiciones de género y clase social presentes en el tiempo diegético y las convierte en prototipos de mujer empoderada del feminismo socialista de nuestro tiempo: mujer heterosexual trabajadora capaz de romper techos de cristal y progresar a escala social gracias a sus capacidades. El acceso al conocimiento dejará de ser solo un dispositivo para la liberación y será entendido también en términos de capacitación profesional que pone en discusión la superioridad masculina en términos intelectuales y subvierte las normas de la división sexual del trabajo. Esa notoria formación que caracteriza las protagonistas viene también a callar el argumento misógino sobre las «mujeres florero» en lo extradiegético y a defender el sistema de cuotas de género en los espacios de toma de decisiones públicos y privados como una cuestión de justicia.

Por otra parte, los demás personajes femeninos en los que también hemos reparado, funcionan como contrapunto semántico al canon de mujer empoderada. Este abanico de prototipos femeninos que se nos presentan bien acompañando, bien antagonizando a las protagonistas ponen en escena diversas maneras de performar la feminidad (de llegar a ser mujer, recordando de nuevo a Beauvoir). Esta diversidad nos inspira el concepto de diferencia, no solo con respecto de la masculinidad sino también respecto a la idea de feminidad perfecta (adecuada al marco desde el cual el feminismo institucional proyecta una sociedad igualitaria ideal) que nos inspiran las protagonistas.

Así, estos personajes femeninos secundarios nos hablarán de la imperfección y, por tanto, del conflicto. O sea, que representan las feminidades que resultan conflictivas a ojos de la audiencia, ya sea por modernas o por desfasadas, en un 
contexto regido por el marco de igualdad formal que clama por un tipo de mujer empoderada, pero que a su vez teme que esta resulte demasiado desafiante. Esto es, los argumentos de las series legitiman el hecho de que una mujer ocupe el espacio de lo público y participe en los procesos de toma de decisiones en casos muy concretos: para estudiar, para reclamar los derechos de las mujeres, para trabajar en la administración pública o para gestionar negocios familiares. En estas circunstancias no se cuestiona la bondad e inocuidad de su feminidad, ya que no causaría conflictos más allá de los que pudieran verse motivados por esquemas de pensamiento misógino. De hecho, son estos esquemas los que vienen a ser cuestionados por este tipo de relatos, los que impiden un reparto igualitario de poder amparados en un sistema de creencias patriarcal, en lugar de por una cuestión de meritocracia.

En este sentido, personajes como los de Vicenta en LS, inspirarán desasosiego en tanto que simbolizan y promueven la permanencia de las estructuras patriarcales e inducen sensación de culpa a través de las continuas muestras de desaprobación ante las acciones o actitudes de personajes como Victoria o Encarna cuando estas desafían las normas del sistema sexo-género de su tiempo. En el lado opuesto, nos encontramos con feminidades como las de Amparo en 14ALR y Lola en EMDT que desafían incluso la propia subversión de los personajes principales y ponen en escena cuestiones como el conservadurismo/ o la heternormatividad en la que se desenvuelven esas mujeres que se nos presentan como «adelantadas a su tiempo».

\subsubsection{La evolución argumental y la relación entre género y memoria}

La estructura que hemos seguido a la hora de presentar las series en nuestro análisis no responde solamente, que también, al orden cronológico de aparición en 
pantalla sino que apreciamos en sus argumentos un cambio de tendencia que va, en primer lugar, a evidenciar la distinta postura ideológica de los gobiernos que se suceden respecto al lugar político de la mujer en la sociedad. En este sentido, la voluntad por seguir las directrices europeas y hacer de la categoría de género un eje transversal desde el que hacer política y, a su vez, transformar los imaginarios sociales, queda patente en esta primera tanda de series protagonizadas por mujeres en las series de la televisión pública estatal. Así, hemos visto como desde el lanzamiento de La Señora existe una tendencia a incorporar en la ficción los elementos de la discusión política y filosófica que constituyen los ejes de debate en los que se basan las políticas feministas de Estado coetáneas.

En este sentido, se aprecia una clara tendencia a denotar en el texto audiovisual lo injusto de las normas sociales de género que perpetúan el orden social patriarcal, así como su carácter anacrónico. El hecho de representar las problemáticas actuales que limitan la libertad de las mujeres como posibles y coherentes en tiempos anteriores (anteriores incluso a la Guerra Civil, período de la Historia de España identificado como «oscuro» por los líderes sociales actuales) incrementa la sensación de anacronismo y de no correspondencia de las normas de género con los tiempos de la democracia, en los que sí que se reconocen los derechos fundamentales de las mujeres, esto es, los tiempos de igualdad formal (De Miguel, 2015).

El salto argumental hacia el spin off de la serie anterior, 14 de abril. La República, hereda el carácter reivindicativo de La Señora, pero deja de lado el discurso tipo soft-feminism, así como la ambientación bucólica rural y el tono autocompasivo que, también hay que decirlo, le insufla el género dramático al que pertenece. En este caso, consideramos que se aprecia mejor el sentido político del término memoria. Así, veremos cómo el personaje de Encarna consigue imbricar la experiencia de su 
feminidad en su conciencia de clase y apela al legado de las mujeres en su defensa del sufragio femenino, dejando constancia -tanto en el espacio diegético como en el plano espectatorial- de ese aprendizaje en lo que a transformación de conflictos inspirados por el orden de género se refiere. Precisamente lo que nos resulta interesante de esa transformación de los conflictos es que es en esos espacios donde se subvierten las violencias y las victimizaciones $\mathrm{y}$, por tanto, donde se representa a la mujer como superviviente y no solo como sufriente de esas violencias.

La cuestión de la supervivencia en esta serie, que irá de la mano de la representación de los afectos entre mujeres y, enmarcados en estos, de las experiencias de sororidad, resultan de vital importancia desde un punto de vista de la reconstructivo. Así, la cuestión de la memoria se centrará en la tarea de la recuperación de un matrilinaje político que no irá necesariamente condicionado por un tipo de representación re-victimizadora de la mujer, sino que el audiovisual apostará por relatar experiencias de resistencia o de paz imperfecta verosímiles en los que la vulnerabilidad de las mujeres no tiene un carácter intrínseco al sujeto sino que viene motivado por la falta de garantías estructurales que se sostienen en el orden cultural de género.

Siguiendo con el caso de 14ALR, del personaje de Encarna y de los espacios de afectos entre mujeres, también resulta interesante la apuesta por visibilizar la homosexualidad no solo como opción personal sino como lugar de reafirmación de la militancia al ser construida a modo de metáfora entre las relaciones de la época entre el socialismo, el comunismo y el anarquismo. La naturalidad con la que Encarna se encuentra corporalmente con Amparo y la ausencia de voces que problematizan necesariamente la sexualidad lésbica en la pantalla, hacen que el tiempo de la diégesis (la II República) sea percibido como un espacio seguro para el ejercicio de la libertad afectiva. 
Otro aspecto relevante que plantean ya las dos series y que enlaza con la cuestión de los afectos, la sororidad y la colaboración entre mujeres, tiene que ver con la representación de la familia. Ya originariamente, se nos presenta una casa Márquez marcada por la ausencia de las figuras materna, primero, y paterna, después. Esto es, se trata de una familia sin modelos claros a seguir, en la que la crianza se sostiene gracias a las trabajadoras del hogar, con las que existe la complicidad afectiva que diluye la sensación de la diferencia de clase. En todo caso, ese apoyo entre mujeres, condicionado -no lo olvidamos- por la relación «laboral», también pone de relieve la importancia de tener cubierta la necesidad de los cuidados (sean o no remunerados) para el desarrollo personal y profesional de las personas, independientemente de su género, pero especialmente en el caso del género (y clase, si es que lo podemos separar en algún momento) al que le han sido asignadas culturalmente esas tareas.

Posiblemente sea el lugar de la mujer en la familia y las paradojas con las que se encuentra a la hora de querer desarrollar otros aspectos de la vida que no pasen por la pareja y la crianza el asunto del debate feminista del momento que vuelve a problematizarse con más fuerza en Isabel. Bajo nuestro punto de vista, esta serie, en su intento por resignificar personajes femeninos de la mitología nacional española, supone un giro conservador en la evolución o complejidad argumentativa que habíamos podido apreciar en el caso de 14ALR. Debemos tener en cuenta que lo que se nos representa en la pantalla es, al fin y al cabo, la figura de la madre patria y que esa metáfora acaba necesariamente problematizando en la ficción las cuestiones que rodean a la maternidad en su conjunción con el Estado: esto es, su relación con las instituciones y el rol de la mujer como sostén de ambas.

En último lugar, hemos situado el relato audiovisual más reciente que conjuga las categorías de mujer y memoria, El Ministerio del Tiempo. Este nos propone 
ya desde un primer momento dar un paso más allá y no abogar simplemente por la presencia del legado femenino (o no exclusivamente masculino) en la Historia si no por las implicaciones reales de aplicar tal perspectiva feminista al relato oficial. Esto es, EMDT nos invita a pensar en cómo puede influir esta mirada a la hora de concebir el relato de lo común, de las identidades modernas, porque el hecho de revisitar los episodios del pasado común desde la diferencia de género, hace también visible otras diferencias y complejizan el concepto de víctima y de poder, entre otros. Esta idea entroncaría con los principios epistemológicos de la Filosofía para Hacer las Paces (Martínez Guzmán, 2000; 2001; Martínez Guzmán, Comins Mingol y París Albert, 2009).

En resumen, en la sucesión de series escogidas, nos encontramos con un abanico de prototipos de mujer que enriquece, desde el plano espectatorial, el imaginario respecto a las posibilidades de empoderamiento femenino, la vulnerabilidad o la sororidad. Si a esto le sumamos además el componente de la ambientación historicista en todas ellas, observaremos que los relatos que hemos seleccionado son pequeñas piezas con las que confeccionar una memoria de tipo matrilineal que se nutre de las historias particulares de resistencia y supervivencia de esos personajes femeninos. Es decir, estas series recrean en la ficción una amalgama de experiencias (ya sean más cotidianas o más extraordinarias) vividas desde la feminidad y con una perspectiva histórica verosímil que aspira a ser compartida por la audiencia de la televisión pública.

En contra de lo que hemos podido oír en algún foro académico a este respecto, este fenómeno poco tiene que ver con un simple, casuístico y/o creativo boom comercial de series de/para/con mujeres; tampoco con un supuesto gusto apolítico por lo antiguo y lo nostálgico. La perspectiva de género histórica se inserta en la narrativa audiovisual del momento porque es el propio momento el que pide este tipo de 
protagonistas, ambientaciones y relatos, como ya venimos apuntando a colación de la contextualización histórico-política de nuestro corpus de estudio. Así pues, en el análisis que hemos llevado a cabo, hemos tenido especialmente en cuenta los mandatos que se promueven tanto a nivel nacional como internacional (los primeros motivados también por los segundos) en materia de reconocimiento y justicia reparativa. Dentro de estas líneas se sitúan las políticas de igualdad de género y de recuperación de la memoria histórica, promovidas durante las legislaturas estatales presididas por el socialista José Luís Rodríguez Zapatero, con las que hemos vinculado el contexto de las series.

Así, podemos ver que existe un recorrido paralelo entre la caracterización de las protagonistas de los relatos audiovisuales que hemos presentado y la asimilación de los discursos contra la violencia de género y por la igualdad efectiva entre hombres y mujeres. Hemos podido dilucidar que, al inicio, el prototipo de mujer que resulta sujeto del debate feminista y sobre el que se articula el discurso del empoderamiento es el que más se aproxima al paradigma de la víctima que no se reconoce como tal (violencia psicológica) por su situación de no-dependencia económica respecto al hombre que la acompaña. En todos los casos y, especialmente, alrededor del personaje de Encarna vemos como se introduce la idea de la sororidad como estrategia feminista contra las violencias (directa, estructural y cultural) de género y, con ella, la idea de que la nocompetencia entre mujeres hace más potente el proceso de consolidación de los derechos en un marco de igualdad incipiente (caso del tiempo diegético) y efectiva (caso del tiempo de producción, emisión y recepción original de las series).

Siguiendo con lo anterior, el caso de Isabel implica la recuperación de un mito nacional a través de la resignificación de la madre patria como mujer de/en el poder desde el paradigma neoliberal. En su argumento podemos ver un salto ideológico en consonancia con los tiempos de emisión que abarca tanto la crisis del discurso del 
empoderamiento femenino (personal y profesional) individual imperante en la etapa socialista y el posterior modelo de igualdad neoliberal que resalta de nuevo los atributos de la feminidad tradicional, muy ligados a los conceptos de maternidad, rectitud y sufrimiento. Nos resulta llamativo en esta serie que, a partir de la segunda temporada, la violencia esté ejercida por parte de esa mujer en el poder en nombre de la nación que, valga la redundancia, nace, y cómo este factor aleja al personaje de los presupuestos feministas de solidaridad y cooperación entre géneros y clases. La encarnación del poder del estado en el cuerpo femenino, parece justificar, en el peor de los casos, o banalizar, en el mejor, las no tan bondadosas maneras del imperialismo occidental.

Y finalmente, en este choque entre el discurso victimizador y bondadoso acerca del empoderamiento femenino, la necesidad de la participación de la mujer en los espacios de decisión política y las violencias que emergen del análisis interseccional, nos encontramos a la mujer de la academia, a Amelia Folch de EMDT, quien se preguntará por las violencias que perpetúan los privilegios y el poder de unos estados sobre otros, de unos individuos sobre otros. Esta se acabará apartando de la institución del tiempo, que perpetúa el sufrimiento en nombre de una nación, poniendo de relieve la necesidad de feminizar los espacios públicos y transformar las decisiones políticas desde el prisma de los cuidados. De otra manera, la mujer en la institución no es más que cómplice de los juegos de poder y violencia de las estructuras patriarcales. 


\section{Conclusions}

This final section of the thesis will be used to summarize and reflect on the most important points of our analysis that corroborate our initial hypothesis and also to propose some lines of research related to the perspective and object of study that has motivated our work. To do this, it is necessary to return to our starting point, which is situated in the academic legacy of the UNESCO Chair of Philosophy for Peace at UJI. Within this area, we focus on the line of research relating to Communication and Peace Education and propose an area of study related to Communication for Social Change from a gender perspective. Within this field we chose to focus on the analysis of the topic of popular culture. More specifically, we focused on fiction series from Spanish public television, since our cultural premise is that the media and the stories they produce are symptomatic of the social conflicts from their context. In the case at hand, the conflicts that articulate these stories are related to the situation of women in the public sphere and from a historic perspective in the Spanish state. Concretely, the objective of the thesis was to analyze how our TV dramas had narrated the place of women in Spanish history by reading it against the contemporary political debates on gender and memory where they emerged.

In this sense, we have had to identify the debates of the public agenda that conform the production and reception context of the series that we have chosen to study. Thus, we have paid close attention to three of the pillars that form the legislative framework set during the two terms served by the socialist José Luis Rodríguez Zapatero, from the PSOE political party (2004-2008 and 2008-2011). The first one focused on dignifying the public media service implementing best practices through the Spanish Radio and Television Law (2006) and the General Law of Audiovisual 
Communications (2010). The second pillar was the bid to recover the Historical Memory (2010). The final pillar was related to the institutional measures addressed to deal with Male Violence against Women (2004), which were subsequently developed in a positive and holistic way with the implementation of the Ministry of Equality and the enactment of the Gender Equality Law (2008), and the approval of the Same-sex marriage law (2006).

However, with regards to this description of the political and historical background in which the series are created, we have not limited ourselves to listing events but have endeavoured to theorize the symbolic significance of the milestones in relation to which the plots, the characters and the actions of the main characters acquire meaning. In this vein, the question considered as an overall result of the thesis is that these narratives are symptomatic of a stage of formalizing gender equality and accountability with the silenced victims of democracy and that both issues (gender equality and memory) acquire a symbolic depth that stems precisely from gender mainstreaming.

More specifically, the most important contribution to this thesis has consisted in establishing an organizational principle for the materials studied. In our analysis, we contend that the series have reworked the imaginary of the democratic identity from the socialist feminist institutionalized agenda, which entails cutting across the categories of women and memory. As a result we identified the following central themes:

Firstly, women are presented as the protagonists of democratic memory from the convergence of two profiles: the liberal bourgeois (the entrepreneur Victoria Márquez, from La Señora) and the socialist (with the character of the suffragette Encarna Alcántara from 14 de abril, La República). This encounter of profiles equates 
to the ideal of the political woman of the extradiegetic present (2008-2011) and is placed as a genealogical precedent prior to the dilemmas of female power in the story (Isabel) and the profiles of institutional empowerment in the present day (Amelia, in $E l$ Ministerio del Tiempo) which we appreciate after the conservative shift in the plots (2011-2017). So, what we see here is a diegetic categorization of the model that precedes the figure of the woman in democracy(which is not only setting the standard for the woman but, at the same time, for what a democratic society should be like if imagining its values from the non-male heteronormative viewpoint). These types of women act as "mnemonic" references for women in contemporary (extradiegetic) democracy.

After the aforementioned, in second place we then focused on how the storylines problematize the relationship between femininity and power, without losing sight of the aspect of memory. What we analysed was the relationship between the personal and political conflicts of the diegetic space and time with the feminist debate of the extradiegetic space and time, related to the concept of empowerment in the context of narratives against gender violence. In this regard, the finding we consider most interesting is that the storylines contribute creative solutions that break the cycle of representing revictimized women and with the idea of empowerment as an individual process. What we find in the scripts are actions in the form of fictionalized caring experiences that evoke female emancipation from a sustained collective project of what they have in common. In this way, plots resolve the problem of revictimizing women (as in the case of Victoria in LS) through the proposal of collective resistance. Fiction ceases to dwell on the pain of the individual victim to allow space for the representation of individual or collective protection and survival strategies. By doing so they invite 
reflection on the structural and cultural scope of patriarchal violence (contribution from the character Encarna in LS and 14ALR).

This bid to portray resistance through female characters and the transformation of violence in general, acquires a genealogical sense due to the historic nature of the series. In this way, the storyline of 14ALR refers to the suffrage movement and to the political matrilineal tradition. Subsequently, this matrilineality will become mythological in Isabel, in line with the model of neoliberal feminism. Finally, and in response to this discourse of the empowered superwoman, the storyline in EMDT emerges, showing the perversions of the official versions in history.

Bearing this in mind, the female protagonists of the storylines analysed interest us particularly due to the dialogue they establish with the context in which they are produced, which also coincides with the context of reception. It is for this reason that we needed to look into the discursive framework about violence against women, gender equality and empowerment set by the Spanish institutional feminist movement during the socialist Zapatero term and which is marked by the conflict of women of the left's political significance since the democratic transition. The hegemonic feminist viewpoint focuses considerably on educating and identifying the obstacles that being female has imposed on women for their incorporation into public life and decision making processes. Thus, it underscores debates such as the cultural aspect of male violence against women (and its effects), the glass ceiling or the invisibility of female references in male-dominated fields, which we also see portrayed in our television narratives.

We have observed firstly that the series LS, 14ALR, Isabel and EMDT seem to have transformed this cultural conflict related to the void (or to the significant lack) of female references in history in a context (the current one) that claims the presence of 
women in all areas of civil society. The emergence of stories such as those starring Isabel, Encarna, Isabel la Católica or Amelia, respectively, in prime time on public television portrays the moment of political and social transformation that was led in this past decade by feminism and the mainstreaming of its agenda to the highest institutional spheres. Furthermore, in the case of Spain, this agenda cuts across the promotion of policies to recover the historical memory which also leads to the emergence in these series of a need, marked by both the feminist and the socialist agenda, to transform the issue of patriarchal cultural violence from a genealogical perspective so that the systematic (and systemic) silencing of the female narrative in history is compensated. More specifically, it could be said that apart from illustrating the mainstreaming of feminism by the State, it amounts to accountability with regards to the women of dual socialist militancy who during the democratic Transition were invited to set aside their vindications for another time in the interest of the reconciliation of the "two Spains".

This type of narrative, founded on the premise of historic plausibility uses the cultural sphere as a space from which to set forth, deconstruct and discredit the patriarchal violence through the portrayal of a wide range of symbolic, structural and direct cases of violence towards a wide range of feminine characters throughout history. Accordingly, offering a feminine narrative told from the female viewpoint also gives visibility to cases of symbolic, structural and direct gender-based violence, which, without the conceptual framework that starts in the period of mainstreaming the feminist agenda, would not have possibilitated a diachronic reading of such cases of genderbased violence. Therefore, we conclude that these series form part of a discursive continuum that opens up the possibility of encoding and reading in another sense the mainstream representational legacy about women in general and more specifically women in the democratic history of the nation-state. 
However, it goes beyond that since not only femininities historically affected by patriarchal violence are represented, but also fictionalize ways of transforming these types of violence. Thus the women who star in the stories we have analysed develop resistance strategies that allow them to survive and subvert their own symbolic limiting conditions, structural injustices or physical, sexual and psychological violence. The importance of this aspect is crucial if seen from the reconstructive perspective of the new agenda of Peace Studies and if we recall the principle of the mnemonic imagination, according to which we can only imagine from what we already know. In this respect, these television stories present a possibility of accessing the knowledge (memories) of women made invisible, erased or simply not included in the history of democracy.

This is so because, after all, these stories are exercises of counter-hegemonic (rather than counter-cultural) creativity that move the traditional locus of enunciation and reconstruct situations of empowerment that finally broaden existing frameworks of reference/recognition to models of women from the past that were missing from the national collective imaginary until now.

Along these lines, we propose that the life projects of the young women who star in the series contribute, from the popular culture of television, a specific genderbased perspective to the history of the Spanish state, particularly with regards to the years prior to the Civil War. The 1920's and early 1930's were characterized, in addition to the class struggle, by the power struggles between the bourgeois and caciques which caused both the progressive policies of the Second Republic and the military reactionary coup of ' 36 . What is interesting is that, on the other hand, a national-catholicist myth, Queen Isabel I de Castilla, is also characterized as a young progressive woman in favour of the politics of democracy in an attempt to establish an 
analogy between this figure and the female ministers of the socialist Zapatero era and to attribute the feminist tradition to a sort of matrilineage with a Spanish national seal.

This break with the masculinised version of history recognizes women as part of the common narrative of national identity and its complexities. But at the same time, that recognition implies a symbolic compensation or accountability not only to the invisibilized women of the past but also for current generations of citizens, regardless of their gender. To stop talking about political transitions, winners and losers, and to face the challenges of our time, citizens need to fill the gaps in their common narrative. Otherwise, until then, all the policies will have been undertaken from a perspective marked by the prejudices of a common biased identity that only serves the needs of the traditionally powerful sectors, which are the same ones that have had access to the control of the means of producing meaning (education and media).

On the other hand, given the political motivation demanded and promoted by the type of narratives we have analysed, we have seen that this patriarchal biased history-break makes use of women's profiles that, from the outset, are not very threatening to the status quo. In other words, the leading TV actresses of this historical complexity share common traits such as their youth, intelligence and tender disposition and it will be from that profile from which they will perform their position of resistance to oppression. We assume that in some way this creative choice responds to a strategy that aims to break down the prejudice of female malice and, consequently, make it easier for the discourse to be more accepted by general audiences.

The interesting point about these proposals, therefore, are the new axes from which this alternative model of femininity arises and the biases that it continues to reproduce or ceases to reproduce. What we have seen is that this new proposal involves offering narrative weight to young girls whose vulnerability does not place them at the 
level of the victim, but rather provides them with a meeting point, a link with their peers, with whom they articulate their resistance activities in presumably more unfavourable structural contexts. We are therefore faced with cases of recognition of the others, whose narrative perspective is included from a desire for horizontality and genealogy. This, in the moment of mainstreaming of feminism, raises two fundamental ideas for the advancement in the implantation of an egalitarian society in terms of gender: the first has to do with the question of having the capacities for public and private management; the second with the fracture of the democratic history narrated from the hegemonic left of the Spanish state, since the plots constructed by and for the protagonists function as testimonials of those other histories that do not figure in the collective memory, the histories of resistance, in general, and of women in particular.

We could conclude that the fact that the audience has female empowered referents, that do not only respond to ideal women of the neoliberal era (the superwoman), but that are also constructed from the paradigm of collectivity and democratic lineage, complicates the possibility of power, survival and governability (not only by women) in our present. These fictional stories give voice to the space of the silence where the female version of the memory of resistance has been relegated to. They also indicate that those women have always been among us. They were our grandmothers and mothers. Today they are sisters. We understand that patriarchal culture has maintained certain models of femininity invisible when political times required another type of woman. What we find paradoxical is that there is still interest in referring to those profiles of women that we can recognize in our daily life as an exception. In other words, the fact that the intertexts with which they dialogue (such as promotions, on-demand contents on the series' official websites or prejudices about the past, which highlight the imposition of gender binarism as outdated) generally present 
them to us as women "ahead of their time" does not fail to point out to the audience that these models of femininity are an exception from a time gone by.

Nor can we make a trivial interpretation of the question of the choice of space on the TV schedule to broadcast this type of story. As we have pointed out, the series starring women have traditionally existed and were scheduled in the after lunch slot, following in the wake of the programming of radio soap operas, whose advertising space were aimed at housewives who at that time remained at home. The fact that during the last decade there has been continuity in programming stories starring women in prime time on public television denotes that the plot is considered of general interest and that, therefore, they are also of interest to the male target.

\subsection{Closure and starting point for future research}

As we have seen, this thesis has focused on analysing how the characters and plots of public television historicist fiction symptomize the debates around the frameworks of recognition of structural and symbolic violence conditioned by the gender factor. The mainstreaming of state feminism in the last decade has devoted significant efforts to analysing the socio-economic causes that make it difficult for women in the last century to translate acquired citizenship rights into real life improvements. In other words, from the Peace Studies perspective, we would say that positive peace, though imperfect, is not contributing to reduce women's suffering, but is giving it other nuances or, at least, suffering can be analysed bearing in mind other factors.

Somehow, this is what the audiovisual narrations we have studied demonstrate. As seen, they imprint a genealogical viewpoint on the question of gender- 
based violence inviting us to deconstruct present cases of violence by recognising past violence. In this way they invite us to reconsider the structure of patriarchal thought (symbolic violence) as anachronistic and how it sustains a binary social division based on gender that conditions the access of non-hegemonically-masculine subjects to welfare. Thus, this conception would include not only heterosexual cisgender women but also homosexual men and women, transsexual people and any fluid or queer manifestation of gender and their sexuality.

It is a fact that over the years in which this thesis has been written, audiovisual products similar to those analysed here have multiplied. Therefore, those analysed are just four examples of a trend that is still present nowadays on Spanish television on both public and private channels. Historic series starring women have been particularly prolific, although on some occasions the question of their plausibility has less weight. We maintain that the extensive list of women who appear in various Spanish series continues to grow in episodes of the History of $20^{\text {th }}$ century Spain and that they provide interesting reflections on the issues of the first and second wave of feminism from a genealogical perspective. This is the case of series similar to those we have analyzed in our thesis, such as El Caso. Crónica de Sucesos (La 1: 2016-?) and La otra mirada (La 1: 2018-?).

As we have seen, the rise of feminism and the mainstreaming of gender equality policies in the Spanish state during the last century led to the appearance of a public media space in which the issues of feminist debate took the prime time of the television audience. Also this phenomenon has been sustained over the last decade regardless of the political party in power and the reflections that they have provoked in the media and academia. 
So, what we have found are stories that make an approach to patriarchal violence from the perspective of institutionalized feminism and with a genealogical intention. The portrayal of this feminist matrilineage, however, is necessarily biased by the particular view of the socio-economic background of the privileged female protagonists. Let us remember that the history of feminism itself and of women in particular has been marked by those (albeit a few) who have had access to the means of producing knowledge. Therefore a logical evolution of this study would lead us to review the format of the state or regional television serial that permits a more intersectional approach to the hegemonic gender perspective.

We must bear in mind that, as academic (especially from Humanities and Social Sciences) and activist discussion incorporates intersectional axes in its analysis and complicates the debate on gender equality, the discourse on equality becomes less ethereal and more attentive to issues of direct violence crossed by different intersectional inequalities and violences.

Hence, the institutional public discourse about violence against women is being challenged. Slogans such as \#YoTeCreo \#HermanaYoSíTeCreo \#TranquilaHermanaAquiEstáTuManada \#NoEsAbusoEsViolación present at the rallies, convened in a few hours by feminist groups of all types across the State (after the public announcement of the sentence), highlight the importance of the take-up and resignification of concepts by women, the need to define the present realities (and not only those past), due to a question of security, citizen justice, self-care and individual freedom from an intersectional perspective.

Curiously, months before the multiple rape was perpetrated at San Fermín, in March 2016 the first and only season of El Caso. Crónica de Sucesos was broadcasted. This series seemed to start again from that revisionist spirit that 
characterises the cultural objects that have formed part of our study. However, this time it focused precisely on the process of investigation and narration of the events with female victims and the journalistic style used to tell the stories which goes hand in hand with the public arena where the feminist movement (particularly through the cases of La Manada and the echos of the \#MeToo movement in Spain), is questioning precisely the enunciation frameworks through which gender violence has been institutionalized politically and mediatically. On a different note, just the day before the media released the court sentence for the wolfpack (la manada) case, the series called La otra mirada, was premiered about a feminist professor in the 1920's who worked at a women's residence, on issues that are related not only to the revival of notable female academics, but also with the question of sexual violence, consent and the chauvinist story that the legal institution constructs regarding violence against women's bodies.

Thus whilst the audiovisual stories set in the atmosphere of the heyday of socialist institutional feminism invited us to revisit matrilineal resistances from the essential pacifism of the resistances of the protagonists (which does not challenge the white male privilege of the ruling class, but tries to live alongside) and to rethink and discuss the gender order as a necessary step for the eradication of direct violence against women, the most current frameworks are concerned with how to give account of such aggressions and murders in a country which is an international referent in terms of gender equality legislation.

In this sense, as a line of future research, it would be interesting to carry out, from these new frames of reference (opened up by demonstrations against male violences against women such as the one on November $\left.7^{\text {th }} 2015\right)$, an analysis of these series. Finally, this, in turn, might take us to broaden the implications of accountability because it could lead us to discuss the chiaroscuros of how feminism has dealt with 
violence against women diachronically and synchronically and, moreover, the state's role in considering past gender violence crimes as prescribed offences. 


\section{BIBLIOGRAFÍA}

Amiguet, Teresa (2014): «Concepción Arenal, la visitadora de prisiones» en La Vanguardia. Recuperado de https://goo.gl/JMmN6s [último acceso: 21/05/2018]

Amorós, Celia (1985): Hacia una crítica de la razón patriarcal. Barcelona: Anthropos.

(2000): Feminismo y Filosofia. Síntesis: Madrid

ANTENTAS COllderam, Josep MARIA (2013): «La indignación, tras la explosión inicial. El 15M en Catalunya durante 2012» en Observatori del Conflicte Social: Anuari del Conflicte Social, n.2. Barcelona: Universitat de Barcelona, 263-274. Disponible en: https://goo.gl/J5wylu [último acceso: 21/05/2018]

ARÓStegui, Julio (2009): «La Ley de Memoria Histórica: reparación e insatisfacción» en Patrimonio Cultural de España, 1 (Conservar o destruir: la ley de Memoria Histórica), 41-60. Disponible en: https://goo.gl/cQuK42 [último acceso: $21 / 05 / 2018]$

Austin, John Langshaw (1971): Palabras y Acciones. Cómo hacer cosas con palabras, Buenos Aires: Paidós.

(1975): Ensayos Filosóficos, Madrid: Revista de Occidente.

BANDRÉS, ELENA (2011): «Propuesta para el tratamiento eficaz de la violencia de género» en Revista de Comunicación Vivat Academia, 116, 19-39. DOI: http://dx.doi.org/10.15178/va.2011.116.19-39 [último acceso: 21/05/2018] 
MARTín BARBERO, Jesús (1987): De los medios a las mediaciones: comunicación, cultura y hegemonia. Barcelona: Ed. Gustavo Gili.

BeAuvoir, Simone (2005 [1949]): El segundo sexo, Madrid: Cátedra.

BERNECKER, WALTHER L. (2003): «España entre amnesia y memoria colectiva. Guerra Civil, Transición, Reconciliación» en Estudios Políticos, 23, 55-78.

Boulding, Elise (1995): «Feminist Inventions in the Art of Peacemaking» en Peace and Change, 20(4), 408-438.

(2000): Cultures of peace: the hidden side of history. Syracuse, N. Y.: Syracuse University Press.

Brock-Utne, Birgit (1987): Educating for Peace: A Feminist Perspective. Nueva York, Pergamon: Teachers College Press.

(1989): Feminist Perspectives on Peace and Peace Education. Nueva York, Oxford, Frankfurt: Pergamon Press.

(1990): «Feminist Perspectives on Peace», en Smoker, Paul et al. (eds.): $A$ Reader in Peace Studies. Oxford: Pergamon Press, 144-150.

Butler, Judith (2009): Dar cuenta de sí mismo, Buenos Aires: Paidós. Selección.

CANDÓn Mena, José (2013): Toma la calle, toma las redes: El movimiento 15M en Internet. Sevilla: Editorial Atrapasueños. Disponible: https://goo.gl/tU1DGX [último acceso: 21/05/2018] 
CASCAJOSA VIRINO, CONCEPCIÓN (2013): «La chica de ayer: memoria y desmemoria televisivas de la Transición en España» en Journal of Spanish Cultural Studies, 13(3), 260- 275. DOI: 10.1080/14636204.2013.788913

(2017): «Tiempos difíciles, mujeres protagonistas: la obra televisiva de Virginia Yagüe» en Investigaciones Feministas, 8(2), 385-400.

Castillo Mateu, Laura (2015): «Yo narro, luego Yo decido. El tren de la libertad» en Nos Aldás, Eloísa; Arévalo Salinas, Álex Iván y Alessandra Farné: \#Comunicambio Comunicación y Sociedad Civil para el Cambio Social. Madrid: Fragua.

(2018): «Revisiting gender discourses: cultural practices to eradicate patriarchal violences Feminist Activism and the Role of Memory in Revisiting the Discourse on Gender Violence in Spain» en Gámez Fuentes, María José y Rebeca Maseda (Eds.): Gender and Violence In Spanish Culture: From Vulnerability to Accountability. New York: Peter Lang.

Chicharro Merayo, Ma Del Mar (2009): «Recreando la sociedad del pasado: modernización y conflicto social en La Señora» en Análisis, 39, 51-70.

Comins, Irene; PARÍs, Sonia y Vicent Martínez GuZMÁn (2011): «Hacer las paces imperfectas: entre el reconocimiento y el cuidado», en Muñoz, Francisco A.; Muñoz, Manuel y Jorge Bolaños (coords.): Los hábitus de la paz: teorías y prácticas de la paz imperfecta. Granada: EUG, 95-122.

Confortini, Catia C. (2006): «Galtung, violence and gender» en Peace\&Change, 31(3), 333-367. 
CORBALÁN, ANA (2009): «Reconstrucción del pasado histórico: nostalgia reflexiva en Cuéntame cómo pasó» en Journal of Spanish Cultural Studies, 10(3), 341-357. DOI: $\underline{10.1080 / 14636200903186897}$

CRUZ, JACQUELINE Y BÁRBARA ZECchi (2004): «Más que evolución, involución: A modo de prólogo» en Cruz, Jacqueline y Bárbara Zecchi (eds.): La mujer en la España actual. ¿Evolución o involución? Barcelona: Icaria, 7-24.

De Grado, Mercedes (2004): «Encrucijada del feminismo español: disyuntiva entre igualdad y diferencia» en Cruz, Jacqueline y Bárbara Zecchi (eds.): La mujer en la España actual. ¿Evolución o involución? Barcelona: Icaria, 25-58.

De Miguel, Ana (1995): «Los feminismos a través de la historia», en Amorós, C. (ed.), Diez palabras clave de feminismo, Estella: Verbo Divino, 93-126. Disponible online en: https://goo.gl/rzteKZ, https://goo.gl/dAznba, https://goo.gl/JGmdjP y https://goo.gl/LucEDk [último acceso: 19/06/2018]

(2015): Neoliberalismo sexual. El mito de la libre elección. Madrid: Cátedra.

EgUZKI, URTEAga (2009): «Las políticas de discriminación positiva» en Revista de Estudios Politicos (nueva época), 146 (octubre-diciembre), 181-213.

Falcón, Lidia (2000): Los nuevos mitos del feminismo. Madrid: Vindicación Feminista Publicaciones.

Fernández Navarrete, Donato (2016): «The Spanish Economic Crisis: A Huge Speculative Operation with Serious Consequences» en Estudios internacionales (Santiago), 48 (183): 119-15. 
FIELD, BonNIE N. (2011): Spain's “Second Transition”? London: Routledge.

Forastelli, Fabricio (2013): «Peace Profile: Vicent Martínez Guzmán» en Peace Review: A Journal of Social Justice, 25(3), 439-446, DOI: $10.1080 / 10402659.2013 .816573$

Foucault, Michael (2002[1977]): «IV. El dispositivo de la sexualidad», Historia de la sexualidad, I: La voluntad de saber, Buenos Aires: Siglo XXI, 112-139. SỆ.

FrANCÉS, M. ÀNGELS (2015): «Associacionisme i visibilitat: reivindicacions feministes en la transició espanyola» en Mañas Viejo, C. et al. (Eds.): I Coloquio Internacional Haciendo Historia: Género y Transición Política 'Transiciones en Marcha', 15-28. Alacant: Universitat d'Alacant.

FriedAn, BetTy (2009 [1963]): La mística de la feminidad. Madrid: Cátedra.

Galtung, JoHAN (1990): «Cultural Violence» en Journal of Peace Research, XXVII(3), 291-305.

GÁMEZ FuENTES, MARÍA José (2002): «Els Estudis Culturals i la crítica als processos i estructures de la comunicació» en Anuari de l'Agrupació Borrianenca de Cultura, 13, 31-36.

(2004): Cinematergrafía. La madre en el cine y la literatura de la democracia. Castellón: Ellago y Universitat Jaume I.

(2012): «Sobre los modos de visibilización mediático-política de la violencia de género en España: consideraciones críticas para su reformulación» en Obets. Revista de Ciencias Sociales, 7(2), 185-213. 
(2014): «Las mujeres en el cine y TV movies españoles (2000-2012): representaciones, sujetos y contextos» en Historia y Comunicación Social, 19, 431-441. DOI: http://dx.doi.org/10.5209/rev_HICS.2014.v19.44968

(2015): «Feminisms and the 15M Movement in Spain: Between Frames of Recognition and Contexts of Action» en Social Movement Studies, 14(5), 359365. DOI: https://doi.org/10.1080/14742837.2014.994492

Gámez Fuentes, María José y AnA M. Rivas (2012): «Feminismo 2.0 y 15-M: cuestionando los cambios en la esfera pública» en Casero, Andreu y Ramón Zallo (Eds.): Comunicación y regeneración democrática. Actas IV Congreso nacional ULEPICC España. Castelló: Ed. Unión Latina de Economía Política de la Información, la Comunicación y la Cultura (ULEPICC), 344-357.

Gámez Fuentes, María José y Sonia NúÑEZ Puente (2013): «Medios, ética y violencia de género: más allá de la victimización» en ASPARKÍA. Investigació Feminista, 24, 145-160.

GOLOB, StePHANIE R. (2008): «Volver: The return of/to transitional justice politics in Spain» en Journal of Spanish Cultural Studies, 9(2), 127141. DOI: $\underline{10.1080 / 14636200802283647}$

Gould LeVINE, LindA (2004): «Feminismo y repercusiones sociales: de la Transición a la actualidad» en Cruz, Jacqueline y Bárbara Zecchi (eds.): La mujer en la España actual. ¿Evolución o involución? Barcelona: Icaria, 59-72.

JiMÉNEZ DÍAZ, JosÉ F. (2011): «Pensamiento feminista en España (1976-2000): debates políticos y controversias sobre la idea de modernidad» en X Congreso Nacional 
de Ciencia Politica y de la Administración, Asociación Española de Ciencia Política y de la Administración (AECPA), Murcia.

Keightley, Emily And Michael Pickering (2012): The Mnemonic Imagination. Remembering as Creative Practice. Palgrave. UK.

Hall, Stuart (1981): «La cultura, los medios y el efecto ideológico», en Curran, James et al.: Sociedad y comunicación de masas. México: Fondo de Cultura Económica.

HANISCH, CAROL (1970): «The personal is political», WLM (Women Liberation Movement) Disponible en: https://goo.gl/usKSEr [último acceso: 21/05/2018]

Haraway, Donna (1995): Ciencia, cyborgs y mujeres. Madrid: Cátedra.

HARDing, SANDRA (1996): Ciencia y feminismo. Madrid: Morata.

Hueso Montón, Ángel Luís (1991): «Planteamientos historiográficos en el cine histórico» en Filmhistoria online, 1(1), 13-24. Disponible en https://goo.gl/eTffF4 [último acceso: 19/06/2018]

LABANYI, Jo (2008): «The politics of memory in contemporary Spain» en Journal of Spanish Cultural Studies, 9(2), 119-125.

Lagarde, Marcela (2006): «Pacto entre mujeres. Sororidad» en Aportes para el debate. Publicado online en: www.celem.org (Coordinadora Española para el lobby europeo de mujeres) 
LAZAR, Michelle M. (2010): «Feminist Critical Discourse Analysis: Articulating a Feminist Discourse Praxis» en Critical Discourse Studies, 4(2), 141-164. DOI: $\underline{10.1080 / 17405900701464816}$

Lederach, John Paul (2010): The moral imagnation. New York: Oxford University Press.

LOBERA, JoSEP Y VÍCTOR SAMPEDRO (2014): «La transversalidad del del 15M entre la ciudadanía» en Serrano, Eunate et al.: 15MP2P. Una mirada transdisciplinar del 15M. Barcelona: UOC, 470-489. Disponible en: http://tecnopolitica.net/sites/default/files/15MP2P_Mayo2014.pdf $\quad$ [último acceso: 21/05/2018]

LOMBARDO, EMANUELA (2003): «La europeización de la política española de igualdad de género» en Revista Española de Ciencia Política, 9(octubre), 65-82.

LOMBARDO, EMANUELA Y MARGARITA LEÓN (2014): «Políticas de igualdad de género y sociales en España: origen, desarrollo y desmantelamiento en un contexto de crisis económica» en Investigaciones Feministas, 5, 13-35.

LÓPEZ DE LA CRUZ, LAURA (2002): «La presencia de la mujer en la universidad española» en Revista Historia de la Educación Latinoamericana, 4, 291-29. Disponible en https://goo.gl/PJX1rt [último acceso: 21/05/2018]

MAGALlÓn PORTOLÉS, CARMEN (2003): «Más igualdad y otros modelos de varón, para erradicar la violencia de género» en Muñoz, Francisco A. et al. (eds.): Actas del I Congreso Hispanoamericano de Educación y Cultura de Paz. Granada: Editorial Universidad de Granada, 395-404. 
(2004): «Mujeres en los procesos de paz: la Resolución de 1325» en Papeles de Cuestiones Internacionales, 87, 97-104.

(2006): Mujeres en pie de paz: pensamiento y prácticas. Madrid: Siglo XXI.

(2007): «Iniciativas de paz de mujeres del Mediterráneo: Bat Shalom, en Israel y Hands Across the Divide, en Chipre», en Martínez López, Fernando y Francisco A. Muñoz (eds.): Políticas de paz en el Mediterráneo. Madrid: Biblioteca Nueva, 245-258. istepi

Martínez GuZMÁn, ViCEnT (2000): «Saber Hacer las Paces. Epistemologías de los Estudios para la Paz» en Convergencia, 23, 49-96.

(2001): Filosofia para hacer las paces. Barcelona: Icaria.

(2002): «Roles masculinos y construcción de una cultura de paz» en Rincón, Ana (ed.): Congreso Internacional: Los hombres ante el nuevo orden social. San Sebastián: Emakunde/Instituto Vasco de la mujer, 135-156.

(2005): «Podemos transformar los conflictos» en Podemos hacer las paces, reflexiones éticas tras el 11-Sy el 11-M. Bilbao: Desclée De Brouwer, 105-137. (2010a): «Cómo pensar la paz: una perspectiva desde la filosofía para hacer las paces» en Fundación Seminario de Investigación para la paz (Ed.): Todavía en busca de la paz. 1984-2009. XXV Aniversario, Zaragoza, Gobierno de Aragón. Departamento de Educación, Cultura y Deporte, 379-405 Disponible en: https://goo.gl/HddKW1 
(2010b): «Filosofía para hacer las paces: fuentes filosófico-bibliográficas de la investigación para la paz» en Comins Mingol, Irene y París Albert, Sonia: Investigación para la Paz. Barcelona, Icaria: 11-24.

(2010c): «Nuevas Masculinidades y Cultura de Paz» en Díez Jorge, Ma Elena y Margarita Sánchez Romero (eds.): Género y Paz. Barcelona: Icaria, 291-313.

Martínez Guzmán, Vicent; Comins Mingol, Irene y Sonia París Albert (2009): «La nueva agenda de la filosofía para el siglo XXI: los estudios para la paz Convergencia» en Revista de Ciencias Sociales, 16, 91-114.

MARTínez GuZMÁn, Vicent y SONIA PARÍs Albert (2006): «Nuevas formas de resolución de conflictos: transformación, empoderamiento y reconocimiento» en Revista Katálysis, 9(1), 27-37. Dsiponible en: https://goo.gl/cVGQ2h [último acceso: $19 / 06 / 2018]$

MATtelart, ARMAND y ÉRIK NeVeu (2003): Introducción a los estudios culturales. Barcelona: Paidós.

Mellado, Judith (09/03/2015): «Amelia Folch, homenaje a las primeras universitarias españolas» [entrada de blog] en Dona havia de ser. Disponible en https://goo.gl/hFYR1T [último acceso: 21/05/2018]

MenÉndeZ MenÉndeZ, MARÍA IsABel (2014): «Ponga una mujer en su vida» en Área Abierta, 14(3), 61-80.

Moreno, Amparo (1977): Mujeres en lucha. El movimiento feminista en España. Barcelona: Anagrama. Disponible en: https://goo.gl/FFgRcY [último acceso: $21 / 05 / 2018]$ 
Monereo AtienZA, Cristina (2007): «Reflexiones crítica sobre la igualdad de género a raíz del proyecto de Ley orgánica para la igualdad entre mujeres y hombres aprobada el 21 de diciembre de 2006» en Cuadernos electrónicos de filosofía del derecho (Ejemplar dedicado a: XXI Jornadas de la Sociedad Española de Filosofía Jurídica y Política: Problemas actuales de la Filosofía del Derecho. Universidad de Alcalá, 28, 29 y 30 de Marzo de 2007), 15, 1-12.

MORENO BENÍTEZ, DAMIÁN (2010): «De “violencia doméstica” a "terrorismo machista": el uso argumentativo de las denominaciones en la prensa» en Discurso \& Sociedad, 4(4), 893-917. Disponible en: https://goo.gl/9JMZPf [último acceso: $21 / 05 / 2018]$

MORRISON, MARY LEE (2005): Elise Boulding: a life in the cause of peace. Jefferson, N.C.: McFarland and Co.

MuÑOZ, FrANCISCO A. (2001): La paz imperfecta. Granada: Universidad de Granada.

Ninyoles, Rafael L. (2017): Conflicte lingüistic valencià: El País Valencià a l'eix mediterrani. Alacant: Servicio de Publicaciones de la UA.

Nos AldÁs, EloÍSA (2010): «La comunicación y los discursos públicos» en Comins Mingol, Irene y Sonia París Albert (coords.): Investigación para la paz: estudios filosóficos. Barcelona: Icaria, 129-144.

PALACIO, MANUEL (2007): «La televisión pública española (TVE) en la era de José Luis Rodríguez Zapatero» en Journal of Spanish Cultural Studies, 8(1), 71-83. DOI: $10.1080 / 14636200601148843$ 
Paleo, Natalia y Alba Alonso (2015): «¿Es únicamente una cuestión de austeridad? Crisis económica y políticas de género en España» en Revista de Investigaciones Feministas, 5, 36-68.

Padilla Castillo, Graciela (2012): «Renacer histórico de la ficción histórica» en Puebla, Belén; Carrillo, Elena y Ana Isabel Íñigo (coords. y eds.): Ficcionando. Series de Televisión a la española. Madrid: Fragua, 39-54.

Peña, Daniel (2010): «Cien años con mujeres en la universidad» en El País. Recuperado de https://goo.gl/keSgxJ [último acceso: 14/04/2018]

PuleO, Alicia (2013): «El concepto de género como hermenéutica de la sospecha: de la biología a la filosofía moral y política» en Arbor, 189(763), a070. DOI: http://dx.doi.org/10.3989/arbor.2013.763n5007.

REVERTER BAÑÓN, SONIA (2011): «Los retos del feminismo institucional» en $\Delta \alpha l^{\prime} \mu \omega v$. Revista Internacional de Filosofia, Suplemento 4, 223-229.

Rodrigo, MiQuel (2001): Teorías de la comunicación: ámbitos, métodos y perspectivas. Barcelona: Servei de Publicacions de la UAB.

RodRÍGUEZ, M. PILAR (2009): «Introducción: Los estudios culturales y de los medios de comunicación» en Rodríguez, M. Pilar (ed.): Estudios culturales y de los medios de comunicación. Bilbao: Publicaciones de la Universidad de Deusto, 31-50.

Rueda LafFond, José Carlos y Amparo Guerra Gómez (2009): «Televisión y nostalgia. "The Wonder Years" y "Cuéntame cómo pasó"» en Revista Latina de Comunicación Social, 12(64), 396 - 409. La Laguna (Tenerife): Universidad de La Laguna. Disponible en: https://goo.gl/nfeks8 [último acceso: 14/04/2018] 
SiLVA V., OMER (2002): «El análisis del discurso según Van Dijik y los estudios de la comunicación» en Del Valle, Carlos (coord.): Razón y Palabra: Aportes y perspectivas en los estudios de la comunicación, (26). Disponible en: https://goo.gl/8M942z [último acceso: 14/04/2018]

Urbain, Melissa (2018): A Feminist Critical Discourse Analysis of the National Board for Professional Teaching Standards (Tesis doctoral). Disponible en: https://goo.gl/c2HtY7 [último acceso: 15/01/2019]

URIBE OTAlORA, AinhOA (2013): «Las cuotas de Género y su aplicación en España: los Efectos de la Ley de Igualdad (LO 3/2007) en las Cortes Generales y los Parlamentos Autonómicos» en Revista de Estudios Políticos (nueva época), 160 (abril-junio), 159-197.

VAlCÁRCEL, AMelia (2001): «La memoria colectiva y los retos del feminismo»en Serie Mujer y Desarrollo, 31. Santiago de Chile: Naciones Unidas. Disponible en https://goo.gl/jR G7N3 [último acceso: 14/04/2018]

VAliente Fernández, Celia (2006): El feminismo de Estado en España: El Instituto de la Mujer (1983-2003). València: Universitat de València. Institut Universitari d'Estudis de la Dona.

VAn DiJK, Teun A. (1992): Text and Context: Explorations in the Semantics and Pragmatics of Discourse. Londres: Longman.

YeSte, ELENA (2010): «La transición española. Reconciliación nacional a cambio de desmemoria: el olvido público de la guerra civil» en Historia Actual Online, 21, 7-12. Disponible en: https://goo.gl/xRkoD4 [último acceso: 14/04/2018] 
Yusta, Mercedes (2008): «La “recuperación de la memoria histórica”, ¿una reescritura de la historia en el espacio público? (1995-2005)» en Revista de Historiografia, 9, 105-117. Disponible pre-print en: https://goo.gl/Achqn8 [último acceso: 21/05/2018] 


\section{BOES:}

BOE n. 71, 23/05/2007, p. 12611-12645: Ley Orgánica 3/2007, de 22 de marzo, para la igualdad efectiva de mujeres $y$ hombres. Disponible: https://www.boe.es/buscar/doc.php?id=BOE-A-2007-6115

BOE n. 79, 01/04/2010, p. 21207-21218: Ley 7/2010, de 31 de marzo, General de la Comunicación Audiovisual. Disponible: https://www.boe.es/buscar/doc.php?id=BOE-A-2006-9958

BOE Núm. 134, de 6 de junio de 2006, 21207-21218): Ley 17/2006, de 5 de junio, de la radio y la televisión de titularidad estatal. Disponible: https://www.boe.es/buscar/doc.php?id=BOE-A-2006-9958

BOE n. 157, de 02/07/2005, p. 23632-23634: Ley 13/2005, de 1 de julio, por la que se modifica el Código Civil en materia de derecho a contraer matrimonio. Disponible: https://www.boe.es/buscar/doc.php?id=BOE-A-2005-11364

BOE $n^{o} 166,12 / 07 / 1985$, p. 22041-22041: Ley Orgánica 9/1985, de 5 de julio, de reforma del artículo 417 bis del Código Penal. Disponible en: https://www.boe.es/buscar/doc.php?id=BOE-A-1985-14138

BOE n. 172, de 16/07/ 2010, p. 1-491. Pleno. Sentencia 31/2010, de 28 de junio de 2010. Recurso de inconstitucionalidad 8045-2006. BOE n. 172, de 16/07/ 2010, p. 1-491. Disposición $11409 . \quad$ Disponible: https://www.boe.es/boe/dias/2010/07/16/pdfs/BOE-A-2010-11409.pdf 
BOE n. 210, 31/08/2009, p. 74003-74015: Ley 8/2009, de 28 de agosto, de financiación de la Corporación de Radio y Televisión Española. Disponible: https://www.boe.es/buscar/doc.php?id=BOE-A-2009-13988

BOE, n. 310, de 27/12/2007, p. 53410-53416: Ley 52/2007, de 26 de diciembre, por la que se reconocen y amplían derechos y se establecen medidas en favor de quienes padecieron persecución o violencia durante la guerra civil y la dictadura. Disponible: https://www.boe.es/buscar/act.php?id=BOE-A-2007$\underline{22296 \& \operatorname{tn}=1 \& p=20081224}$

BOE, n. 313, de 29/12/2004, p. 42166-42197: Ley Orgánica 1/2004, de 28 de diciembre, de Medidas de Protección Integral contra la Violencia de Género. Disponible: https://www.boe.es/buscar/act.php?id=BOE-A-2004-21760 
